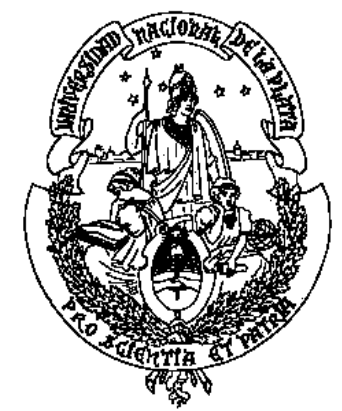

\title{
UTILIZACIÓN COMBINADA DE eCG Y hCG PARA INDUCIR CICLOS FÉRTILES EN PERRAS EN ANESTRO
}

Trabajo de Tesis realizado como requisito para optar por el título de Doctor en Ciencias Veterinarias

Autor: MV, María Cecilia Stornelli Director: MV, DrCVet, María Alejandra Stornelli

Lugar de Trabajo: Cátedra y Servicio de Reproducción Animal,

Facultad de Ciencias Veterinarias, Universidad Nacional de La Plata

Miembros Titulares del Jurado:

Dra. Damasia Becú Villalobos, Instituto de Biologia y Medicina Experimental (IByME)-CONICET, Buenos Aires, Argentina

Dr.Gabriel Bo. Instituto de Reproducción Animal Córdoba (IRAC), Córdoba, Argentina

Dra. Maria Denise Lopes Departamento de Reprodução Animal e Radiologia Veterinária Faculdade de Medicina Veterinária e Zootecnia, UNESP, Botucatu, SP, Brasil 
A mi esposo Fernando, a mi hija María Belén, por su apoyo permanente y los momentos robados

A mi hermana y amiga Alejandra

A mis padres 


\section{AGRADECIMIENTOS}

Quiero agradecerle muy especialmente a mi directora de tesis, la Dra María Alejandra Stornelli, por su apoyo aliento y colaboración en todo momento. Agradezco también muy especialmente al Dr Luzbel de la Sota por su continua ayuda y por aportar siempre todos sus conocimientos y experiencia sin reservas. Por confiar siempre en el grupo que trabaja a su lado dando dando su apoyo incondicional.

Quiero también dar un agradecimiento especial a todos los integrantes de la Cátedra de Reproducción Animal, por su compañerismo y muy especialmente a todos los integrantes del grupo de trabajo de pequeños animales: Candela Bonaura, Carla Garcia Mitacek, Claudia Tittarelli, y Romina Nuñez Favre por su ayuda y apoyo constantes.

Al MV Ignacio Videla Dorna y al Laboratorio Sintex SA, por el soporte económico para la realización de mi trabajo de tesis.

A la Dra Nora Mestorino por su colaboración en el desarrollo del Experimento I, ya que su aporte fue imprescindible para la realización del mismo.

Al Dr Marcelo Aba del Laboratorio de Endocrinología de la Universisdad del Centro de la Provincia de Buenos Aires quien realizó las determinaciones de eCG mediante ELISA.

Al Dr Rodolfo Goya y a Yolanda Elena Sosa por su continua colaboración en las determinaciones hormonales por RIA.

Al MV Nazareno Soto por su colaboración en los inicios de mi trabajo de tesis.

Agradezco muy especialmente al Profesor Ángel Russo por las correcciones realizadas durante la redacción de la tesis. 
A la Dra Sandra Arauz por permitirme realizar parte de mi trabajo de tesis en el horario de trabajo del Servicio Central de Laboratorio a su cargo.

A mi esposo, a mi hija y a mis padres, por su continuo apoyo. 


\section{ÍNDICE}

Página

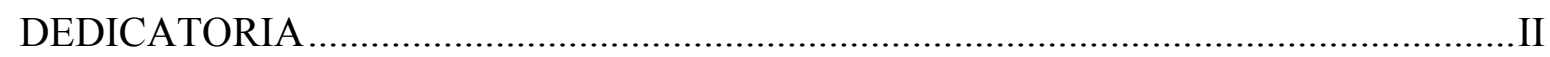

AGRADECIMIENTOS ....................................................................................... III

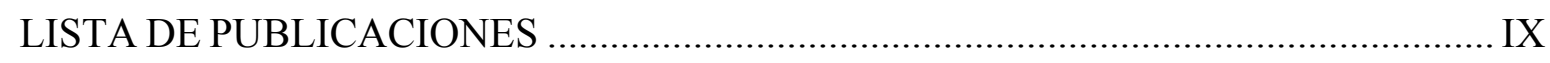

LISTA DE ABREVIATURAS ............................................................................ XI

LISTA DE TABLAS …...........................................................................................

LISTA DE FIGURAS …................................................................................... XIV

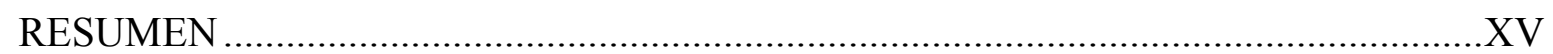

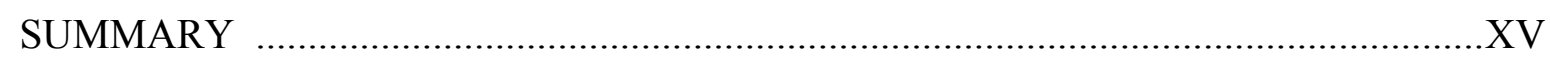

\section{CAPITULOS}

I. INTRODUCCION GENERAL

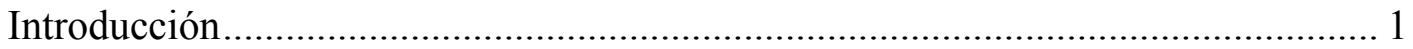

Hormonas de la Adenohipófisis ............................................................. 1

Hormonas Gonadales.............................................................................. 7

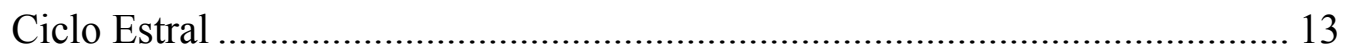

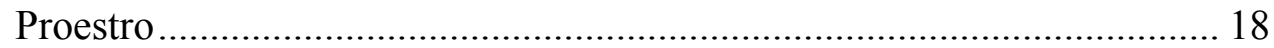

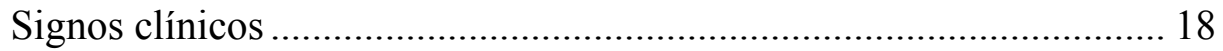

Hallazgos en la vaginoscopía.......................................................... 20

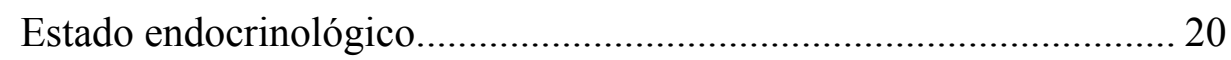

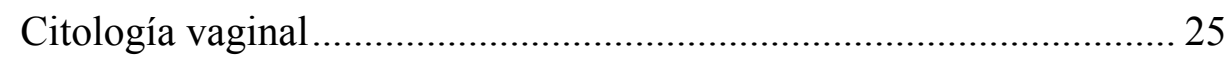

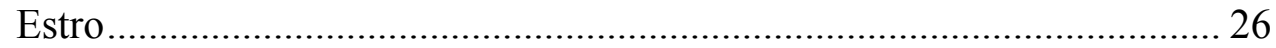




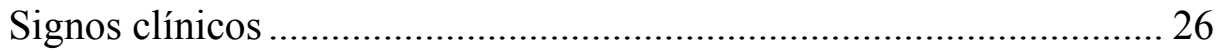

Hallazgos en la vaginoscopía....................................................... 28

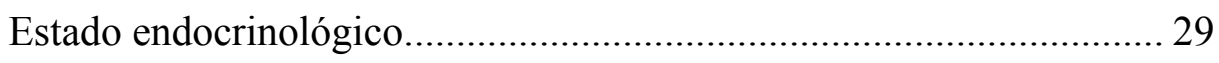

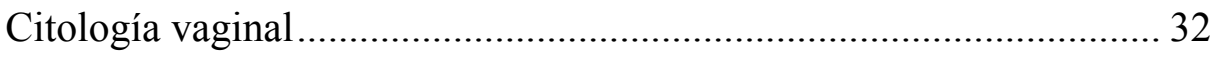

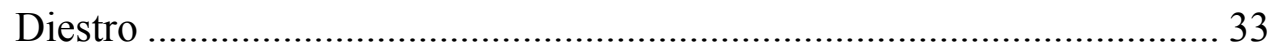

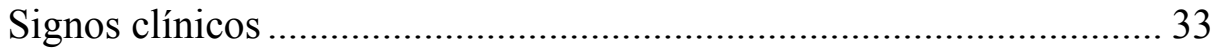

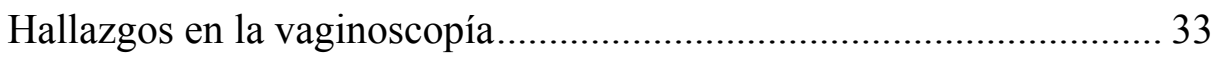

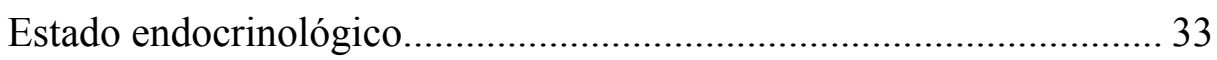

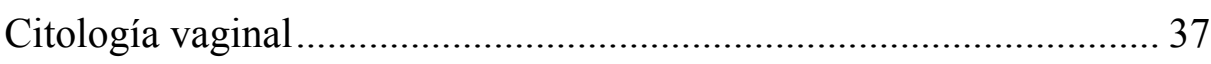

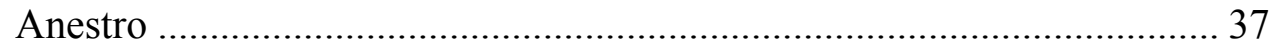

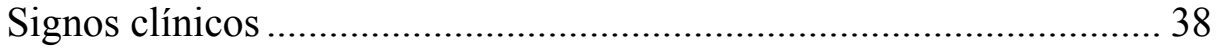

Hallazgos en la vaginoscopía.............................................................. 38

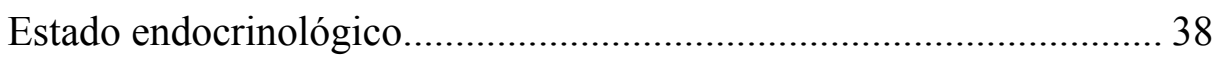

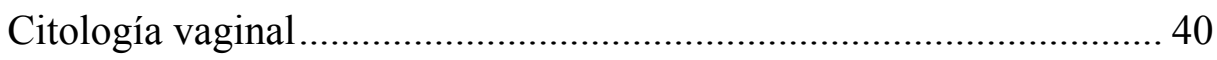

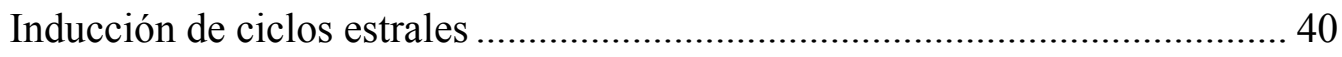

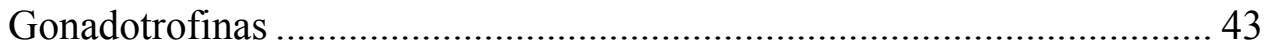

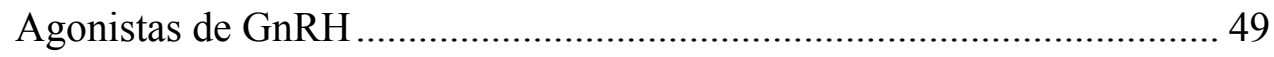

Agonistas dopaminergicos............................................................... 51

II. ESTUDIO DE LA SOBREVIDA PLASMÁTICA DE LA eCG

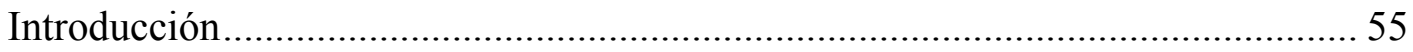

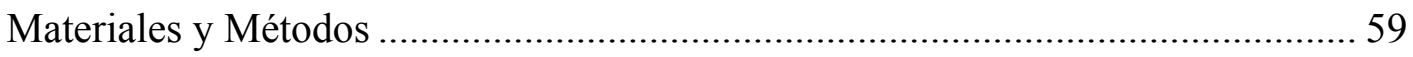

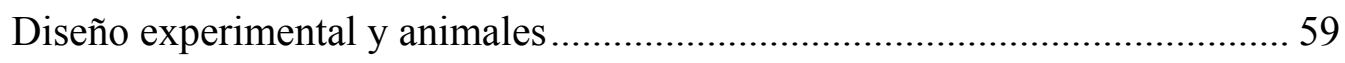

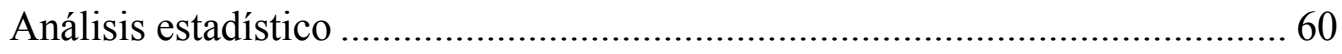




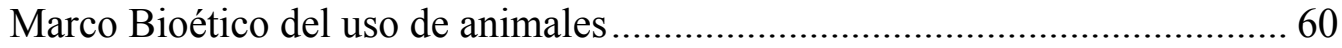

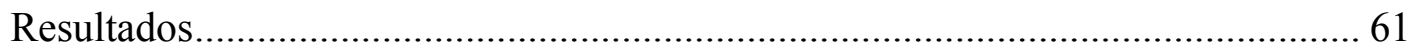

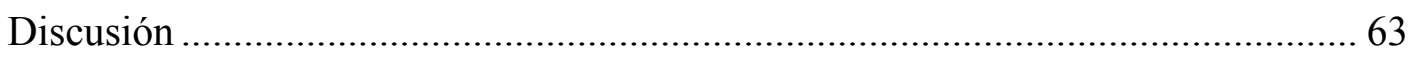

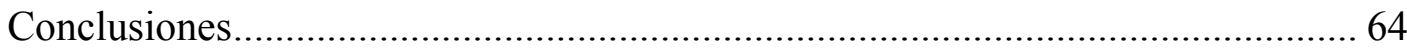

III. BÚSQUEDA DE LA DOSIS EFECTIVA DE eCG

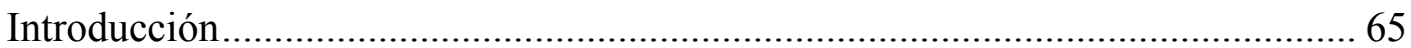

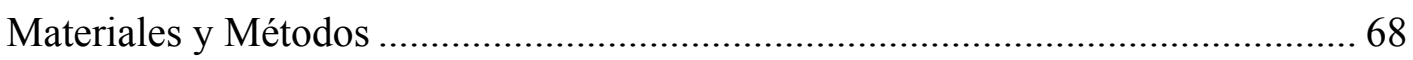

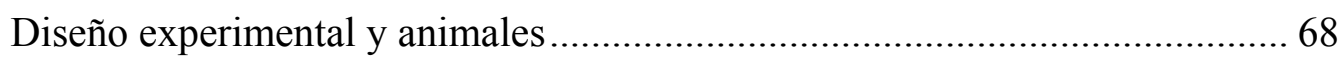

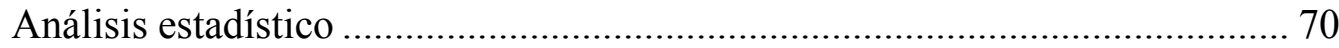

Marco Bioético del uso de animales............................................................ 70

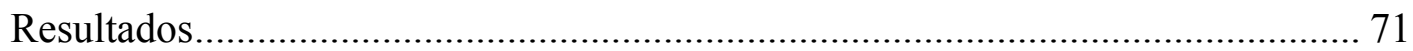

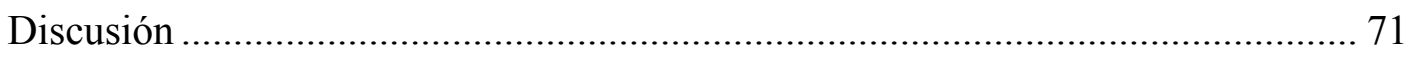

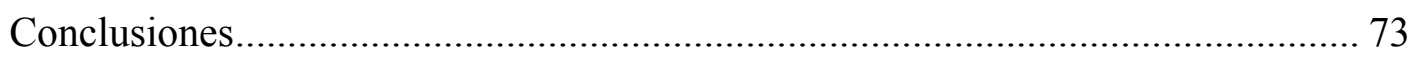

IV. ESTUDIO DE LA RESPUSTA HORMONAL Y EL DESARROLLO

FOLICULAR INDUCIDO LUEGO DE LA ADMINISTRACIÓN DE eCG

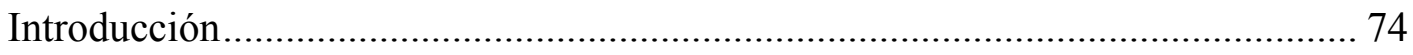

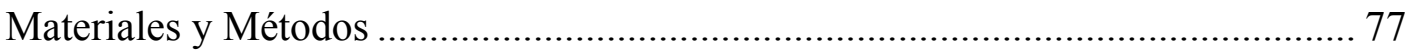

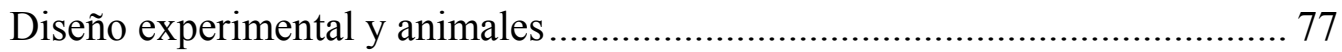

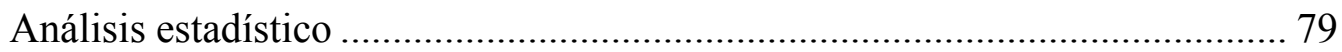

Marco bioético del uso de animales .................................................................. 79

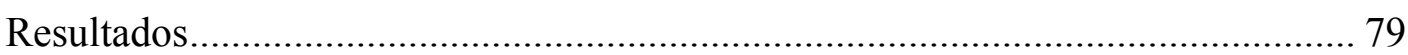




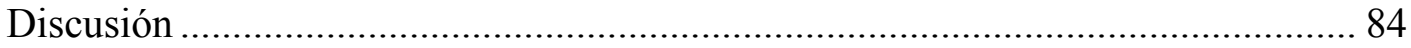

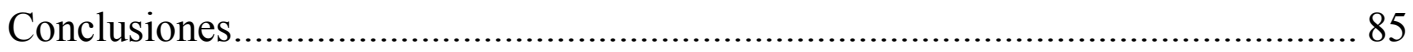

V. ESTUDIO DE LA EFICACIA REPRODUCTIVA DEL USO COMBINADO DE eCG Y hCG

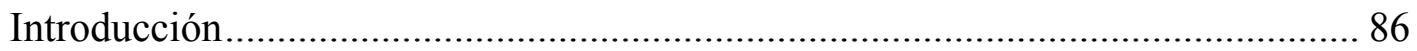

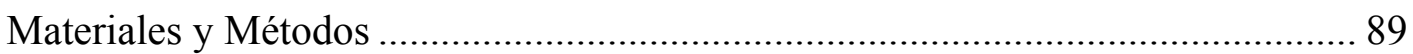

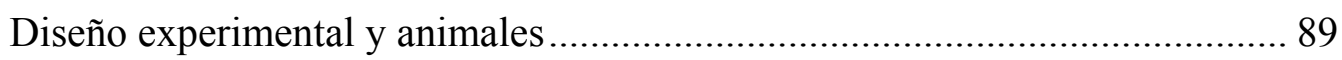

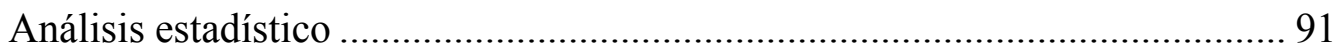

Marco bioético del uso de animales.......................................91

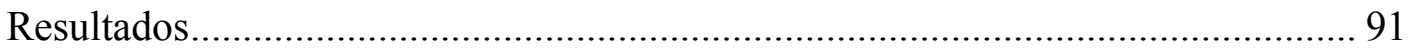

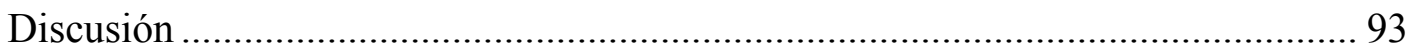

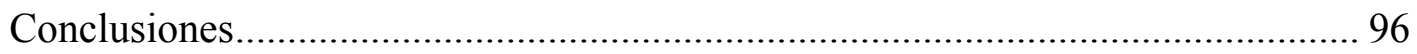

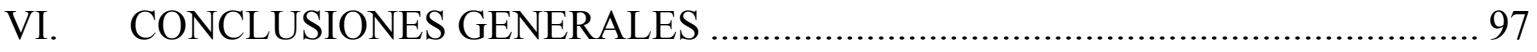

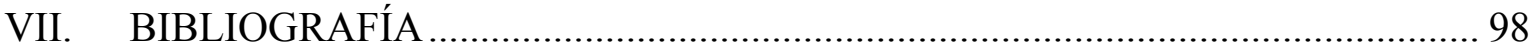

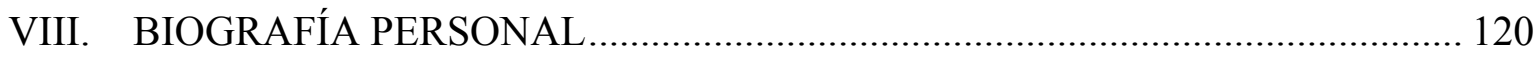




\section{LISTA DE PUBLICACIONES}

1. MC Stornelli, F Gimenez, CM Tittarelli,CA Savignone, RL de la Sota, MA Stornelli. Inducción de ciclos estrales en la perra: Actualización bibliográfica. Analecta Veterinaria. 2006; 26(2): 5-8.

2. MC Stornelli, CA Savignone, F Gimenez, CM Tittarelli, RL de la Sota, MA Stornelli. Particularidades del ciclo estral canino. aspectos clínicos y endocrinológicos. Revista Veterinaria Cuyana. 2006, 1(2): 26-35.

3. MC Stornelli, MA Stornelli, CA Savignone, R Nuñez Favre, CM Tittarelli, N Mestorino, I Videla Dorna, RL de la Sota. Pharmacokinetics and ovarian stimulatory effects of eCG in the bitch. 2009 Annual Conference of Society for Theriogenology (SFT) and American College of Theriogenologists (ACT). Clinical Theriogenology, 571 .

4. MC Stornelli, MA Stornelli, CA Savignone, MC García Mitacek, CM Tittarelli, I Videla Dorna, RL de la Sota. Induction of fertile estrus in bitches using eCG followed by hCG. 2009 Annual Conference of Society for Theriogenology (SFT) and American College of Theriogenologists (ACT). Clinical Theriogenology, 539.

5. MC Stornelli, MC García Mitacek, F Giménez, MC Bonaura, I Videla Dorna, RL de la Sota, MA Stornelli. 2012 Pharmacokinetics of eCG and induction of fertile estrus in bitches using eCG followed by hCG. Theriogenology. 78:1056-64.

6. MC Stornelli, MC Garcia Mitacek, R Nuñez Favre, R Praderio, RL de la Sota, MA Stornelli. 2012 Prolactin, androstenedione and IGF1 serum concentrations during induced follicular growth by eCG administration in the bitch. 17th 
International Congress on Animal Reproduction (ICAR). Vancouver Canada. Reproduction in Domestic Animal, 47(4): 497. 


\section{LISTA DE ABREVIATURAS}

PRL Prolactina

CL Cuerpo lúteo

$\mathrm{P}_{4} \quad$ Progesterona

$\mathrm{E}_{2} \quad 17 \beta$ estradiol

$\mathrm{E}_{1} \quad$ Estrona

PGF Prostaglandina $\mathrm{F}_{2 \alpha}$

PMSG Gonadotrofina sérica de yegua gestante

eCG Gonadotrofina coriónica equina

hCG Gonadotrofina coriónica humana

TSH Hormona estimuladora de la tiroides

GH Hormona de crecimiento

h Horas

d Días

DES Dietilestilbestrol

hMG Gonadotrofina de mujer menopáusica

ELISA Enzyme Linked Immuno Sorbent Asssay

IM Intramuscular

IV Intravenoso

SC Subcutánea

TRT Tratamiento

IGF1 Factor de crecimiento similar a la insulina

UI Unidades internacionales 
FSH Hormona Folículo estimulante

LH Hormona Luteinizante

GnRH Hormona Liberadora de Gonadotrofinas 


\section{LISTA DE TABLAS}

Tabla

Página

1.1. Protocolos de inducción de ciclos estrales en perras ......................................... 50

3.1. Clasificación de grados de comportamiento y signología de estro........................ 74

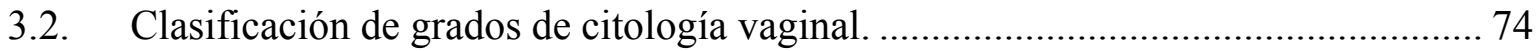




\section{LISTA DE FIGURAS}

Figura

Página

1.1. Ruta para la síntesis de esteroides biológicamente activos a partir de acetato.

1.2. Cambios de conducta, citología vaginal y variaciones hormonales durante el proestro y estro en la perra.

1.3. Cambios de la citología vaginal y variaciones hormonales durante el ciclo estral de la perra

1.4. Cambios en la citología vaginal y estrogenemia durante el ciclo estral de la perra 28

2.1. Cuadrado medio mínimo y error estándar de las concentraciones de eCG en suero sin extracción luego de la administración IM o IV en perras

3.1 Concentraciones séricas de prolactina antes y después de administrar eCG

3.2 Concentraciones séricas de prolactina ants del clo, en el celo y en diestro.

3.3 Concentraciones de androstenediona antes y después de la administración eCG

3.4 Concentraciones séricas de androstenediona antes del celo, en el celo y en diestro. 82

3.5 Concentraciones de IGF1 antes y después de la administración eCG 83

3.6 Concentraciones de IGF1 antes y después de la administración eCG 


\section{RESUMEN}

\section{Utilización combinada de ecg y hcg para inducir ciclos fértiles en perras en anestro}

El objetivo del trabajo fue diseñar un protocolo de inducción de ciclos fértiles en la perra utilizando eCG y hCG. En el experimento uno se evaluaron las características farmacocinéticas de eCG, la concentración maxima observada Cmax) fue semejante entre las vías im e iv (6.1 \pm 0.9 vs. $8.6 \pm 0.5 \mathrm{IU} / \mathrm{mL}, \mathrm{P}>0.08)$, mientras que el tiempo en el que alcanzó la concentración máxima observada (Tmax) fue más largo para la via im que iv.m (17.5 \pm 0.5 vs. $11.6 \pm 0.3 \mathrm{~h}, \mathrm{P}<0.01)$. El área bajo la curva (AUC) fue similar para las vías im e iv ( $\mathrm{P}>0.48)$. Así mismo eCG se detectó en suero por al menos $144 \mathrm{~h}$. En el experimento dos se buscó la dosis efectiva de eCG. Pudo observarse que con 50 $\mathrm{UI} / \mathrm{Kg}$ (TRT 50) de eCG se pudieron observar signos externos, comportamiento y citología vaginal de estro en todos los animales tratados La media del intervalo tratamiento - estro fue de $4.0 \pm 0.4 \mathrm{~d}$. En el experimento tres se estudiaron las fluctuaciones de androstenediona, prolactina e IGF1 en relación al desarrollo folicular en las perras inducidas. Pudo observarse que las concentraciones séricas de estas sustancias varían a lo largo del desarrollo folicular. En el experimento cuatro se evaluó la eficacia reproductiva del uso combinado de eCG y hCG. Todas las perras que recibieron tratamiento respondieron manifestando comportamiento, signos externos y citología vaginal compatible con estro. El 94\% de las perras recibieron servicio natural o inseminación artificial y el 80\% quedaron preñadas y parieron 3,62 \pm 0,41 Cachorros. No se observan efectos adversos en ninguna de las perras tratadas. 


\section{SUMMARY}

\section{Induction of fertile estrus in late anoestrus bitches using eCG followed by hCG}

The aim of this study was to design a protocol combining eCG followed by hCG for estrus induction in the bitch. In Experiment one, we study pharmacokinetics analyses of eCG. Maximum observed concentration (Cmax) eCG were similar between im and iv routes $(6.17 \pm 0.97$ vs. $8.69 \pm 0.50 \mathrm{IU} / \mathrm{mL}, \mathrm{P}>0.08)$, whereas Tmax was longer for im compared to iv delivery route $(17.5 \pm 0.5$ vs. $11.66 \pm 0.33 \mathrm{~h}, \mathrm{P}<0.002)$. Elimination halflive was shorter for im than for iv delivery routes $(38.19 \pm 2.81 \mathrm{vs} .59 .08 \pm 2.81 \mathrm{~h} ; \mathrm{P}<$ $0.03)$. The AUC concentrations were similar im and iv delivery routes $(307.70 \pm 5.71 \mathrm{vs}$. $381.10 \pm 70.90 \mathrm{IU} \mathrm{h} / \mathrm{mL} ; \mathrm{P}>0.48)$ and $\mathrm{eCG}$ was detectable in serum for at least $144 \mathrm{~h}$ for both routes. In Experiment two, ovarian stimulatory effects of eCG was studied using one of five doses of eCG $(5,10,15,20,44$, or 50 IU/kg eCG im; [TRT5-TRT50]). Three to five days after treatment, all bitches in TRT50 had higher scores compared to TRT5-44 animals $(\mathrm{P}<0.01)$. In TRT50, mean interval from treatment to estrus was $4.0 \pm 0.4 \mathrm{~d}$. No detectable clinical side effects were observed in bitches during treatment. In experiment three studied hormonal response and follicular development after eCG administration. We observed that prolactin, IGF1 and androstenedione serum concentration change with follicular growth induced by a single dose of $50 \mathrm{IU} / \mathrm{kg}$ of eCG similar to dose occurring during spontaneous oestrous cycle. In experiment four reproductive efficacies of eCG and hCG in oestrus induction was studied. In treatment group all bitches responded to treatment by coming into clinical estrus within 3-5 d after eCG-hCG administration. Ninety four percent of animals were bred (15/16; AI, n=7; 
natural mating, $n=8)$, and $80 \%(12 / 15)$ became pregnant. The average litter size was $3.62 \pm 0.41$. None of the bitches showed any side-effects to the eCG and hCG therapy. 


\section{CAPITULO I}

\section{INTRODUCCIÓN GENERAL}

Para implementar el manejo del ciclo reproductivo canino, es preciso un acabado conocimiento de la fisiología reproductiva de la perra así como de la estructura y función de las hormonas intervinientes en el desarrollo del mismo. El conocimiento de la estructura, mecanismo de acción y función de las hormonas hipotalámicas, hipofisiarias, gonadales y de las hormonas del tipo hipófisis anterior, nos permitirá una mejor comprensión de las variaciones hormonales del ciclo estral canino así como las posibilidades de manejo del mismo. De esta manera se podrán diseñar nuevos protocolos para la inducción de ciclos fértiles en perras en anestro.

\section{Hormonas de la Adenohipófisis}

La adenohipófisis produce tres hormonas de importancia en la reproducción de la hembra que son la FSH, LH y PRL. La FSH y LH poseen restos de carbohidratos y junto con la hormona tirotrópica, forman un grupo de hormonas hipofisiarias clasificado como glucoproteicas. Las hormonas glucoproteicas poseen dos subunidades unidas en forma no covalente. En una misma especie, las subunidades $\alpha$ para todas las hormonas glucoproteínicas son idénticas, mientras que las $\beta$ son diferentes en el contenido de aminoácidos y carbohidratos, lo que confiere especificidad de acción a la hormona. Las principales funciones de la FSH son estimular el crecimiento de los folículos antrales e inducir la expresión de receptores de LH en las células de la teca interna y de la granulosa. Por otra parte, la FSH también regula la actividad de aromatasa en células de 
la granulosa lo que estimula la producción de $17 \beta$ estradiol (Parker y Schimmer, 2003). La LH actúa sobre las células de la teca para estimular la síntesis de androstenediona, precursor del $17 \beta$ estradiol ovárico. LH, en la mujer, induce la expresión del receptor de FSH por las células de la granulosa, por lo tanto esta hormona posee una acción permisiva en la acción de FSH (Parker y Schimmer, 2003). Se requiere de LH para la ruptura de los folículos dominantes durante la ovulación y para la síntesis de progesterona. Por lo tanto $\mathrm{LH}$ es necesaria para el proceso ovulatorio y para la luteinización de la granulosa y la teca interna lo que resulta en la formación del cuerpo lúteo. Es así que la las acciones de las hormonas FSH y LH son coordinadas y diferenciales durante el ciclo estral.

La tercera hormona de importancia reproductiva es la PRL. Esta hormona y la GH son hormonas proteicas de alto peso molecular. La PRL tiene características atávicas comunes con la hormona del crecimiento. Las dos son proteínas globulares simples de una sola cadena, con un peso molecular similar (22.000 a 24.000) y un número semejante de residuos de aminoácidos (190 a 200). La PRL se caracteriza por contener tres puentes disulfuro y dos moléculas de triptófano. En los mamíferos las funciones más importantes de la PRL se relacionan con el desarrollo del tejido secretor de la glándula mamaria y el mantenimiento de la lactación. En algunas especies como en la rata, ratón, oveja y la perra esta hormona es luteotrófica, siendo uno de los factores luteotróficos de mayor importancia. Es así que en la perra el CL es autónomo hasta el día 20 de preñez, necesitando el soporte de la PRL para el mantenimiento de la gestación durante el tercio medio y final de la misma (Concannon y col., 1987, Okkens y col., 1986). Este hecho fue demostrado en 1986 realizando hipofisectomía en perras (Okkens y col., 1986). Más tarde se logró interrumpir la gestación tardía al administrar 
agonistas dopaminérgicos (antiluteotróficos) a perras gestantes el día 42 de preñez. Cuando se administró bromocriptina el día 22 de gestación si bien no disminuyeron las concentraciones séricas de $\mathrm{P}_{4}$, siendo las mismas significativamente diferentes en las muestras pre tratamiento versus las muestras postratamiento, no se interrumpió la gestación (Concannon y col., 1987). Estos estudios demostraron la autonomía del CL en el primer tercio de la gestación y la acción luteotrófica de la PRL durante el tercio medio y final de la preñez.

Muchos factores fisiológicos influyen sobre la secreción de PRL, así, el sueño, el estrés, la hipoglucemia, el ejercicio y los estrógenos aumentan la secreción de esta hormona. De igual forma que otras hormonas de la parte anterior de la hipófisis, la PRL se secreta de manera pulsátil (Goodman y Gilman, 1996).

La secreción de PRL desde la pituitaria está gobernada por señales hipotalámicas estimuladoras e inhibidoras. La dopamina es la principal señal neural inhibitoria en la regulación de la liberación de PRL (Ben-Jonathan, 1985; Kooistra y Okkens 2002; Lopez y col, 1989). Además existen diversas sustancias, como serotonina, hormona liberadora de tirotrofina y óxido nítrico que actúan sobre la liberación de PRL (Garthwaite y Hagen, 1979; Lafuente y col., 1994; Yen y Pan, 1999). Así mismo, fue identificado y caracterizado un péptido específico, que promueve la liberación hipotalámica de PRL (Hinuma y col, 1998; Matsumoto y col, 1999). Estudios con ratas han provisto evidencia de que sustancias que derivan de la pars intermedia de la pituitaria, juegan un rol importante en la secreción de PRL desde el lóbulo anterior de la glándula (Frawley, 1994).

Por otra parte las hormonas esteroides gonadales, juegan un rol muy importante en la modulación de la secreción de PRL. Los estrógenos son potentes estimuladores de 
la síntesis, almacenamiento, liberación y expresión de los genes de PRL (Kooistra y Okkens 2002).

Las hormonas proteícas actúan mediante la unión a receptores específicos ubicados en la superficie de las células blancos, este mecanismo de acción contrasta con la unión citoplasmática de las hormonas esteroides. El receptor de la superficie celular está integrado con un receptor en la membrana celular. Cuando ocurre la unión de la hormona proteíca con el receptor se genera un segundo mensajero intracelular que es el mediador de los efectos de la hormona sobre: enzimas intracelulares, expresión de genes y la membrana celular en si misma. El segundo mensajero puede ser una enzima (i.e., proteincinasa), iones (i.e., $\mathrm{Ca}^{++}, \mathrm{H}^{+}$), o monofosfato de adenosina cíclico (AMPc). En algunos casos la unión hormona receptor activa la enzima adenilatociclasa para convertir el trifosfato de adenosina (ATP) en el nucleótido monofosfato de adenosina (3,5-AMP), el AMPc (el segundo mensajero) que activa a las proteinquinasas intracelulares. Estas quinasas activan los sistemas enzimáticos que determinan el efecto de la hormona.

Los receptores de PRL son proteínas formadas por una cadena polipeptídica con un segmento transmembrana y pertenecen a la superfamilia de receptores de citoquinas. La PRL se une de manera específica al receptor, la dimerización inducida por la hormona recluta cinasas Jak y las activa. La fosforilación de cinasas Jak 2 induce fosforilación, dimerización y translocación nuclear del factor de transcripción Stat 5 (Parker y Schimmer, 2003).

El control hipotalámico de la secreción de la adenohipófisis está a cargo de hormonas peptídicas pequeñas que se liberan en la eminencia media y se transportan hacia la adenohipófisis por medio de un sistema portal de irrigación. La hormona GnRH 
(un péptido de 10 aminoácidos) regula la síntesis de FSH y LH y, la secreción de las mismas, por gonadotropos hipofisiarios (Goodman y Gilman, 1996). La GnRH se libera en forma de pulsos los cuales pueden ser regulados por señales externas al hipotálamo, como hormonas esteroideas. Este decapéptido posee una vida media muy corta que se estima es menor a 10 minutos (Prieto Gómez y col, 2002).

La liberación de GnRH es gobernada por un generador neural de pulsos localizado en la parte mediobasal del hipotálamo, que controla la frecuencia de liberación y la amplitud de la misma. A pesar de que la actividad del generador de pulsos de GnRH es activo al final de la vida fetal y durante un breve período luego del nacimiento, la actividad del mismo disminuye como consecuencia de la inhibición ejercida por el sistema nervioso central, hasta poco antes de la pubertad momento en el que aumenta la amplitud y frecuencia de secreción de GnRH. La liberación intermitente de este péptido es crucial para la síntesis y liberación apropiadas de las gonadotrofinas. La administración continua de GnRH lleva a la desensibilización y regulación decreciente de los receptores de la misma sobre los gonadotropos hipofisiarios. Estas acciones constituyen la base para el uso clínico de los análogos de GnRH (Goodman y Gilman, 1996).

Por lo tanto existen básicamente dos formas de influenciar la secreción de gonadotrofinas. Una es variar la frecuencia y amplitud de los pulsos de liberación de GnRH ya que se ha demostrado que la liberación pulsátil de la misma es esencial para mantener la secreción de LH y FSH por la adenohipófisis. Otra es cambiar la sensibilidad de la adenohipófisis a los pulsos de GnRH, por medio de los efectos moduladores de $\mathrm{E}_{2}$ y $\mathrm{P}_{4}$. El incremento de las concentraciones de $\mathrm{E}_{2}$ aumenta la 
sensibilidad a la $\mathrm{GnRH}$ y aumenta la liberación de gonadotrofinas; la $\mathrm{P}_{4}$ posee el efecto opuesto.

Es muy interesante la manera contrastante en que los $E_{2}$ afectan la liberación de gonadotrofinas. El $\mathrm{E}_{2}$ causa un efecto de retroalimentación positiva con la consiguiente liberación de grandes cantidades de GnRH a partir del centro preovulatorio, lo cual produce un pico de gonadotrofinas en respuesta a concentraciones de $\mathrm{E}_{2}$ que aumentan gradualmente. En contraposición la retroalimentación negativa requiere la exposición a concentraciones de $\mathrm{E}_{2}$ basales o mínimas y de corta duración conjuntamente con altos niveles de $\mathrm{P}_{4}$.

El centro hipotalámico conocido como centro preovulatorio es responsable de la liberación preovulatoria de GnRH que estimula el pico de LH que causa la ovulación. Este centro libera niveles basales de GnRH hasta que recibe el estímulo positivo apropiado, este estímulo se conoce como nivel umbral de $\mathrm{E}_{2}$ en ausencia de $\mathrm{P}_{4}$. Cuando las concentraciones plasmáticas de $\mathrm{E}_{2}$ alcanzan cierto nivel una gran cantidad de $\mathrm{GnRH}$ es liberada desde el centro preovulatorio. El pico preovulatorio de GnRH ocurre solo una vez durante el ciclo estral, sin embargo la liberación tónica de GnRH ocurre durante todo el ciclo. El pico preovulatorio de GnRH está controlado por la combinación de concentraciones altas de $\mathrm{E}_{2} \mathrm{y}$ bajas de $\mathrm{P}_{4}$. El $\mathrm{E}_{2}$ en presencia de bajas concentraciones de $\mathrm{P}_{4}$ ejerce un efecto diferencial sobre la GnRH. Es así que las bajas concentraciones de $E_{2}$ causan un efecto de supresión del centro preovulatorio, sin embargo cuando los niveles de $\mathrm{E}_{2}$ son altos como ocurre durante la fase folicular media o tardía el centro preovulatorio responde con la liberación de grandes cantidades de GnRH. Esto se conoce como retroalimentación positiva. Cuando los niveles de $\mathrm{E}_{2}$ son bajos $\mathrm{y}$ los 
niveles de $\mathrm{P}_{4}$ altos ocurre el proceso de retroalimentación negativa previniendo la liberación de pulsos de gran amplitud de GnRH (Senger, 2003).

Por otra parte el control de la secreción de PRL se relaciona con la inhibición de la secreción mediante factores hipotalámicos. La dopamina, una catecolamina, es un factor inhibidor de la PRL. La dopamina es liberada por las neuronas en la eminencia media y es transportada por el sistema portal hipofisiario hacia adenohipófisis. Es así que la disminución de la síntesis de dopamina aumenta la liberación de PRL. La prohormona de la GnRH y el ácido gamma aminobutírico también inhiben la secreción de PRL. La PRL también se libera en forma pulsátil, posiblemente a causa del aumento y disminución del factor inhibidor (Parker y Schimmer, 2003). Se han descripto diversos factores que serían liberadores de PRL como, TRH, péptido intestinal vasoactivo, péptido liberador de PRL y péptido hipofisiario activador de la ciclasa de adenilo, pero no están claras sus funciones fisiológicas (Parker y Schimmer, 2003).

\section{Hormonas Gonadales}

Los principales tipos de hormonas esteroides que participan en los procesos de la reproducción de la hembra son los pregnanos y los estranos. El pregnano más importante es la $\mathrm{P}_{4}$, la cual es producida por el CL, la placenta y la corteza adrenal. La síntesis de $\mathrm{P}_{4}$ que realiza el CL está controlada por la LH.

Los principales estranos son la estrona (E1) y el $\mathrm{E}_{2}$. El estriol (E3), otro estrógeno importante, se encuentra solo en los primates durante la gestación. Los sitios de producción de $\mathrm{E}_{2}$ son el ovario (células de la granulosa de los folículos ováricos), la unidad fetoplacentaria y la corteza adrenal. En la Figura 1.1 se pueden observar que todos los esteroides se obtienen mediante rutas biosintéticas comunes (Stabenfeldt y 
Edqvist, 1999). La FSH controla la síntesis estrogénica de los folículos ováricos y actúa sobre las células de la granulosa. La LH también actúa sobre la síntesis de estrógenos ya que controla la producción de la molécula precursora esencial (androstenediona) por las células de la teca interna. Las hormonas esteroides son liposolubles y se unen para su transporte a proteínas plasmáticas como por ejemplo la globulina fijadora de hormonas sexuales que posee gran afinidad por los $\mathrm{E}_{2}$. Las proteínas que se unen a esteroides con mucha afinidad poseen poca capacidad de transporte. Por otro lado, la albúmina, que es una proteína con poca afinidad de unión por los esteroides, es un vehículo de transporte importante debido a su gran concentración en el plasma. Menos del 5\% de las hormonas esteroides permanecen en forma libre. Para realizar su función estas hormonas se unen a receptores específicos citoplasmáticos y este complejo se transfiere al núcleo donde se une a sitios específicos de la cromatina (Funakoshi y col., 2006; Goodman Gilman y col., 1996; Loose-Mitchell y Stancel, 2003). Recientemente se ha demostrado que diferentes acciones de los esteroides estarían mediadas por receptores de membrana. Se ha descubierto un receptor de membrana receptor 30 ligado a proteína G (GPR30). El GPR30 es activado por $\mathrm{E}_{2}$ y esta activación lleva a su internalización (Funakoshi y col., 2006). 
Síntesis de esteroides

Acetato

Colesterol

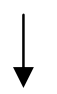

5-Pregnenolona

$\longrightarrow$ Progesterona

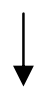

$17 \alpha$ Hidroxipregnenolona $\longrightarrow \quad 17 \alpha$ Hidroxiprogesterona

Corticoides
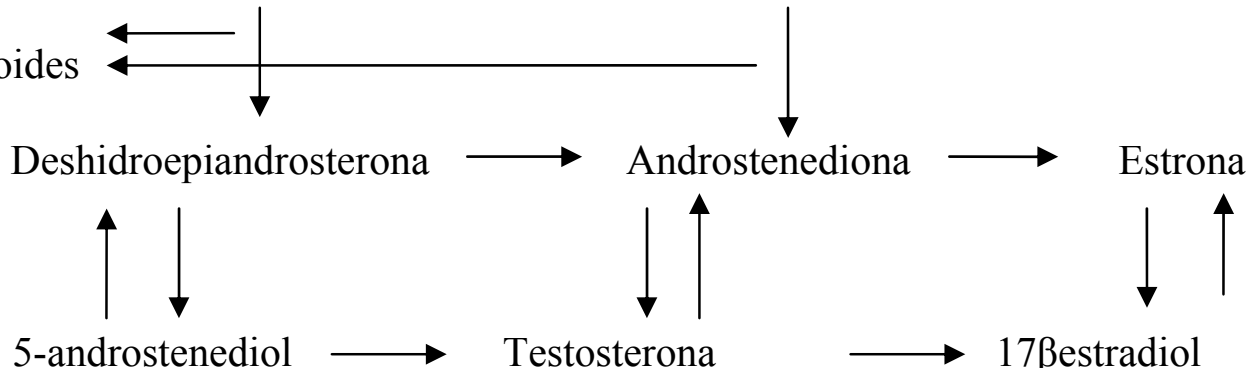

Figura 1.1. Ruta para la síntesis de esteroides biológicamente activos a partir de acetato. Los esteroides secretados por las gónadas y la corteza adrenal se forman a partir del acetato y del colesterol (Stabenfeldt y Edquist, 1999).

Los $\mathrm{E}_{2}$ estimulan el crecimiento de las glándulas endometriales (necesario para el mantenimiento del cigoto antes de la implantación), estimulan el crecimiento de los conductos de la glándula mamaria, causan actividad secretora en el oviducto (lo que favorece la supervivencia de óvulo y espermatozoide), regulan la secreción de gonadotrofinas, pueden ser los causantes de la liberación de PGF por el útero grávido y no grávido, detienen el crecimiento de los huesos largos al iniciar el cierre de la placa epifisiaria de crecimiento y favorecen el anabolismo proteínico (Stabenfeldt y Edqvist, 1999). 
A su vez, la $\mathrm{P}_{4}$ estimula el crecimiento de las glándulas endometriales, estimula el crecimiento lóbulo-alveolar de la glándula mamaria, estimula la actividad secretora del oviducto y de las glándulas endometriales, estimula la conducta de estro en distintas especies (oveja, perra, yegua, cabra, vaca) en coordinación con el $\mathrm{E}_{2}$, evita la contractilidad del útero durante la gestación y regula la secreción de las gonadotrofinas. Es importante considerar que las acciones de la $\mathrm{P}_{4}$ ocurren a menudo en coordinación con el $E_{2}$ y muchas veces requieren la acción previa del mismo (Stabenfeldt y Edqvist, 1999).

Existen tejidos diferentes a los de la hipófisis que son capaces de producir gonadotrofinas, a estas hormonas se las conoce como hormonas del tipo hipófisis anterior. Las dos fuentes más importantes de tales hormonas, de interés en medicina veterinaria, son el suero de yegua gestante y la gonadotrofina coriónica de mujer embarazada. Del primero se obtiene la eCG, y de la segunda la hCG.

La eCG fue descubierta por Harold Cole y George Hart en el departamento de ciencia animal de la Universidad de California en Davis, USA, en 1930 (Cole y col, 1930 en Allen y col, 1993). Fue denominada como gonadotrofina sérica de yegua gestante (PMSG) y en la actualidad se la denomina gonadotrofina coriónica equina (eCG).

La eCG es una glicoproteina ácida, con un peso molecular de 68.000 y alto contenido de carbohidratos $(45 \%)$ constituidos principalmente por ácido siálico galactosa y glucosamina. Posee una punto isoeléctrico bajo de solo 2,4 y una gran resistencia a la hidrólisis ácida. Al igual que las gonadotrofinas de la pituitaria y coriónicas así como la TSH en todos los mamíferos, eCG es una glicoproteína heterodimérica formada por dos subunidades, $\alpha$ y $\beta$ unidas de forma no covalente. La 
subunidad $\alpha$ es idéntica dentro de cada especie, mientras que la $\beta$ difiere lo que indica que la especificidad de acción reside en la subunidad $\beta$ (Allen, 1982). Por otra parte posee una vida media de aproximadamente $26 \mathrm{~h}$. Esta hormona se forma en las copas endometriales del útero de yegua gestante y está presente en la sangre del animal entre los días 40 y 140 de gestación, alcanzando un máximo el día 80 (McDonald 1996).

Probablemente la característica más inusual e interesante de la molécula de eCG es su propiedad de expresar actividad tanto de FSH como de LH cuando es administrada a otras especies mamíferas. La base estructural para esta actividad dual de la eCG aún no se conoce, pero se presume que se encuentra dentro de la sub unidad $\beta$ (Allen, 1982)

Es así que en la mayoría de las especies la actividad biológica de la eCG es similar a la de FSH, presentando también algunas acciones semejantes a LH. Por lo tanto la eCG puede sustituir a la FSH. Su período de acción es largo, debido a que no pasa el filtro renal, y se mantiene en circulación tanto si ha sido inyectada como si ha sido producida por el mismo animal. Recientemente se ha demostrado en ratas, que la eCG y la hCG producen la liberación de FSH y LH desde la pituitaria, observándose la elevación sérica de las hormonas hipofisiarias 12 h después de la administración de eCG (Lecompte y col, 2010). En la yegua, la eCG tiene actividad luteotrófica, provee estimulación para el mantenimiento de los CL primarios y es responsable del control de la formación y mantenimiento de los CL secundarios. Con el incremento de la eCG, a menudo la yegua ovulará generándose los cuerpos lúteos secundarios. La ovulación inducida por esta hormona ocurrirá entre los días 40 y 70 de preñez, ocurriendo también luteinización en los folículos antrales que no ovularon. Por lo tanto la eCG posee en la yegua, un importante impacto sobre la habilidad del ovario para producir $\mathrm{P}_{4}$. Esta hormona atraviesa la placenta por lo que también son estimuladas la gónadas del feto. 
En adición a su acción luteotrófica, la eCG posee una fuerte acción semejante a FSH cuando es administrada a hembras de otras especies. En realidad esta hormona causará un marcado desarrollo folicular en la mayoría de las especies y es utilizada para inducir superovulación (Senger, 2003).

La eCG es utilizada ampliamente en medicina veterinaria como un método eficaz y de bajo costo para inducir el desarrollo folicular en los ovarios inactivos de animales sexualmente maduros. Por otra parte, si bien esta hormona posee predominantemente acción FSH también posee cierta acción LH y en algunas ocasiones podría provocar ovulación cuando es administrada (Stabenfeldt y Edqvist 1999) Los ovarios inactivos que por cualquier causa se encuentran en estado quiescente pueden entrar en actividad luego de la administración de eCG. Una sola administración por vía subcutánea de eCG suele producir crecimiento folicular en la vaca luego de 2 a 5 d, en esta especie se ha documentado una vida media para esta hormona de $40 \mathrm{~h}$, mientras que con dosis elevadas se puede producir superovulación. Se han evaluado en detalle varios procedimientos de inducción de la ovulación en vacas, yeguas, ovejas, cabras y cerdas.

La hCG es una glicoproteína que consta de dos cadenas peptídicas $(\alpha, \beta)$ y que contiene galactosa y hexosamina, su peso molecular es de 30.000 y posee una vida media de 8 a 12 h. Es químicamente diferente de la hormona luteinizante pero su acción biológica es muy semejante, teniendo también cierta actividad semejante a FSH. La hCG se forma en los citotrofoblastos de las vellosidades coriónicas de la placenta humana y aparece en la orina a las pocas semanas de la concepción, alcanzando su valor máximo hacia el día 50 de gestación, a partir del cual decrece hasta valores casi nulos. Desde el punto de vista farmacológico la hCG es un producto de bajo costo que causa 
ovulación en la hembra y estimula las células de Leydig aumentando la producción de andrógenos en el macho. Su uso en medicina veterinaria es amplio, para provocar ovulación en la yegua en el momento de ser servida, como agente terapéutico para inducir luteinización y posible ovulación en quistes ováricos en el ganado vacuno y en la terapéutica para el criptorquidismo en todas las especies. La administración de hCG puede estimular los ovarios de cualquier especie animal (Stabenfeldt y Edqvist, 1999).

\section{Ciclo Estral}

Con el conocimiento del mecanismo de acción de las hormonas hipotalámicas, hipofisiarias, gonadales y del tipo hipófisis anterior así como con la correcta comprensión de las particularidades del ciclo estral canino, podremos evaluar los diferentes protocolos existentes para inducir ciclos fértiles en perras. Es necesaria la total comprensión de los diferentes estadios del ciclo reproductivo de la perra, para poder actuar luego sobre el mismo utilizando diversos estímulos hormonales.

Si se compara a los caninos con otros animales domésticos, se puede observar que la perra posee varias características reproductivas que la distinguen de otras especies. La perra es monoéstrica con escasa o nula estacionalidad (Hoffman y col, 1996). Luego de la ocurrencia del ciclo estral se produce un período de anestro de duración variable lo que da como resultado un intervalo entre los ciclos que puede oscilar entre 5 y 12 meses. El período de proestro y comportamiento de estro es prolongado y variable (3-20 d), el inicio del comportamiento de estro puede ser tan temprano como 5 d antes de la ovulación o tan tardío como 3 d después. La ovulación ocurre 2 d después del pico de LH. La hembra canina, a diferencia de otras especies, ovula ovocitos primarios que tardarán 2 o $3 \mathrm{~d}$ en madurar en el oviducto momento en el 
cual podrán ser fecundados es decir aproximadamente $4 \mathrm{~d}$ después del pico preovulatorio de LH. En contraste a lo que ocurre en otras especies domésticas, la función lútea es prácticamente igual en la perra preñada que en la vacía, con la única diferencia que en la perra preñada la $\mathrm{P}_{4}$ retorna a niveles basales en forma abrupta inmediatamente antes del parto mientras que en la perra vacía decrece paulatinamente durante el final del diestro (Hoffman y col, 1996). En esta especie no existe un mecanismo luteolítico por lo tanto la $\mathrm{P}_{4}$ permanecerá elevada durante la fase lútea en la hembra vacía, aproximadamente $75 \mathrm{~d}$. No se han identificado gonadotrofinas ni $\mathrm{P}_{4}$ de origen placentario que sean secretadas durante la gestación y los esteroides sexuales son enteramente de origen ovárico. La liberación feto-placentaria de PGF induce la luteólisis pre parto (Concannon, 2009). Por otra parte, en la perra no gestante, la larga duración de la fase lútea resulta en agrandamiento mamario. En las perras al final del diestro y en concordancia con el descenso de la concentración de $\mathrm{P}_{4}$ a niveles basales sin descenso de la concentración sérica de PRL, puede ocurrir desarrollo mamario con secreción láctea y cambios de conducta, condición clínica denominada seudopreñez (Concannon, 2011).

Puede definirse a la perra como monoéstrica, no estacional, politoca, con ovulación espontánea, con una fase lútea de larga duración seguida de un anestro obligado (Concannon, 2011). La fisiología reproductiva particular de la perra doméstica hace necesario un acabado conocimiento del ciclo estral y del período periovulatorio para poder realizar un correcto manejo reproductivo, una adecuada implementación de la inseminación artificial así como el diagnóstico y tratamiento de enfermedades relacionadas con la reproducción (Concannon, 2003). Estos hechos han impulsado a los investigadores a estudiar extensamente la biología reproductiva de la hembra canina en 
los últimos años (Concannon y col., 1989; Johnston y Romagnoli 1991; Noakes y col., 2001).

Como se mencionó anteriormente, la perra puede clasificarse como monoéstrica no estacional lo cual significa que solo ocurrirá un estro por ciclo y que el mismo no es estacional ya que la perra podrá ciclar en cualquier momento independientemente de la estación (Sokolowski, 1977). Esto da como resultado la ocurrencia de camadas a lo largo de todo el año. Si bien el perro doméstico (canis lupus familiaris) y el dingo junto con otras seis subespecies del lobo gris muestran estacionalidad reproductiva, la perra doméstica a diferencia de otras especies de canis lupus, ha perdido la fotoperiodicidad reproductiva observada en lo cánidos silvestres (Concannon, 2009). Algunos autores discuten un aumento estacional de la actividad sexual en correlación a lo que ocurre en otros cánidos como el zorro, el coyote, el perro salvaje y el perro basenji africano, que ciclarán solo una vez por año y la estación reproductiva dependerá del hemisferio en el que habiten (Fuller 2001; Jochle y Andersen, 1977). La actividad sexual estacional ligeramente aumentada durante el período primavera-verano podría ser el resultado de algunos elementos ambientales que estimulan el eje hipotálamo- hipófisis-ovario. Sin embargo al estudiar los establecimientos de cría puede observarse que en los mismos las pariciones dependen de factores genéticos y de manejo, ya que existe una preferencia de los criadores para que las camadas nazcan cuando mejoran las condiciones ambientales, relacionándose también con las preferencias que establece el mercado de venta de cachorros. Es así que los picos de parición tienden a ocurrir hacia fines del año (diciembre) en el hemisferio sur, mientras que son más tempranos (julio) en el hemisferio norte. Es por todo esto que para evaluar los patrones estacionales del ciclo estral de la perra se debe considerar la compleja interacción de factores genéticos, 
climáticos y de manejo (Feldman y Nelson, 1987). En relación a lo anteriormente discutido diferentes estudios realizados han demostrado que el medio ambiente, puede influir en la estacionalidad del ciclo estral, pero que esta influencia es escasa en la perra doméstica. Diversos trabajos donde se evaluaron varios criaderos demostraron que los nacimientos de cachorros ocurren en todos los meses del año (Fosberg y, Wallen 1992).

La pubertad puede definirse como el momento a partir del cual un individuo es capaz de reproducirse. En la perra la pubertad puede reconocerse por el comienzo del primer proestro. El inicio de la pubertad se correlaciona con el momento en que la perra alcanza la talla de adulto. Por lo tanto puede ocurrir entre los 6 y 10 meses en las perras de talla pequeña, mientras que en las de talla grande puede demorarse hasta aproximadamente los dos años (Sokolowski, 1977). La madurez sexual o máxima capacidad reproductiva puede ser alcanzada recién en el segundo, tercer o cuarto celo (Feldman y Nelson, 1987; Johnston y col., 2001). La duración y las características del proestro y el estro pueden diferir entre las perras púberes y maduras. Es probable que las perras púberes demuestren un comportamiento de estro menos manifiesto durante la ovulación pudiendo ser menor la duración del proestro y el estro (Wildt y col., 1981). Así mismo se ha comunicado que en algunos ciclos de perras púberes, los patrones de $\mathrm{E}_{2}$, LH y $\mathrm{P}_{4}$ fueron irregulares (Johnston y col., 2001, Wildt y col, 1981). Por otra parte las perras púberes pueden manifestar celo fragmentado con mayor frecuencia, durante el cual la hembra mostrará algunos signos verdaderos de proestro-estro, como descarga vulvar serosanguinolenta, edema vulvar, atracción del macho y en algunos casos pueden ser receptivas. Sin embargo no ocurre ovulación y a los pocos días los signos regresan hasta que el estro verdadero comienza luego de varios días o semanas. No ocurrirá la ovulación durante la primer mitad o falso celo, pero si en el celo verdadero, y si se le da 
servicio en el momento adecuado puede ocurrir concepción (Feldman y Nelson, 1987). Las perras púberes, más frecuentemente que las adultas, mostrarán celos silentes, durante los cuales ocurrirá ovulación pero en ausencia de comportamiento o signos clínicos notables de proestro-estro (Johnston y col., 2001).

Hace más de 100 años Heape describió los estadios clásicos del ciclo estral canino (Heape 1900). Sin embargo como este hecho fue anterior a la comprensión de los mecanismos hormonales, dicha clasificación solo se basó en la fisiología y comportamiento sexual de la hembra canina. En la actualidad el ciclo reproductivo de la perra doméstica (canis lupus familiares), puede describirse en base a los cambios de comportamiento, clínicos, fisiológicos, citológicos y endocrinológicos ocurridos en ella. El mismo incluye cuatro estadios: proestro, estro, diestro y anestro, considerándose como día cero del ciclo al pico pre-ovulatorio de LH (Concannon, 2011). La duración del intervalo interestral es variable pudiendo oscilar entre 4 a 10 meses con un promedio de 7 meses. Existen diferencias entre perras de una misma raza y entre diferentes razas (Sokolowski 1977). Si bien las hembras de talla pequeña tienden a tener más ciclos estrales por año que las de talla grande, esto no siempre ocurre, ya que el ovejero alemán tendrá más ciclos estrales por año que el Boston Terrier (Johnston y col., 2001, Sokolowski, 1971). Los intervalos interestrales más frecuentes que cada 4 meses se asocian con infertilidad y los que demoran más de 11 meses con subfertilidad. Las razas caninas africanas como el Basenji ciclan una vez por año siendo las únicas razas que poseen un intervalo interestral normal de más de 11 meses (Feldman y Nelson, 1987). Diferencias en la duración del anestro entre diversas razas y dentro de una raza, entre diversas familias indica una base genética en las variaciones de los intervalos interestrales (Okkesns y Kooistra, 2006). La heredabilidad del intervalo interestral ha 
sido estimada en un 35\% (Johnston y col., 2001). Así en perros Collies por ejemplo, el intervalo interestral es de aproximadamente 36 semanas y en Ovejeros Alemán es de 20 semanas (Okkens y Kooistra, 2006). Los factores ambientales pueden también afectar la duración del intervalo interestral, así una perra en anestro acortará su intervalo interestral si se la ubica en las proximidades de una en estro debido al efecto estimulador de las feromonas (Okkens y Kooistra, 2006).

Como se mencionó anteriormente el ciclo reproductivo canino puede dividirse en cuatro estadios (proestro, estro, diestro y anestro) los cuales describiremos a continuación.

\section{Proestro}

El proestro ha sido definido clínicamente como el estadio del ciclo estral en el que son fácilmente reconocidos en la hembra cambios externos (vulva edematosa y turgente, con descarga serosanguinolenta de origen uterino) que indican la proximidad del estro (Johnston y col., 2001). Este estadio habitualmente se extiende desde la primera observación de sangrado hasta que la perra acepta al macho (Feldman y Nelson, 1987). En las perras maduras, la duración promedio es de 9 d con un rango de 0 a 27 d (Bell y Christie, 1971).

\section{Signos clínicos}

Durante el proestro, la perra usualmente atrae al macho pero no está receptiva, de manera que no permite el servicio. En el proestro temprano, la hembra desalienta activamente todo intento de cópula por parte del macho, puede reaccionar gruñendo, mostrando los dientes, tirando dentelladas y manteniendo la cola pegada contra el 
periné, entre los miembros posteriores cubriendo la vulva (Dumon y Fontbone, 1992). Este patrón de conducta cambia gradualmente a medida que avanza el proestro y la perra se torna más pasiva en su resistencia a la aproximación del macho. La hembra se vuelve más juguetona pero responderá gruñendo cuando el macho intente acercarse a sus cuartos traseros o se sentará para impedir el servicio. El macho será atraído por la presencia de feromonas en la descarga vulvar, la secreción de los sacos anales y la orina (Feldman y Nelson, 1987).

El proestro en general pero no siempre está asociado a cantidades variables de secreción vaginal sanguinolenta que proviene del útero y pasa a través del cuello uterino ligeramente relajado hacia la bóveda vaginal. Esta hemorragia es el resultado de la diapédesis y ruptura capilar subepitelial dentro del endometrio (Feldman y Nelson, 1996). El sangrado varía de perra a perra, siendo también variable la respuesta del animal ya que algunas perras se higienizarán más que otras, por lo cual será más dificultoso detectar el comienzo del proestro, a esto se añade en algunas razas como el collie la presencia de pelo largo y cola caída (Feldman y Nelson, 1987). En ocasiones una secreción mucoide parduzca puede observarse antes del sangrado verdadero y tumefacción vulvar, algunas hembras cesan el sangrado a medida que avanzan hacia el estro mientras que en otras la secreción se decolora y se torna transparente (Dumon y Fontbone 1992).

A medida que avanza el proestro, la vulva se agranda y esto está asociado al edema y tumefacción de los labios vulvares. En el proestro tardío la vulva estará hinchada y turgente para luego ablandarse de manera notable en el estro al disminuir la misma (Feldman y Nelson 1987; Concannon, 2003). Ya hacia el final del proestro pueden ser observados tres reflejos sexuales: 1) inclinación hacia arriba o guiño de la 
vulva en respuesta a la fricción de la piel inmediatamente dorsal a la vulva; 2) curvatura ipsilateral de los miembros posteriores en respuesta a golpes suaves en la piel a la derecha o izquierda de la vulva; y 3) desviación contralateral o vertical de la cola en respuesta a golpes suaves en la piel a cada lado de vulva. Estos reflejos sexuales están ausentes en el anestro, aparecen y se incrementan durante el proestro tardío y alcanzan su pico máximo de expresión durante el estro temprano y medio (Beach y col, 1982).

\section{Hallazgos en la vaginoscopía}

La observación macroscópica de la mucosa de la vagina mediante vaginoscopía permite observar que en el proestro temprano, la mucosa se torna edematosa, gruesa, de color rosa pálido, con pliegues redondeados, de borde liso que llenan la luz vaginal. El fluido uterino, a veces abundante es claro y de color rojo brillante. A medida que avanza el proestro los pliegues se tornan más turgentes e hiperémicos, mientras que el fluido observado puede mantener la cuantía del proestro temprano y medio o disminuir (Feldman y Nelson, 1996).

\section{Perfiles hormonales}

Esta fase se encuentra bajo influencia de los Estrógenos (dominancia estrogénica).El proestro forma parte de la fase folicular y las fluctuaciones hormonales ocurridas en este estadio se relacionan con la concentración creciente de estrógenos relacionada con el desarrollo folicular. Los estrógenos son sintetizados y secretados por los folículos ováricos en desarrollo que crecen por influencia de las hormonas gonadotróficas hacia el final del anestro. En el anestro los folículos comienzan a crecer en forma continua, pero no logran madurar sin el apoyo hormonal de la pituitaria. 
Aquellos folículos que desarrollan en el momento que coincide con la estimulación gonadotrófica (aumento de LH) maduran y son capaces de sintetizar y secretar estrógenos. En el proestro temprano los folículos miden 2-3 mm y llegan al final de este estadio a 5-8 mm (Concannon, 2009). El $\mathrm{E}_{2}$ es el responsable de los cambios de conducta, secreción vaginal, atracción del macho, preparación del útero para la gestación y otros cambios del proestro.

Las concentraciones circulantes de $E_{2}$ durante el anestro suelen ser de 5 a 15 pg/ml (Concannon 2009; Feldman y Nelson 1996; Johnston y col., 2001) Inmediatamente antes del proestro clínico se produce un incremento por encima de 15 $\mathrm{pg} / \mathrm{ml}$, durante este período ocurre un importante incremento en la producción de andrógenos, presumiblemente por las células de la teca y que sirve como precursor para el incremento del $\mathrm{E}_{2}$. El aumento de andrógenos se evidencia como elevaciones periféricas de testosterona y androstenediona que acompañan los aumentos del $\mathrm{E}_{2} \mathrm{y}$ que alcanzan picos de 800 y 300 pg/ml respectivamente (Concannon 2011; Concannon y Castracane, 1985). Las concentraciones séricas de $E_{2}$ comienzan a elevarse $15 \mathrm{~d}$ antes del pico de LH y alcanzan sus valores máximos $(79,1 \pm 9,2 \mathrm{pg} / \mathrm{ml}) 24-48 \mathrm{hs}$ antes del pico de LH (Onclin y col, 2002). El proestro temprano cursa con concentraciones séricas de $E_{2}$ mayores a $25 \mathrm{pg} / \mathrm{ml}$ y en el proestro tardío alcanza picos que suelen superar los 60 a $70 \mathrm{pg} / \mathrm{ml}$, con un rango de 40-120 pg/ml, para retornar en forma progresiva a los niveles basales durante los próximos 5 a 9 d. El pico de concentración sérica de $E_{2}$ se produce 24 a 48 h antes de que ocurra la aceptación del macho y comience la declinación de las concentraciones de esta hormona (Figura 1.2, Figura $1.3)$. 


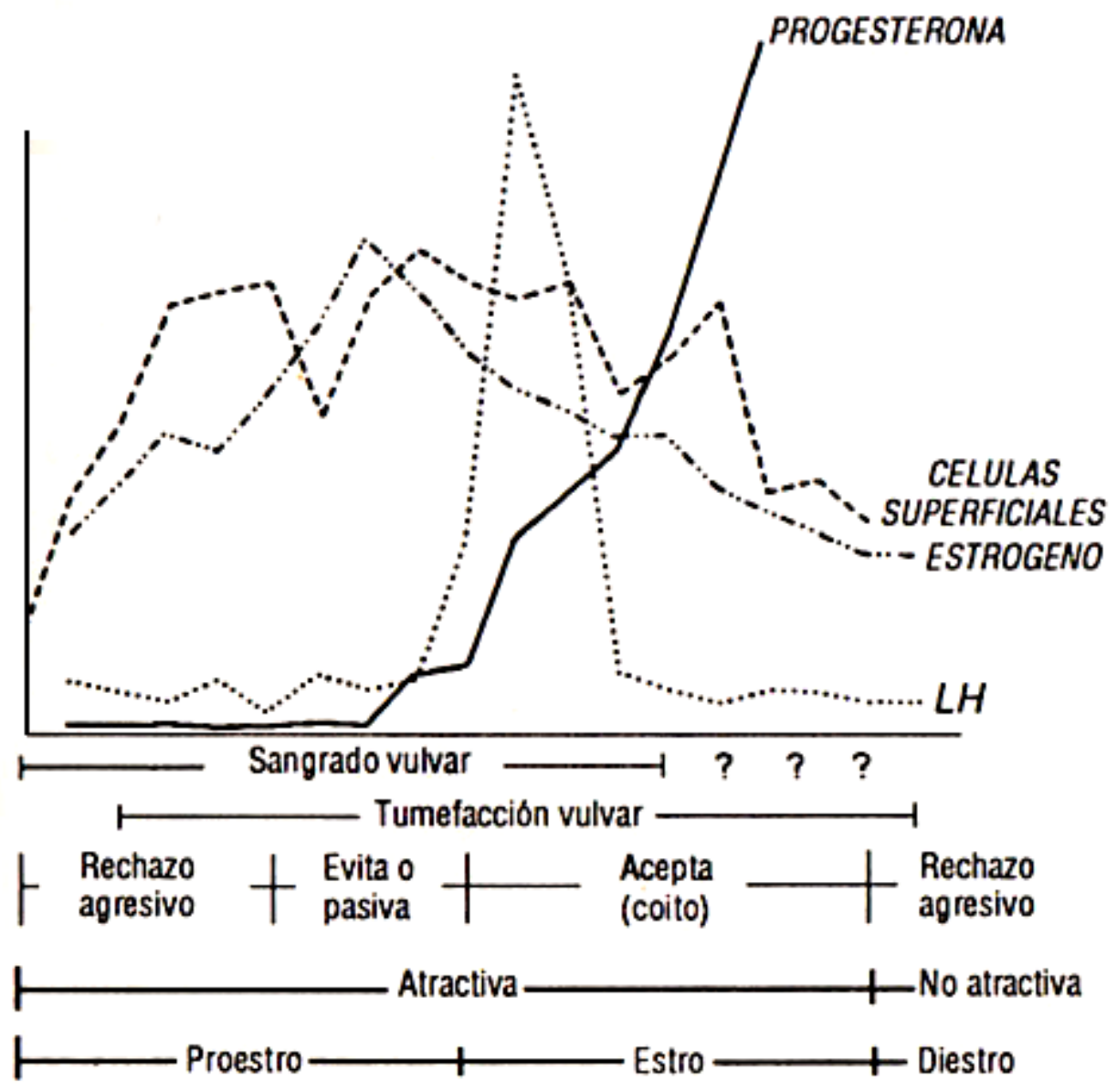

Figura 1.2. Cambios de conducta, citología vaginal y variaciones hormonales durante el proestro y estro en la perra (Feldman y Nelson, 1987). 


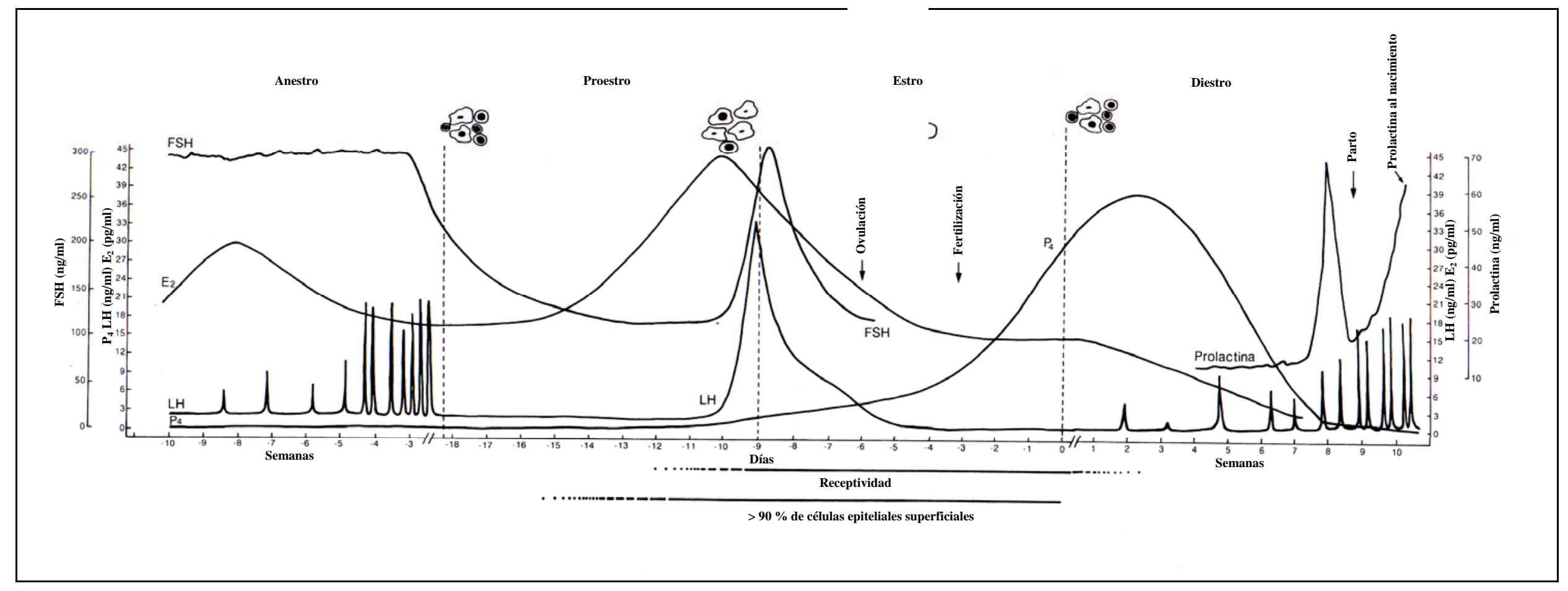

Figura 1.3. Cambios de la citología vaginal y variaciones hormonales durante el ciclo estral de la perra (Jhonston y col, 2001). 
Las concentraciones de $\mathrm{P}_{4}$ se encuentran basales $(<0,5 \mathrm{ng} / \mathrm{ml})$ durante todo el proestro salvo en las últimas 12 a $48 \mathrm{~h}$. El final del proestro y el comienzo del estro están caracterizados por concentraciones séricas de $\mathrm{P}_{4}$ que se elevan por encima de 0,5 ng/ml, al mismo tiempo que la concentración sérica de $\mathrm{E}_{2}$ deisminuye. Este incremento de la $\mathrm{P}_{4}$ sérica está relacionado con la luteinización preovulatoria de los folículos (Olson y col, 1982). Es importante remarcar que ya durante el proestro medio, los folículos de la perra doméstica muestran evidencia morfológica de luteinización (Zhou y col, 1996). Los niveles séricos de LH permanecen cerca de los valores basales durante la mayor parte del proestro, habiéndose comunicado valores superiores a estos en el anestro tardío y proestro temprano (Olson y col., 1982, Wildt y col., 1978).

Durante el proestro, los niveles de LH se vuelven progresivamente más bajos y sus pulsos menos detectables o no detectables debido al feedback negativo inducido por los $\mathrm{E}_{2}$ (Concannon, 2009). Las concentraciones de LH al final del proestro (entre $28 \mathrm{~h}$ y $72 \mathrm{~h}$ antes del pico de $\mathrm{LH}$ ) poseen un valor promedio de 1,9 ug/L. Las concentraciones de gonadotrofinas elevadas en el proestro temprano retornan a niveles basales hasta la próxima onda en el comienzo del estro (Feldman y Nelson, 1987). Las concentraciones de FSH disminuyen durante el proestro, (Olson y col., 1982) probablemente en relación a la retroalimentación negativa sobre FSH ejercida por una hormona producida por el folículo ovárico en desarrollo denominada inhibina (Mondain-Monval y col., 1993). Entre 28 y 72 h antes del pico preovulatorio, la FSH alcanza valores promedio de 1,6 UI/L. El proestro finaliza cuando comienza la conducta receptiva entre 0,5 y $3 \mathrm{~d}$ después del pico de $\mathrm{E}_{2}$. Endocrinológicamente el proestro termina con la ocurrencia de la onda preovulatoria de LH (Concannon, 2011). 
Olson y col (Olson y col., 1982), comunicaron elevadas concentraciones de prolactina cinco días previos a la onda preovulatoria de LH, (Jones y Boyns, 1976) comunicaron que el $\mathrm{E}_{2}$ estimula la liberación de prolactina desde la pituitaria, por lo tanto altas concentraciones de PRL, podrían ser esperadas durante el proestro (Olson, 1982).

\section{Citología vaginal}

La apariencia de las células exfoliadas de la vagina refleja el aumento de las concentraciones séricas de $\mathrm{E}_{2}$. En las muestras de citología vaginal obtenidas durante el proestro temprano se observa una imagen similar a la del anestro tardío, pero con una gran diferencia, la presencia de sangrado vaginal, por lo tanto se observará un número variable de eritrocitos junto con escasas células parabasales, numerosas células intermedias y escasas células intermedias superficiales. Es corriente observar neutrófilos aunque en bajo número, pudiendo también estar presentes bacterias en pequeñas o grandes cantidades. El fondo de estos extendidos a menudo tiene aspecto sucio debido a la presencia de secreciones cervicales y vaginales viscosas. En el proestro medio, el primer indicio de un efecto estrogénico continuo sobre la citología vaginal es la desaparición de los neutrófilos. Estas células entran a la luz vaginal a través del epitelio vaginal pero luego ya no pueden atravesar la pared vaginal de múltiples capas inducida por los $\mathrm{E}_{2}$, los neutrófilos no deberían ser observados nuevamente hasta el diestro. El número de células parabasales e intermedias pequeñas disminuye y son reemplazadas por células intermedias grandes e intermedias superficiales. Los eritrocitos pueden o no estar presentes y el fondo es sucio o claro. En el proestro tardío el frotis vaginal no contiene neutrófilos, la presencia de eritrocitos es 
variable y el fondo es claro. Más del $80 \%$ de las células vaginales son superficiales con núcleos picnóticos o anucleadas (Feldman y Nelson, 1987; Johnston, 2001, Figura 1.4).

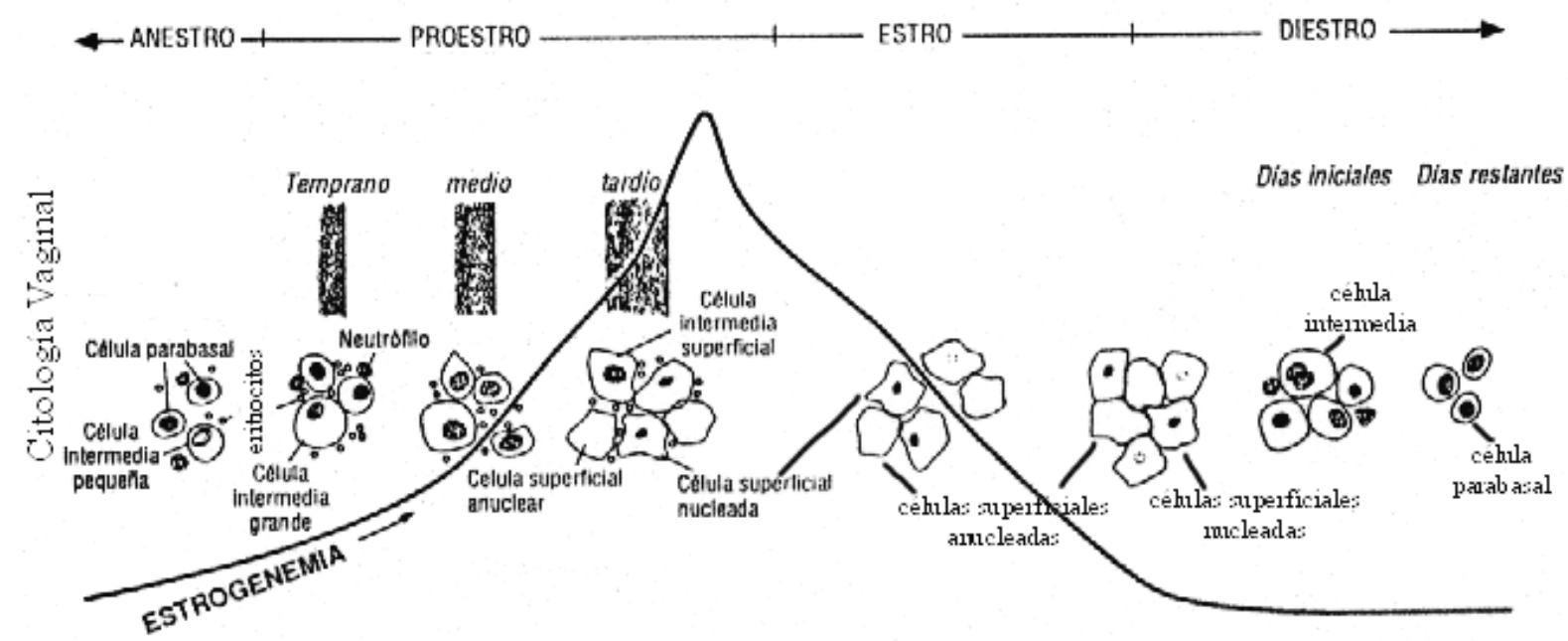

Figura 1.4. Cambios en la citología vaginal y estrogenemia durante el ciclo estral de la perra (Feldman y Nelson, 1987).

\section{Estro}

El comienzo del comportamiento de estro se caracteriza por la receptividad de la hembra que permite el servicio y la aparición de reflejos posturales específicos. El primer día que la hembra permite la cópula es el comienzo del periodo de comportamiento de estro y esta fase finaliza cuando esta ya no acepta el servicio (Feldman y Nelson, 1996).

\section{Signos clínicos}

El comienzo de período receptivo a menudo coincide con la onda de $\mathrm{LH}$, aunque puede ocurrir 1-4 d después o en algunas ocasiones nunca producirse a pesar de perfiles hormonales normales y ovulaciones fértiles demostradas por la ocurrencia de preñez 
luego de la inseminación artificial. La causa de esta desconexión entre la onda de LH y el comportamiento de aceptación del macho aún no se conoce pero indica que existen diferentes vías nerviosas con diferente sensibilidad a los cambios en la relación $\mathrm{E}_{2}: \mathrm{P}_{4}$ (Concannon, 2009).

Los cambios de conducta relacionados con el estro son los de una creciente receptividad al macho. Las perras se agachan y elevan el perineo hacia el macho. La presión sobre o cerca de la grupa hará que la cola sea corrida hacia lateral y se hace evidente la tensión del tren posterior para sostener el peso de la monta (Feldman y Nelson, 1996). La perra en celo puede ser pasiva y aceptar al macho o puede abordarlo activamente. Se ha considerado que la perra solo aceptará un macho dominante y rechazará a los sumisos; de esta manera la hembra llevada al territorio del macho tiene más probabilidades de mostrar sumisión y recepción (Concannon, 2003). La vulva continúa aumentada de tamaño pero el edema disminuye siendo entonces más flácida que en el estadio anterior para favorecer la penetración del macho. La descarga vulvar disminuye en grado variable y contiene menos sangre que en el proestro, por lo que se vuelve de coloración más clara, sin embargo algunas hembras pueden tener descarga sanguinolenta sin variaciones de color entre el estro y el proestro. En ocasiones, la secreción vaginal puede contener suficiente glucosa como para obtener un registro positivo en las tiras reactivas para orina. Esto puede estar causado por las crecientes progesteronemias que promueven intolerancia a los carbohidratos mediante la estimulación de la GH inducida por la progesterona (Feldman y Nelson, 1996). 


\section{Hallazgos en la vaginoscopía}

Luego del pico preovulatorio de LH, los pliegues de la mucosa desarrollan surcos en su superficie, con borde arrugado, el color es más pálido y su tonalidad es grisácea, disminuye el edema y ya no ocupan toda la luz vaginal (Feldman y Nelson 1996; Johnston y col., 2001). Se puede observar que los pliegues pierden progresivamente el edema, ya no ocupan toda la luz, son más bajos y se hacen menos turgentes a medida que se acerca la ovulación (Concannon, 1989; Lindsay, 1983). Estos cambios observados en la mucosa vaginal ocurren como respuesta a la abrupta declinación en el rango $\mathrm{E}_{2}$ : $\mathrm{P}_{4}$, la máxima crenulación suele observarse entre los días 4 y 5, si se considera día cero al día del pico pre ovulatorio de LH (Concannon, 2011).

La duración promedio del celo (comportamiento de estro) es de 9 d con un promedio de 4 a 24 d (Bell y Christie, 1971). Debido a las variaciones observadas en el comienzo del comportamiento de estro en relación a la ovulación es preferible tanto para fines clínicos como de investigación considerar un estro endocrinológico. Este comienza con el pico de LH y termina cuando la observación del extendido vaginal indica el primer día del diestro, momento en que la mayoría de los ovocitos oviductales han degenerado. La abrupta caída en el porcentaje de células superficiales que indica el comienzo del diestro, ocurre en promedio, 8 d después del pico de LH. Pudiendo ocurrir tan temprano como 6 y tan tarde como 11 d después del pico de LH. Tanto la fertilidad como el número de ovocitos fértiles declinan rápidamente entre los días 6 y 9 luego del pico de LH (Concannon, 2003). 


\section{Perfiles hormonales}

La estrogenemia alcanza su pico, 1 o $2 \mathrm{~d}$ antes del comienzo del estro. El estro está asociado con una continua declinación de las concentraciones séricas de $\mathrm{E}_{2}$. La perra comienza a ser receptiva cuando la concentración sérica de $E_{2}$ cae a niveles basales y la concentración sérica de $\mathrm{P}_{4}$ supera los niveles basales es decir alcanza niveles superiores o iguales a $2 \mathrm{ng} / \mathrm{ml}$ alcanzando luego valores de $4-10 \mathrm{ng} / \mathrm{ml}$ lo cual marca el comienzo de la fase lútea (Concannon 1989, Johnston y col., 2001). Es probable que la disminución en la relación $\mathrm{E}_{2}: \mathrm{P}_{4}$ tenga también un efecto en la secreción de feromonas responsables de la atracción del macho (Concannon, 2009). De esta manera las concentraciones de $\mathrm{P}_{4}$ el día del pico de $\mathrm{LH}$ estarán entre 0,8 y 3,0 ng/m, dos días después cuando ocurre la ovulación los valores se encontrarán entre 1,0 y $8,0 \mathrm{ng} / \mathrm{ml}$ (Concannon, 2003). La disminución de las concentraciones séricas de $\mathrm{E}_{2}$ es un reflejo del proceso madurativo final de los folículos varios días antes de la ovulación (Feldman y Nelson, 1987). La declinación de las concentraciones séricas de $\mathrm{E}_{2}$, precede e influye sobre el pico de LH que ocurre el día 0 del ciclo y antecede a la ovulación (Concannon y col, 1979). Existe evidencia de que el pico de LH es iniciada por la declinación en las concentraciones séricas de $\mathrm{E}_{2} \mathrm{y}$ es facilitada por el incremento simultáneo en las concentraciones de $\mathrm{P}_{4}$ (Concannon, 1993; Concannon, 2003).

Es así que la combinación de concentraciones séricas crecientes de $\mathrm{P}_{4}$ y decrecientes de $\mathrm{E}_{2}$ estimula dos eventos mayores. El primero es el cambio en la conducta de la hembra que se vuelve receptiva y el segundo es la retroalimentación positiva que estimula un pico de FSH y LH cuando comienza la aceptación del macho.

Las concentraciones séricas de androstenediona se encuentran elevadas y con variaciones $(73 \pm 13 \mathrm{ng} / \mathrm{dl})$ cerca del pico de $\mathrm{LH}$, declina durante el estro y aumenta 
nuevamente alcanzando valores de entre 40 y $127 \mathrm{ng} / \mathrm{dl}$ entre los días 6 y 18 tanto en perras preñadas como vacías para declinar nuevamente alrededor del día 20 (Concannon y Castrance, 1985). Si bien se observaron elevaciones de testosterona y androstenediona durante la fase folicular, en la fase lútea sólo se observó incremento de androstenediona (Concannon y Castrance, 1985). Además se observó un pico preovulatorio de PRL, que fue también reportada en otras especies como ratas, ovejas (de Gier y col., 2006).

La $\mathrm{P}_{4}$ aumenta poco a poco durante el proestro, desde sus valores basales de 0,20,4 $\mathrm{ng} / \mathrm{ml}$ a valores pre-ovulatorios de $0,6-1,0 \mathrm{ng} / \mathrm{ml}$, lo que refleja la luteinizaión parcial de los folículos visible histológicamente $6 \mathrm{~d}$ antes del pico de LH (Concannon, 1993). Luego la $\mathrm{P}_{4}$ sufre un incremento rápido y manifiesto $(\geq 0,9 \mathrm{y}$ en general de 1,0 2,0 ng/ml) concomitante con el pico de LH y la intensa luteinización pre-ovulatoria de los folículos. Es decir que las células luteinizadas capaces de sintetizar y secretar $\mathrm{P}_{4}$, son funcionales antes que aparezca el CL. Estas células son las responsables de la elevación pronunciada inicial de la $\mathrm{P}_{4}$ sérica asociada con el inicio de la aceptación del macho. La declinación del nivel de $\mathrm{E}_{2}$ junto con el aumento de la $\mathrm{P}_{4}$ sérica puede ser necesaria para la conducta estral de receptividad máxima (Feldman y Nelson, 1996). Se considera también que esta combinación hormonal inicia el pico de LH en la perra (Concannon y col., 1979). Las concentraciones séricas de LH desde el comienzo del pico preovulatorio hasta la concentración máxima fluctúan entre 4,0-40,0 ng/ml, dicho pico ocurre 1-3 d después del pico de estradiol (Concannon y col., 1975). El pico de LH posee una fase de elevación de 12 a 24 h de duración y una de descenso de 12 a 36 h con un promedio de duración de aproximadamente 1,5 d (Concannon, 2009). El pico preovulatorio de LH es relativamente más largo, en comparación con lo que ocurre en otras especies como los bovinos en los que posee una duración de 8 h (de Gier y col., 
2006). Durante el pico pre ovulatorio de LH aumentan simultáneamente FSH y LH. La elevación de FSH resulta en un pico 0,5-1 d después del pico de LH y la fase de declinación hasta los niveles basales es 1-2 d más larga que para LH. Por lo que la duración del pico de FSH es mayor que el de LH. Mientras que para FSH el pico de elevación es dos veces la media de los valores del anestro, para LH es de 10-100 veces la media de los valores del anestro (Concannon, 2009). El pico de LH es seguido por el inicio de la ovulación 24 a 48 h más tarde, para luego producirse la formación del CL. La concentración de $\mathrm{P}_{4}$ sérica aumenta constantemente en estos días y continúa incrementándose por 1 a 3 semanas. Es así que el estro es un período en el que ocurre progresiva caída de $\mathrm{E}_{2}$, progresivo aumento de la $\mathrm{P}_{4} \mathrm{y}$ un pico breve (12 a $24 \mathrm{~h}$ de duración) de liberación de LH (Jeffcoate, 1998).

Algunos cambios hormonales y de comportamiento, relacionados con el comienzo del estro pueden ser variables. Mientras que algunos investigadores han reportado que el pico de LH ocurre el primer día que aparecen los signos de estro otros no hallaron esta correlación (Olson y col., 1982; Wildt y col., 1978). En algunas hembras el comienzo del comportamiento de estro puede ocurrir tan temprano como 2-3 d antes del pico de LH, mientras que en otras no comienza hasta 4 o 5 d después del pico de LH. La duración del pico preovulatorio de LH puede variar, con rangos de 24 a 96 h (Johnston y col., 2001; Olson y col., 1982; Wildt y col., 1978). Luego del pico de LH, las concentraciones de esta hormona permanecen bajas con valores semejantes a los del anestro, proestro temprano o diestro debido a la depleción de la LH pituitaria (Olson y col., 1982). La ovulación ocurre aproximadamente 2 o 3 d después de que ocurre la onda preovulatoria de LH. La perra ovula ovocitos primarios, por lo tanto, no podrán ser fertilizados hasta 48 o 72 h luego de ocurrida la ovulación, cuando se produce la primer 
división meiótica y se transforman en secundarios. En este momento los ovocitos han descendido dos tercios a través de los oviductos y se encuentran listos para ser fecundados (Phemister y col., 1973). Estos ovocitos secundarios serán viables durante 24-48 h en la mayoría de las perras, durante 72-96 h en algunas hembras y pueden llegar en unas pocas a ser viables durante 120 a 144h (Concannon, 2011).

El incremento gradual de las concentraciones séricas de $\mathrm{P}_{4}$ resultantes de la luteinización preovulatoria de los folículos continúa hasta después del pico de LH, cuando sufre el incremento más importante. Los cánidos parecen ser los únicos en mostrar comportamiento de estro en la fase de altas concentraciones de progesterona. Esta variación en las concentraciones de $\mathrm{P}_{4}$ durante el estro puede ser utilizado, junto con otros parámetros como citología vaginal, vaginoscopía y determinación de LH para estimar el momento de ovulación (Johnston y col., 2001; Jeffcoate, 1998). Se ha demostrado que la perra normal tiene un aumento de los niveles séricos de testosterona durante el proestro. La testosterona alcanza la máxima concentración cerca de la onda preovulatoria de LH y la conducta de receptividad. Luego de esto los niveles declinan (Olson, 1984a).

\section{Citología vaginal}

Durante el celo, la citología vaginal se mantiene constante, no existen modificaciones que sugieran el pico de LH o de ovulación o el momento de la fertilización. Las células superficiales nucleadas y anucleadas representan más del $80 \%$ del las células vaginales totales y a menudo alcanzan el $100 \%$. No se observan neutrófilos, los eritrocitos pueden o no estar presentes y el fondo del extendido está limpio. Si bien el porcentaje de células superficiales puede fluctuar, nunca será menor al 
$60 \%$ y por lo general se mantiene entre el $80 \%$ y el $100 \%$. La citología vaginal es un parámetro que por sí sólo es de poca utilidad para predecir el primer día de estro (Olson, 1982b; Figura 1.2).

\section{Diestro}

\section{Signos clínicos}

El diestro comienza con el cese del celo, la perra rechaza al macho, al tiempo que es menos atractiva. La descarga vaginal disminuye hasta desaparecer al igual que el edema vulvar.

\section{Hallazgos en la vaginoscopía.}

En la vaginoscopía se observa que los pliegues de mucosa se tornan delgados, lisos y flácidos. El mucus es de color amarronado y filamentoso (Concannon, 1989; Feldman y Nelson, 1996; Lindsay, 1983).

El primer día del diestro es fácilmente identificado por la mayoría de los veterinarios realizando citología vaginal. En este momento la perra ya no está en su periodo fértil por lo que este método puede utilizarse retrospectivamente, para saber si el servicio fue realizado en el momento adecuado, pero no para determinar el momento óptimo de servicio.

\section{Perfiles hormonales}

Las células del CL canino, aparentemente están pre-programadas para crecer diferenciarse y sobrevivir durante el período de tiempo de una gestación normal, con un promedio de 65 días. Las células lúteas desarrollan rápidamente a partir de sus 
progenitoras en la teca y/o granulosa por mitosis e hipertrofia, junto con el crecimiento de capilares y estroma que llenará todo o casi todo el antro lúteo por 10-15 d en la mayoría de los casos. Durante la luteinización de los folículos, se puede observar en cortes histológicos, que la misma involucra la pérdida de la integridad morfológica de las células de la granulosa y el crecimiento y conservación de la morfología de las células de la teca interna, esto sugiere que es esta última la que contribuye en mayor parte a la formación del CL en los caninos. Tanto la LH como la PRL actúan como hormonas luteotróficas a partir del día 14 o antes. El útero no gestante carece de efecto sobre la función lútea y la histerectomía no alarga la fase lútea. Por otra parte a diferencia de lo que ocurre en otras especies, no existe un mecanismo uterino luteolítico que acorte el ciclo en ausencia de gestación. Sin embargo la PGF es luteolítica después del día 20 y puede suprimir la producción de $\mathrm{P}_{4}$ y por lo tanto inducir el aborto (Concannon, 2009).

La duración de la fase lútea en las perras no preñadas es mayor que en las preñadas, y juega un rol importante en la duración del intervalo interestral en las perras, en las que los niveles de $\mathrm{P}_{4}$ por encima de $2 \mathrm{ng} / \mathrm{ml}$ previenen el incremento preproestro en los pulsos de GnRH. La duración del anestro puede en parte ser dependiente de la duración de la fase lútea (Concannon, 2009).

Se ha comunicado cierta influencia racial en la duración de las fases del ciclo en los perros. Los perros de raza Ovejero Alemán presentan intervalos interestrales más cortos, fases lúteas y períodos de anestro más cortos que en otras razas (Gunzel-Apel y col., 2006).

Las concentraciones de $\mathrm{P}_{4}$ sérica aumentaran rápidamente por encima de 1 o 2 ng/ml 72 a 96 h antes de la ovulación y continuarán aumentando durante el estro 
alcanzando picos de 15 a $90 \mathrm{ng} / \mathrm{ml}$ durante 15 a 30 d después del pico de $\mathrm{LH}$ (Concannon, 1989). Luego las concentraciones de $\mathrm{P}_{4}$ comenzarán a declinar gradualmente durante las próximas 5 o 6 semanas (Figura 1.3). Las perras normales no gestantes que han pasado el celo poseen CL funcionales a pesar de la ausencia de gestación, el CL de las perras no gestantes posee un período funcional mayor que el de las gestantes (Olson, 1984b). Siempre ocurrirá una importante estimulación del tejido mamario a causa de la $\mathrm{P}_{4}$ y este desarrollo mamario puede persistir 1 o dos meses después de que los niveles de $\mathrm{P}_{4}$ retornaron a sus valores basales (Concannon, 2003). Una vez transcurrido el período de meseta de la concentración de $\mathrm{P}_{4}$ sérica diestral, sigue una declinación prolongada de la función lútea. La fase lútea finaliza abruptamente en la perra gestante con el parto (aproximadamente $65 \mathrm{~d}$ pos fertilización). Mientras que en la no gestante la fase lútea cae lentamente durante un lapso adicional de 10 a 20 d (Feldman y Nelson, 1987; Feldman y Nelson, 1996). Es decir que la duración del diestro será de 2 a 3 meses en ausencia de preñez (Feldman y Nelson, 1987; Feldman y Nelson, 1996). Las concentraciones de $\mathrm{P}_{4}$ sérica son semejantes en hembras preñadas y en hembras no preñadas en diestro. Se observó que las concentraciones de $\mathrm{P}_{4}$ sérica serán levemente mayores en perras preñadas, pero las diferencias individuales hacen que la medición sérica de esta hormona no sea de utilidad en el diagnóstico de preñez (Concannon y col., 1975).

En esta especie el mantenimiento de la preñez depende de la producción ovárica de $\mathrm{P}_{4}$ (Sokolowski, 1971). El CL parece ser la única fuente de $\mathrm{P}_{4}$ durante la preñez y la inducción de luteólisis en cualquier momento de la gestación causa interrupción de la preñez o parto prematuro (Wildt y col., 1978). La caída abrupta de la $\mathrm{P}_{4}$ a valores por debajo de 1 a $2 \mathrm{ng} / \mathrm{ml}$ ocurre antes del alumbramiento y es necesaria para que ocurra un 
parto normal. Puede observarse desarrollo mamario durante el diestro, tanto en hembras preñadas como no preñadas debido al aumento de la $\mathrm{P}_{4}$ circulante (Johnston y col., 2001). Se requiere la secreción normal de PRL para que se produzca el pico de secreción de $\mathrm{P}_{4}$ entre los días 8 y 30 de gestación y parece ser un requerimiento absoluto para la secreción de $\mathrm{P}_{4}$ después del día 30 (Concannon, 2003). Los trabajos realizados indican que el CL requiere soporte de luteotropinas durante el diestro, siendo este imprescindible a partir del día 21 (England, 2004). En perras, la LH y la PRL son luteotróficas aproximadamente a partir de la segunda semana después de la ovulación y durante toda la fase lútea tanto en hembras preñadas como en no preñadas. Si bien algunos autores han sugerido que la LH juega un rol secundario al de la prolactina (Vestergen y Onclin, 2008). Existe evidencia que sugiere que por el contrario la LH juega en rol central y activo en la función lútea (Concannon, 2009). La disminución en la $\mathrm{P}_{4}$ circulante como consecuencia de una inmunoneutralización de LH o la disminución de la PRL por agonistas dopaminérgicos como bromocriptina, lleva a algunos investigadores a concluir que en perros, la función lútea durante la última mitad del diestro requiere tanto de LH como de PRL (Concannon, 1987). Por otra parte, otros investigadores sostienen que la PRL pero no la LH es necesaria durante la segunda mitad del periodo lúteo (Okkens y col., 1990). En la perra, la función luteal durante la primera mitad del diestro puede ser menos dependiente de la pituitaria (Johnston y col., 2001). La razón de esta diferencia es aún desconocida, pero se sabe que no es debida a las fluctuaciones en los receptores para LH y PRL en el tejido lútea (Fernandes y col., 1987). La concentración de PRL se incrementa en las perras no preñadas concomitantemente con la disminución de la $\mathrm{P}_{4}$ (Concanon, 1993), un fenómeno a menudo asociado con la ocurrencia de seudopreñez (Gerres y Hoffman, 1994). Se 
observó también que la concentración de receptores de PRL en el cuerpo lúteo se mantiene constante durante el diestro (Concannon, 2009; Fernandes y col, 1987). Se podría concluir entonces que la regresión del cuerpo lúteo ocurre independientemente de la disponibilidad de PRL.

\section{Citología vaginal}

La citología vaginal de una perra que entra en el diestro está claramente demarcada de la que se observa en una perra al final del estro, ya que el porcentaje de células superficiales cae hasta casi el $20 \%$ y el resto de las células son por lo general intermedias. Esto marca un cambio abrupto y evidente en la citología. Pueden reaparecer los leucocitos en el frotis, pero esto no siempre ocurre. Algunas veces pueden observarse células metaestrales, que son células epiteliales vaginales con uno o dos neutrófilos en su interior, pero también pueden ser observadas en otros momentos del ciclo en los que se encuentren neutrófilos y células espumosas que son células epiteliales vaginales con citoplasma espumoso. Luego de los primeros días del diestro, la citología vaginal es similar a la del anestro con leucocitos y eritrocitos en cantidades escasas y las células epiteliales corresponden a intermedias y parabasales (Beach y col., 1982; Feldman y Nelson, 1996; Figura 1.4).

\section{Anestro}

La transición de la fase lútea al anestro es gradual y en general se considera el final de la primera cuando las concentraciones de progesterona se encuentran por debajo de $1 \mathrm{ng} / \mathrm{ml}$. La duración del anestro varía entre las perras, por variaciones de origen 
genético y en la duración del intervalo interestral debidas por ejemplo a diversas condiciones medioambientales y de salud (Concannon, 2003; Okkens y Kooistra, 2006).

\section{Signos clínicos}

Es la fase de reposo del ciclo reproductivo canino que puede ser definida sobre la base de los signos clínicos y de comportamiento. La perra en anestro, no atrae al macho y no está receptiva para el servicio. La vulva es pequeña y la descarga vaginal escasa o ausente. En la hembra no preñada, no existe una demarcación clínica obvia entre el diestro y el anestro.

\section{Hallazgos en la vaginoscopia}

En el estudio vaginoscópico de la mucosa se pueden observar pliegues delgados, flácidos y pálidos. La mucosa es delgada frágil y de apariencia rosada debido a que se pueden observar los vasos sanguíneos que se encuentran por debajo (Concannon, 2003). La duración del anestro es variable y depende de la edad, salud, raza y otros factores. En la perra promedio durará aproximadamente 16 a 18 semanas Si bien pueden ocurrir extremos de 8 a 40 semanas (de Gier y col., 2006).

\section{Perfiles hormonales}

Endocrinológicamente, el anestro suele ser definido como el periodo que sigue al diestro, cuando las concentraciones de progesterona sérica alcanzan niveles basales por debajo de 0,5 a 1,0 ng/ml. 
La progresión desde el anestro temprano al tardío en la perra, se caracteriza por el incremento en la liberación de GnRH desde el hipotálamo. Así, en el anestro tardío, se produce el aumento en la liberación pulsátil desde el hipotálamo de GnRH que induce la liberación de gonadotropinas pituitarias, FSH y LH cuya pulsatilidad aumentan con la proximidad del proestro (Concannon y col., 1986; Olson 1984a; Feldman y Nelson 1996; Shille y col., 1987). A medida que avanza el anestro, se produce un aumento de la sensibilidad de la pituitaria a GnRH y de la respuesta del ovario a las gonadotrofinas (Okkens y Kooistra, 2006). Luego de la estimulación pituitaria, el patrón de liberación será rápido y transitorio para LH y lento y sostenido para FSH (Feldman y Nelson, 1996; Figura 1.3). Las concentraciones séricas de FSH aumentan, alcanzando en el anestro tardío niveles semejantes a los observados durante la onda preovulatoria de FSH durante el estro. Concannon (1993, 2009) y Hoffman y col. (1996), mencionan que el incremento de LH al final del anestro es el principal factor involucrado en la reanudación de una completa función ovárica y la FSH que se encuentra presente durante la mayor parte del anestro podría no ser biológicamente activa.

Durante la mayor parte del anestro, la LH permanece en valores basales, $\leq$ $1 \mathrm{ng} / \mathrm{ml}$, y a medida que se acerca el anestro tardío los pulsos son de 2-25 ng/ml cada 6 a $24 \mathrm{~h}$ y en los últimos $14 \mathrm{~d}$ si bien mantienen la amplitud, disminuyen los intervalos que ahora son de 60-90 minutos, para finalmente elevarse por encima de $3 \mathrm{ng} / \mathrm{ml}$. Sesenta días antes del proestro ocurre un aumento mucho menos pronunciado de FSH (Concanon, 2009).

Por otra parte Okkens (2006) y Onclin (2002), observaron que el incremento de FSH circulante es el evento clave en la foliculogénesis y por lo tanto en la terminación 
del anestro (Okkens y Kooistra, 2006). Las concentraciones de LH y FSH aumentan dramáticamente en hembras ovariohisterectomizadas cuando se las compara con las perras en anestro (Olson y col., 1992). Las concentraciones de $\mathrm{E}_{2}$, durante el anestro permanecen bajas observándose un pico de secreción aproximadamente un mes antes del pico pre ovulatorio de LH aumentando luego, en el proestro con el desarrollo folicular (Jeffcoate 1992; Jeffcoate 1993; Olson y col., 1982).

La PRL podría influenciar el fin del anestro y el inicio del proestro, sus niveles séricos han sido comunicados como variables a lo largo del proestro (Olson, 1982). Existen diversos trabajos que han logrado buenos resultados al utilizar agonistas dopaminérgicos en la inducción de celo. Sin embargo trabajos más recientes indicarían que solo el descenso de la prolactina no sería suficiente para lograr el fin del anestro, por lo cual bromocriptina y cabergolina lograrìn el inicio del proestro por otros mecanismos. (Kooistra y col, 2001; Spattani y col, 2007; Vetergen y col, 1999)

\section{Citología vaginal}

En los extendidos vaginales predominan las células parabasales y las intermedias pequeñas. Los neutrófilos pueden o no estar presentes y los eritrocitos suelen no observarse. Pueden o no encontrarse bacterias y la apariencia del fondo del extendido puede ser clara o sucia (Feldman y Nelson, 1996; Figura 1.4).

\section{Inducción de ciclos estrales}

El conocimiento de las diversas hormonas que participan en la reproducción así como las características peculiares del ciclo reproductivo canino nos permitirá evaluar los diversos métodos para inducir ciclos fértiles. Podremos así implementar el uso de 
nuevos protocolos en un intento de lograr mejores resultados. Los avances logrados en los últimos años en el conocimiento de la biología reproductiva de la perra doméstica, junto a la disponibilidad de nuevos productos hormonales ha permitido mejorar el manejo del ciclo estral de la hembra canina. El aumento del valor y las posibilidades de comercialización de los cachorros de pura raza, así como la creciente importancia de la cría canina tanto desde el punto de vista económico, recreativo o para la obtención de perros de trabajo ha impulsado el estudio y desarrollo de diversos métodos orientados al manejo del ciclo estral de la perra. En concordancia con estos hechos, una práctica en continuo estudio y desarrollo es la inducción de ciclos fértiles que hagan posible el nacimiento de cachorros en relación a las necesidades del criador. También, la inducción de ciclos estrales puede implementarse en aquellas perras con diagnóstico de intervalos interestrales prolongados no relacionados con enfermedad subyacente que pueda considerarse la causa de los mismos. La mayoría de los protocolos utilizados fueron evaluados en perras normales, por esto al implementarse en hembras con problemas subyacentes que afecten el normal funcionamiento del eje hipotálamopituitaria-ovario los resultados son pobres.

La inducción de ciclos estrales para lograr nacimientos en épocas del año en que aumenta notablemente la demanda de cachorros en el mercado (navidad, día del niño, etc.), permite concentrar las pariciones de un gran número de perras en estos períodos del año. Este hecho se encuentra íntimamente relacionado con la obtención de mejores precios por la venta de cachorros.

Como ya se ha discutido, el ciclo estral de los cánidos difiere de manera considerable del de otras especies. En la perra doméstica, la fase folicular y ovulación espontánea son seguidas de una fase lútea con una duración promedio de 75 d (Johnston 
y col., 2001). Un periodo de anestro no estacional y de duración variable, (2-10 meses), le sigue a cada ciclo estral (Bouchard y col., 1991). Los factores que regulan la duración del anestro y terminación del mismo y el comienzo de una nueva fase folicular en las perras aun no se comprenden en su totalidad. En perras normales la progresión desde el anestro temprano al tardío, se asocia con el incremento en la concentración plasmática de FSH, luego de un aumento de la pulsatilidad de GnRH siendo este un evento crítico para la iniciación de la folículogénesis (Kooistra y col., 1999). También se ha observado durante esta transición un aumento en la sensibilidad de la pituitaria a la GnRH (Johnston y col., 2001), un aumento en la respuesta ovárica a las gonadotrofinas (Jeffcoate, 1993), un incremento en las concentraciones plasmáticas de LH hacia el final del anestro (Olson y col., 1982) y un breve período de aumento pulsátil de LH, considerándose a estos eventos determinantes en el inicio de una nueva fase folicular (Concannon y col., 1986).

Por otra parte se ha sugerido que los cambios en la secreción de LH pueden ser más importantes que los cambios en la secreción de FSH para el inicio de una nueva fase folicular que conducirá a la ovulación (Feldman y Nelson, 1996; Johnston, 2001). Es también importante observar que se produce un aumento en las concentraciones de $\mathrm{E}_{2}$ antes del comienzo del proestro, unos $30 \mathrm{~d}$ antes del estro, la significancia de este incremento aún no está bien entendida, pero puede ser el principal estímulo sobre el eje hipotálamo-pituitaria-ovario para iniciar la liberación pulsátil de LH. Este mecanismo de acción es confirmado por la inducción de celos fértiles lograda en perras luego de la administración de DES (Jeffcoate, 1993; Olson y col., 1992).

La inducción de ciclos y la reducción del intervalo interestro pueden realizarse en la perra mediante cuatro alternativas (Concannon y Vestergen, 1997). La primera 
alternativa incluye la utilización de una combinación de gonadotrofinas con o sin DES (eCG y hCG o hMG), gonadotrofinas de la pituitaria (FSH y LH) o DES y FSH. La segunda alternativa incluye la utilización de GnRH y sus agonistas (buserelina y cistorelina) o superagonistas (nafarelina, lutrelina), para estimular la liberación de hormonas gonadotrópicas endógenas de la hipófisis. La tercera alternativa incluye la utilización de prostaglandinas para inducir luteólisis y acortar el diestro. La cuarta y última alternativa incluye la terminación del anestro mediante la utilización de los agonistas dopaminérgicos (bromocriptina, cabergolina, metergolina) que actúan inhibiendo la PRL y acortando así los períodos interestrales (Johnston y col, 2001; Tabla 1.1).

\section{Gonadotrofinas}

Las gonadotrofinas disponibles comercialmente y utilizadas en perros son la FSH, la eCG, la LH porcina, la hCG y la hMG (de la Sota y col., 2002).

Los métodos de inducción utilizando gonadotrofinas exógenas comprenden: 1) administración seriada de FSH o eCG para inducir el desarrollo de los folículos y el proestro, 2) administración seriada de FSH o eCG para inducir el desarrollo folicular seguida de la administración de LH o hCG para provocar la ovulación de los folículos desarrollados, 3) protocolos similares a los descriptos en el punto 1 y 2 precedidos por tratamientos con estrógenos para lograr la sensibilización estrogénica del eje hipofisis/ovario, 4) LH porcina purificada, y 5) hMG (de la Sota y col., 2002).

En la perra se ha estudiado la eficacia de varios protocolos combinando eCG y hCG habiéndose observado diferentes resultados. La eCG se utilizó con dosis de 20 $\mathrm{UI} / \mathrm{kg} / \mathrm{d}$ vía IM o SC durante 5 o 10 d o con una dosis de $44 \mathrm{UI} / \mathrm{kg} / \mathrm{d}$ durante 9 d. En 
ambos casos la inducción de la ovulación se obtuvo con una dosis IM o SC de 500 UI de hCG (Johnston y col., 2001). Los resultados comunicados fueron la inducción de ciclos en el 60 al 100\% de los casos, la ovulación en el 40 al 80\% de los casos y la preñez en el 9 al $56 \%$ de los casos. Por otra parte cuando se utilizaron altas dosis de eCG, como $250 \mathrm{UI} / \mathrm{kg}$ SC durante $20 \mathrm{~d}$ o hasta aparición de proestro, seguida de $500 \mathrm{UI}$ de hCG o 500 UI sc durante 10 d seguida de la administración de 500 UI SC de hCG, se observaron signos de proestro en el $90 \%$ a $100 \%$ de las perras tratadas pero las tasas de preñez fueron de alrededor del 20\%. En líneas generales y como conclusión de la revisión de diversos trabajos, cuanto menos fueron los días de administración de la eCG, mayor fue el porcentaje de preñez (i.e. 5 d, 50-56\% vs. 9-10 d 9-35\%; Johnston y col., 2001). De hecho, se ha comunicado trombocitopenia debido a hiperestrogenismo en el $29 \%$ de las perras tratadas con una dosis de $20 \mathrm{UI} / \mathrm{kg} / \mathrm{d}$ durante $10 \mathrm{~d}$ (Arnold y col., 1989). En aquellas perras que fueron tratadas con $500 \mathrm{UI} / \mathrm{kg}$ IM durante $10 \mathrm{~d}$ seguido de una dosis de GnRH de 50 ug se observaron signos proestro en el $100 \%$ de las perras mientras que las tasas de preñez fueron del 0\% (Johnston y col., 2001).

Puede observarse que, durante las décadas de los 70 y 80 se trabajó intensamente en protocolos de inducción de celos con eCG y hCG. Sin embargo con dichos protocolos se obtuvo una mediana a baja fertilidad con rango muy amplio de variabilidad de los mismos. Una posible explicación de dichos resultados es la utilización de dosis de eCG muy elevadas (44UI $/ \mathrm{kg} / \mathrm{d}$ ) y durante un período muy prolongado (9-10 d). Por ejemplo una perra de $25 \mathrm{~kg}$ recibía una dosis diaria de 1100 UI/d y una dosis total de 11000 UI. La dosis recomendada para la vaca es de 500-1000 UI en una sola dosis. De esto se desprende que tal vez la dosis utilizada en la perra es demasiado alta y el hiperestrogenismo que se produce es el resultado de administrar una 
dosis superovulatoria. De hecho, la utilización de un protocolo con dosis más reducidas (29 UI/kg/d, $500 \mathrm{UI}$, perra $25 \mathrm{~kg}$ ) y durante un período más corto (5 d) alcanzó resultados cercanos al 50\% de preñez (Johnston y col., 2001). Si se utilizara una dosis de $20 \mathrm{UI} / \mathrm{kg}$ como dosis total al inicio y al final, una dosis de 500UI de hCG 48 h más tarde, talvez se podría mejorar la fertilidad debido a que se disminuirían los efectos colaterales mencionados.

Los protocolos que utilizan FSH como estimulo foliculotrópico tienen menos éxito en el logro de inducción de ovulación y gestación que los que utilizan eCG (Shille y col., 1984). Sin embargo, la utilización de inyecciones seriadas de FSH o LH después de un régimen de preparación con estrógenos usando DES ha tenido éxito en la inducción del estro y ovulaciones fértiles. Cuando se utilizó DES a dosis de $5 \mathrm{mg}$ diarios durante 5 a $7 \mathrm{~d}$ para producir signos de proestro y luego se administró $5 \mathrm{mg}$ de LH vía intramuscular el d 5 después del comienzo del proestro o $10 \mathrm{mg}$ de FSH por vía intramuscular los días 9 y 11 a partir del primer día del proestro, todas las perras quedaron preñadas (Moses y Shille, 1988). En un estudio en el que se sustituyó LH por hCG la fertilidad y la incidencia de comportamiento estral no fueron tan exitosos (Shille y col., 1989).

En la tabla 1 se pueden observar los protocolos de inducción utilizados por diferentes grupos de trabajo, en las últimas tres décadas. 
Tabla 1. Protocolos de inducción de ciclos estrales en perras (adaptado de Johnston y col., 2001).

\begin{tabular}{|c|c|c|c|c|}
\hline Protocolo & Proestro & Ovulación & Preñez & Referencia \\
\hline eCG 150-300 UI d alternos 3 veces & $0 \%$ & - & - & Van Haften y col,(1989) \\
\hline eCG $20 \mathrm{UI} / \mathrm{kg} \mathrm{c} / 24$ h $5 \mathrm{~d}+500 \mathrm{UI}$ hCG IM & - & - & $50 \%(n=6)$ & Arnold y col, (1989) \\
\hline eCG 20 UI/kg c/24 h 10 d + 500 UI hCG IM & - & - & $35 \%(n=17)$ & Arnold y col, (1989) \\
\hline eCG 20 UI/kg c/24 h 5 d + 500 UI hCG IM & - & $56 \%(n=25)$ & $56 \%(\mathrm{n}=9)$ & Levya-Ocariz,( 1993) \\
\hline eCG $20-500 \mathrm{UI} / \mathrm{kg} \mathrm{c} / 24 \mathrm{~h} 10 \mathrm{~d}+500 \mathrm{UI}$ hCG SC & - & $56 \%(n=25)$ & - & Thun y col,( 1977) \\
\hline eCG 44-UI/kg c/24 h $9 \mathrm{~d}+500 \mathrm{UI} \mathrm{hCG} \mathrm{SC}$ & $64 \%(n=11)$ & - & $18 \%(\mathrm{n}=11)$ & Nakao y col,( 1985) \\
\hline eCG 44-UI/kg c/24 h $9 \mathrm{~d}+500 \mathrm{UI}$ hCG SC & $100 \%(\mathrm{n}=5)$ & $80 \%(n=5)$ & - & Archabald, (1980) \\
\hline eCG 44-UI/kg c/24 h $9 \mathrm{~d}+500 \mathrm{UI}$ hCG SC & $60 \%(n=5)$ & $80 \%(n=5)$ & - & Archabald (1980) \\
\hline eCG 44-UI/kg c/24 h 5-9 d + 500 UI hCG SC & - & - & $9 \%(n=11)$ & Tsuda, (1995) \\
\hline eCG $250-\mathrm{UI} / \mathrm{kg} \mathrm{c} / 24 \mathrm{~h} 20 \mathrm{~d}$ o hasta aparición de celo $+500 \mathrm{UI}$ hCG SC & $62.5 \%(\mathrm{n}=8)$ & $40 \%(n=5)$ & - & Wright, ( 1982) \\
\hline eCG 500-UI/kg IM c/24 h $10 \mathrm{~d}+500 \mathrm{UI}$ hCG IM & $100 \%(n=15)$ & - & $20 \%(n=15)$ & Chaffaux y col,( 1984) \\
\hline eCG 500-UI/kg IM c/24 h $10 \mathrm{~d}+\mathrm{GnRH} 50 \mathrm{ug} \mathrm{SC}$ & $100 \%(n=5)$ & & $0 \%(n=5)$ & Chaffaux y col,( 1984) \\
\hline eCG $20 \mathrm{UI} / \mathrm{kg} \mathrm{IM} / \mathrm{d} / 5 \mathrm{~d}$. El quinto día 500 UI de hCG I & $0 \%$ & & $0 \%$ & Weilenmam (1993) \\
\hline eCG $110 \mathrm{UI} / \mathrm{kg} 3$ veces & & & & Wrigth $(1980)$ \\
\hline HMG 75 UI IM X 9 d & $90 \%(n=9)$ & $67 \%(n=9)$ & $44 \%(n=9)$ & Wanke y col, (1997) \\
\hline
\end{tabular}


Tabla 1. (Continuación).

\begin{tabular}{|c|c|c|c|c|}
\hline Protocolo & Proestro & Ovulación & Preñez & Referencia \\
\hline eCG 33,3-71,4 UI/KSC por 10d & & - & $0 \%$ & Handaja Kusuma(1977) \\
\hline LH $0,1 \mathrm{UI} / \mathrm{kg} 3$ veces/d por $7 \mathrm{~d}$ IM & $100 \%(n=16)$ & - & $31 \%(n=16)$ & Vestergen y col, (1993) \\
\hline FSH 25-50- UI SC o IM + DES 0.1-0.5 mg SC o IM & $94 \%(n=67)$ & - & - & Arbeiter y Dreier, (70) \\
\hline FSH 10 mg 1 aplicación & $40 \%(n=5)$ & - & - & Shille y col, (1984) \\
\hline FSH $1,2,4,8$ y $16 \mathrm{mg}$ durante $2 \mathrm{~d}$ cada vez & $50 \%(n=4)$ & - & - & Shille y col, (1984) \\
\hline FSH + LH 1:1, 1:1, 2:1, 4:1, 8:2,5, 16:5 en los d 1,3,5,7,9, y11 & $0 \%(n=4)$ & - & - & Shille y col, (1984) \\
\hline DES 5 mg/día VO por 6-9 d, hasta inducir proestro & $100 \%(n=5)$ & - & $100 \%(n=5)$ & Bouchard y col, (1993) \\
\hline $\begin{array}{l}\text { DES } 5 \mathrm{mg} / \mathrm{d} \text { VO por } 7 \mathrm{~d} \text {, hasta inducir proestro }+ \text { LH } 5 \mathrm{mg} \text { IM el d } 5 \text { del } \\
\text { proestro inducido y FSH los d } 9 \text { y } 11 \text { del proestro inducido }\end{array}$ & $100 \%$ & - & - & Moses y col, (1988) \\
\hline $\begin{array}{l}\text { DES } 5 \mathrm{mg} / \mathrm{d} \text { VO por } 5-14 \mathrm{~d} \text {, hasta inducir proestro + hCG } 1000 \text { UI IM } \\
\text { el d } 5 \text { del proestro inducido y FSH los d } 9 \text { y } 11 \text { del proestro inducido }\end{array}$ & $\begin{array}{c}100 \%(n=5) \\
(40 \% \text { de estros })\end{array}$ & - & - & Shille y col, (1989) \\
\hline GnRH, $0.04-0.43 \mathrm{ug} / \mathrm{kg}$ SC cada 90 min por $6-12 \mathrm{~d}$ & $83 \%(n=6)$ & $80 \%(n=5)$ & $69 \%(n=6)$ & Vanderlip y col,(1987) \\
\hline
\end{tabular}


Tabla 1. (Continuación).

\begin{tabular}{|c|c|c|c|c|}
\hline Protocolo & Proestro & Ovulación & Preñez & Referencia \\
\hline GnRH, $1.25 \mathrm{ug} / \mathrm{kg}$ SC cada $90 \mathrm{~min}$ por $11-13 \mathrm{~d}$ & - & - & $86 \%(n=7)$ & Cain y col, (1988) \\
\hline GnRH, 280-500ng/kg SC cada 90 min por 7-9 d & $100 \%(n=12)$ & $89 \%(n=12)$ & $33 \%(n=12)$ & Concannon, (1997) \\
\hline GnRH, 87-270 ng/kg SC cada 90 min por 7-9 d & $84 \%(n=12)$ & $42 \%(n=12)$ & $8 \%(n=12)$ & Concannon y col, (1997) \\
\hline GnRH, $15-85 \mathrm{ng} / \mathrm{kg} \mathrm{SC}$ cada $90 \mathrm{mi}$ por $7-9 \mathrm{~d}$ & $58 \%(\mathrm{n}=12)$ & $33 \%(n=12)$ & $8 \%(n=12)$ & Concannon y col, (1997) \\
\hline Lutrelina SC por infusión constante por $14 \mathrm{~d}$ & - & $75 \%(n=24)$ & $37.5 \%(n=24)$ & Concannon y col, (1997) \\
\hline Bromocriptina $20 \mathrm{ug} / \mathrm{kg} 2$ veces/d por $21 \mathrm{~d}$ & $100 \%(n=6)$ & - & $83 \%(n=6)$ & Van Haaften y col, (1989) \\
\hline $\begin{array}{l}\text { Bromocriptina } 20 \mathrm{ug} / \mathrm{kg} 2 \text { veces } / \mathrm{d} \text { por } 21 \mathrm{~d}+\text { eCG } 300 \text { UI } 3 \text { veces en } \mathrm{d} \\
\text { alternados }\end{array}$ & $71 \%(n=4)$ & $57 \%(n=7)$ & - & Van Haaften y col, (1989) \\
\hline Bromocriptina $100 \mathrm{ug} / \mathrm{kg} 1$ o 2 veces/d VO hasta inducir el proestro. & $100 \%$ & & & $\begin{array}{l}\text { Concannon y Vestergen, } \\
\qquad(1997)\end{array}$ \\
\hline Bromocriptina $250 \mathrm{ug} / \mathrm{kg} 2$ veces $/ \mathrm{d} \mathrm{VO}$ hasta inducir el proestro. & $199 \%(n=4)$ & - & - & Okkens y col,( 1985) \\
\hline Cabergolina $5 \mathrm{ug} / \mathrm{kg} 1 \mathrm{vez} / \mathrm{d}$ VO por $7-10 \mathrm{~d}$ & $100 \%(n=28)$ & - & $93,3 \%(n=28)$ & Jochle y col, (1989) \\
\hline Cabergolina $5 \mathrm{ug} / \mathrm{kg} 1 \mathrm{vez} / \mathrm{d} \mathrm{VO}$ hasta inducir el proestro & $93 \%(n=15)$ & - & $86 \%(n=14)$ & Vestergen y col, (1994) \\
\hline
\end{tabular}


Otros métodos de inducción implican la administración de GnRH exógena o agonistas de GnRH para producir la liberación de gonadotrofinas endógenas desde la hipófisis, crecimiento folicular y estro. La ovulación en estos casos ocurre como resultado del pico endógeno de gonadotrofinas, el crecimiento folicular y secreción de estrógenos. Sin embargo no se disponen de datos sobre la administración de LH o hCG para facilitar la ovulación de los folículos inducidos.

\section{Agonistas de GnRH}

Los agonistas de GnRH, son péptidos semejantes a GnRH, pero con modificaciones en los sitios de degradación enzimática; esto aumenta su resistencia a las peptidasas e incrementa la afinidad de unión al receptor. De esta manera los agonistas de GnRH poseen una mayor vida media en circulación. Los agonistas GnRH inducen inicialmente un incremento sustancial en las concentraciones de LH y FSH, pero la exposición continua frena la secreción de LH como respuesta a una falta de regulación de los receptores GnRH en las células gonadotropas (Herbert y col, 2005).

Los protocolos descriptos incluyen 1) administración endovenosa pulsátil de GnRH cada 90 min durante 6 o 12 d (Vanderlip y Wing, 1987), 2) goteo subcutáneo constante de un agonista de la GnRH durante 14 d (Concannon, 1989) y 3) administración por vía subcutánea de un agonista de GnRH 3 veces por d durante 14 d (Cain y col., 1988). 4) Utilización de implantes subcutáneos (en matriz biodegradables o silastic sólido) de agonistas GnRH, en este caso se documentó la inducción del estro entre 4y 8 días postimplante, cuando se utilizó deslorelina (Trigg y col., 2001), el implante debe ser removido el primer día del proestro para evitar la ocurrencia de efectos negativos sobre el desarrollo folicular debidos a la regulación decreciente que 
ocasionaría el agonista GnRH. Se han utilizado implantes con 1,05 mg, 2,10 mg y 4,70 mg de deslorelina y varios investigadores coinciden en sus resultados y comunican altas tasas de inducción de ciclos y preñez (Fontaine y col., 2011; Kutzler, 2010; Volkman y col., 2006), mientras que Walter y col. (2011), obtuvieron altas tasas de inducción de ciclos, pero el número de ovocitos y embriones fueron menores que los obtenidos por otros investigadores.

En perras en anestro, la administración de GnRH en forma pulsátil utilizando 40 a $400 \mathrm{ng} / \mathrm{kg}$ cada 90 min produjo la aparición de proestro en 3 a 6 d seguido de estro y ovulación en 2 semanas con tasas de fertilidad del 37\% al 85\% (Vanderlip y col., 1987; Cain y col., 1988). Sin embargo el costo que insume la utilización de bombas de infusión, lo hace poco práctico para su uso rutinario. El goteo subcutáneo también indujo proestro y estro, con tasas de fertilidad del $25 \%$ si se lo administraba después del final de la lactación y del $50 \%$ si se administraba durante el anestro después de ciclos sin gestación (Concannon, 1989). Concannon utilizó lutrelina mediante bomba de infusión subcutánea y obtuvo mejores resultados con bajas dosis, posiblemente porque con dosis mayores ocurría una regulación negativa del eje hipotálamo hipofisisario gonadal (Concannon, 2006). Este método también carece de practicidad ya que la implantación y extracción subcutánea de las bombas de infusión osmóticas requieren una cirugía menor. La administración subcutánea de un agonista de GnRH (DTrp-6 $\mathrm{GnRH}$ ), a dosis de $1 \mathrm{ng} / \mathrm{kg}$ cada $8 \mathrm{~h}$, durante $3 \mathrm{~d}$, dio lugar a estro entre los 9 y $11 \mathrm{~d}$ en el $80 \%$ de las perras, quedando todas preñadas. A pesar del inconveniente de las tres inyecciones diarias este protocolo parece presentar la mejor combinación de eficacia y utilidad clínica en la utilización de GnRH (Cain y col., 1988; Concannon 1989; Vanderlip y col., 1987). 


\section{Agonistas dopaminérgicos}

Los agonistas dopaminérgicos como la bromocriptina y cabergolina, han sido también utilizados con éxito para la inducción de ciclos estrales. La dopamina inhibe la liberación de PRL desde la pituitaria anterior; concomitantemente el tratamiento con inhibidores de la PRL disminuye el intervalo interestral e induce el estro en perras con anestro prolongado.

Si los agonistas dopaminérgicos son utilizados durante la fase lútea, el acortamiento del intervalo interestral se debe a un acortamiento de la fase lútea como resultado de la supresión en la secreción de PRL, el principal factor luteotrófico en la perra (Okkens y Kooistra, 2006).

Si bien anteriormente se creía que la inducción de ciclos estrales en la hembra canina, por agonistas dopaminérgicos se debía a la supresión en la secreción de PRL, debido a que está comprobado que elevadas concentraciones de esta hormona inhiben la liberación de LH, en la actualidad la mayoría de los investigadores coinciden que no es este el mecanismo, y que la indución de ciclos se debe a otras acciones aún no bien comprendidas (Okkens y Kooistra, 2006). En condiciones fisiológicas, la concentración de PRL plasmática se mantiene baja durante el anestro y no se han evidenciado fluctuaciones en la transición entre el anestro y la fase folicular (Okkens y Kooistra, 2006).

La administración de agonistas dopaminérgicos a perras en anestro, no solo disminuye la concentración de PRL sérica, sino que también induce desarrollo folicular y estros fértiles probablemente por el incremento en la secreción de gonadotrofinas y de la respuesta ovárica a las mismas. Estos efectos se correlacionan con un incremento en 
la FSH plasmática pero no en la LH (Cirit y col., 2007; de Rensis y col., 2006). Diversos autores coinciden en que la PRL por sí sola no posee un rol predominante en el control de la foliculogénesis en la perra o sobre la transición del anestro al proestro (Spattini y col., 2007).

Los agonistas dopaminérgicos han sido utilizados satisfactoriamente en muchas perras, pero este método de inducción de estro puede requerir más de treinta días de tratamiento, dependiendo del estadio del anestro (temprano o tardío) en el que se encuentra la perra (Vestergen y col., 1999).

La bromocriptina está disponible comercialmente para la utilización en humanos y se ha utilizado en dosis de 20 a $250 \mathrm{ug} / \mathrm{kg}$ observándose una incidencia de aparición de signos de estro y tasas de preñez del 71 al 100\% y 100\% respectivamente. Pueden ser necesarios tratamientos de 1 a 3 meses antes de observar los signos de proestro. Rara vez se observan efectos secundarios importantes pudiendo aparecer vómitos cuando se utilizan dosis altas (Okkens, 1985; Zoldag y col., 2001). La cabergolina es el agonista dopaminérgico con el que se obtuvieron los mejores resultados, posee una alta afinidad por los receptores dopaminérgicos D2, baja afinidad por los receptores serotoninérgicos y acción de larga duración (de Rensis y col., 2006). Está disponible para su utilización en medicina veterinaria y utilizado a dosis de $5 \mathrm{ug} / \mathrm{kg}$ se lograron tasas de preñez del 83 a 93\% (Kooistra y col., 1999). Sin embargo es importante destacar que el tiempo transcurrido entre la realización del tratamiento y la ocurrencia del proestro post tratamiento es sumamente variable (entre 1 y 3 meses). Este hecho hace que no puedan utilizarse estas drogas para sincronizar los ciclos en las perras, de tal manera que las pariciones ocurran en la épocas de mayor demanda de cachorros. Así mismo el tiempo prolongado de administración se relaciona con el incremento del costo del tratamiento, 
la complicación de la administración diaria de la droga y el desaliento del propietario. Por otro lado el escaso número de animales con el que se realizan los ensayos hace difícil realizar una adecuada evaluación de los protocolos de inducción en la perra.

En resumen, los fármacos que más se han utilizado en los últimos años para inducir ciclos en la hembra canina comprenden agonistas GnRH, agonistas dopaminérgicos y en menor medidas las gonadotrofinas exógenas. La mayoría de los autores ha comunicado muy buenos resultados al utilizar implantes de agonistas GnRH siendo el más utilizado deslorelina; sin embargo estos implantes no están disponibles en nuestro país. Si bien en Argentina se ha utilizado en gran medida y con buenos resultados a los agonistas dopaminérgicos para inducir ciclos fértiles, el período desde el inicio del tratamiento hasta el comienzo del proestro es muy variable y en muchas ocasiones prolongado (más de $40 \mathrm{~d}$ ), esto eleva los costos del tratamiento e impide predecir la fecha del ciclo y su sincronización. En relación a lo mencionado aanteriormente y considerando la necesidad de contar con un método de sencilla aplicación en la práctica diaria y que permita establecer el momento en que ocurrirá el celo, la utilización combinada de eCG y hCG podría ser una opción que permitirá buenos resultados con bajo costo.

Considerando que en los protocolos que incluyen eCG y hCG las dosis usadas de eCG son elevadas y el tiempo de administración prolongado, es probable que el uso de dosis reducidas durante períodos más cortos permita la inducción de ciclos fértiles con altas tasas de ovulación y de preñez evitando efectos colaterales indeseables en la madre. De esta manera podrá darse una respuesta adecuada a la insistente demanda de los criadores en relación a la obtención de cachorros en épocas determinadas del año en las que aumenta considerablemente la demanda de los mismos. En la actualidad, no se 
puede responder de manera adecuada a esta necesidad de los productores caninos y esto se relaciona con importantes pérdidas de dinero.

En virtud de lo anteriormente expuesto, los cuatro objetivos de esta tesis fueron: 1) estudiar la vida media de eCG administrada por via IM o IV en caninos; 2) estudiar el efecto estimulatorio de diferentes dosis de eCG sobre la actividad ovárica; 3) evaluar las fluctuaciones séricas de PRL, androstenediona, e IGF1 durante el desarrollo folicular en perras tratadas con eCG, y buscar el momento de administración de hCG para inducir ovulación; y 4) evaluar la eficacia de un protocolo de $50 \mathrm{UI} / \mathrm{kg}$ de eCG im seguido siete días después de 500 UI totales de hCG im en la inducción de ciclos fértiles y sincronización de la ovulación en la perra. Para cumplir con estos cuatro objetivos se realizaron cuatro experimentos que se describen en los siguientes capítulos. 


\section{CAPITULO II}

\section{ESTUDIO DE LA SOBREVIDA PLASMÁTICA DE LA eCG}

\section{INTRODUCCIÓN}

La implementación de protocolos terapéuticos con gonadotrofinas es uno de los puntos centrales en protocolos de inducción y sincronización de ciclos en la perra. Una gran cantidad de investigaciones y descubrimientos han sido realizados a lo largo de aproximadamente 100 años para lograr los productos seguros y efectivos que se encuentran disponibles en el mercado en la actualidad. Runner (Runner 1947 en Comité of American Society 2008) utilizó por primera vez eCG y hCG en ratones para lograr desarrollo folicular y ovulación y las primeras investigaciones de importancia en el ratón fueron publicadas en 1957 (Runner, 1957 en Comité of American Society 2008). En mujeres, la estimulación ovárica fue realizada por primera vez en 1931 utilizando PMSG (Fevold, 1931 citado por Comité of American Society, 2008). A partir de este momento se realizaron múltiples estudios que culminaron en diferentes descubrimientos los cuales han permitido el uso de gonadotrofinas en la terapéutica humana y animal.

La eCG ha sido usada por varias décadas para lograr la inducción de ovulación y superestimulación en varias especies de mamíferos. Puede aislarse de suero, su vida media es prolongada y en especies diferentes de la equina posee tanto efecto FSH como LH. Sus propiedades han hecho que sea ampliamente utilizada en medicina veterinaria. Esta hormona es una glicoproteína que se caracteriza por su alto contenido en carbohidratos, principalmente ácido siálico, galactosa y glucosamina, los cuales constituyen aproximadamente el 45\% de la molécula. Es así que aproximadamente el 20 
$\%$ de la subunidad $\alpha$ y el $50 \%$ de la subunidad $\beta$ están constituidos por carbohidratos. El carbohidrato que se encuentra en mayor proporción es el ácido siálico ( $\mathrm{N}$-acetilneuraminico), que participa en la regulación de la actividad biológica de la hormona ya que hace posible su prolongada permanencia en circulación luego de su secreción o administración. La presencia de un péptido carboxi terminal (PCT) en la sub unidad $\beta$ es la que le confiere una vida media prolongada a las hormonas glicoproteicas. El hecho de que eCG posea una vida media aún mucho mayor, que otras hormonas glicoproteícas, es debido a la presencia de una cadena de ácido siálico en su PCT mucho más larga que la que poseen otras hormonas como por ejemplo la LH de diferentes especias (i.e. eLH [LH equina, 2h], oLH [LH ovina, $23 \mathrm{~min}$ a $2 \mathrm{~h}$ ], pLH [LH porcina, 2h]; Lecompte y col., 2010, Uribe Velazquez y col., 2010). Trabajos en bovinos han demostrado que eCG puede permanecer en circulación entre 10 y 16 días luego de su administración (Martinuk y col 1991).

Aggarwal y Papkoff (1985) demostraron que el clearance de plasma y consumo tisular de eCG en ratas es un proceso bifásico que consiste en una fase inicial caracterizada por un rápido clearance seguida por un período de clearance más lento (Martinuk y col 1991). Más tarde otros investigadores observaron un proceso semejante en otros mamíferos como por ejemplo en ovinos (Martinuk y col., 1991) y en felinos (Swason y col 1997). Los estudios realizados por Martinuk y col. (1991), confirmaron la significancia del ácido siálico sobre el metabolismo y actividad biológica de eCG. Estos investigadores observaron que la pérdida de ácido siálico de la molécula de eCG incrementa su volumen de distribución en el cuerpo, reduciendo los niveles séricos y aumentando la tasa de clearance de la misma, mientras que la tasa de eliminación se mantiene sin variaciones (Martinuk y col., 1991). 
Por otra parte, la vida media excepcionalmente prolongada de la molécula de eCG puede ser en algunos casos una desventaja ya que una sola inyección estimula dos o más ondas asincrónicas de desarrollo folicular en los ovarios animales; el componente semejante a LH de la molécula de eCG puede inducir la ovulación de los folículos maduros y la $\mathrm{P}_{4}$ secretada por los CL puede interferir con la ovulación de las ondas foliculares estimuladas por el componente semejante a FSH de la molécula de eCG. Es por esta razón, que en mucho programas de transferencia de embriones bovinos se realiza un tratamiento previo con dosis luteolíticas de PGF (Allen y Stewart, 1993). Debido a su vida media prolongada, la presencia de eCG en circulación causa sobreestimulación en el desarrollo folicular, lo cual resulta en un gran número de folículos no ovulados, incremento en los niveles de $E_{2}$ y una pobre calidad de los embriones (Martinuk y col, 1991). Esta hormona es utilizada también en felinos domésticos y salvajes para lograr desarrollo folicular, en programas de fertilización in vitro e inseminación artificial. En la gata doméstica una sola inyección de esta hormona es suficiente para lograr desarrollo folicular y esto está relacionado con su vida media larga (Yu y col, 2010). En gatas, se observó una baja fertilidad luego de la implementación de tratamientos con gonadotrofinas exógenas para inducir ciclos fértiles, esto podría deberse a un inadecuado ambiente materno para soportar el desarrollo embrionario (Swanson y col, 1996). Se ha demostrado que las gatas tratadas con eCG/hCG desarrollan folículos ováricos varios días después de inducida la ovulación y que estos folículos formarán CL secundarios que crearán una alteración en el medio ambiente materno. Se cree que debido a su permanencia prolongada en circulación, la eCG contribuye al desarrollo de estos folículos posovulatorios, Sawson y col 1996 observaron que luego de la administración iv de eCG a gatas, la hormona 
permanece en circulación por al menos 120 h y posee una vida media de entre 39 y $55 \mathrm{~h}$. La gonadotrofina coriónica equina ha sido ampliamente utilizada en la perra, en protocolos de inducción de ciclos en las últimas décadas. Aunque la mayoría de los investigadores lograron altos porcentajes de perras en las que se evidenció desarrollo folicular, las tasas de ovulación y de preñez fueron muy variables. En algunos trabajos se ha comunicado el número de cachorros nacidos pero en muchos estudios la ocurrencia del parto y el tamaño de camada no se informa, por lo que no se sabe si la gestación llegó a término y los cachorros fueron normales (Allen 1982; Archbald y col., 1984; Chaffaux y col., 1984; Kutzler 2007; Nakao 1985; Nikson y col., 1992; Okkens y Kooistra 2006; Thun y col., 1977). Al evaluar los protocolos implementados en los últimos años, se puede inferir que estos hechos pueden estar relacionados con las dosis administradas debido a que en los estudios se han utilizado dosis altas de eCG durante varios días lo cual ejercería un efecto sumatorio de las dosis aplicadas. En las primeras investigaciones realizadas durante las décadas del 70 y 80 se utilizaron dosis elevadas durante períodos prolongados de tiempo (10-20 d), más tarde se redujeron las dosis pero se continuó administrando la hormona durante largos períodos, por lo que la dosis total por perra continuó siendo elevada (Tabla 1). Arnol y col. (1989), compararon dos grupos de animales en las que utilizaron dos protocolos de eCG diferentes y observaron que la respuesta al tratamiento fue mejor en aquellas perras en las que utilizaron dosis reducidas durante períodos de tiempo corto. Al revisar la bibliografía pudo observarse que existen datos sobre la vida media de eCG en otras especies como bovinos $40 \mathrm{~h}$ (Martinuk 1991), ovinos 72 h (Pugh D G, 2002), felinos 39-55 h (Sawson y col., 1997) pero no hay datos de la vida media de esta hormonan en caninos. Al estudiar los trabajos realizados en diferentes especies puede observarse que la vida media de la eCG 
es prolongada. Es así que a partir de estas observaciones surge la hipótesis de que el uso de una única dosis de eCG permitiría lograr mejores resultados ya que evitaría la sobreestimulación ovárica con el consecuente hiperestrogenismo y presencia de un ambiente uterino inadecuado para el embrión. Al no contarse con datos sobre la vida media de eCG el primer paso fue estudiar la farmacocinética de esta hormona. Por lo tanto el objetivo de este capítulo fue estudiar la vida media de eCG en caninos. Se planteó la hipótesis de que la vida media de eCG sería superior a 24 h.

\section{MATERIALES Y METODOS}

\section{Diseño experimental y Animales}

Se utilizaron perras $(n=3)$ mestizas, sanas, ovariectomizadas y con un peso de 15 , 20 y $22 \mathrm{~kg}$ en un diseño reversible o switch back (Petersen 1985). Las perras fueron alojadas en caniles individuales acondicionados para tal fin. Cada animal recibió una inyección IM de eCG el primer día del tratamiento (Novormon ${ }^{\circledR}$, Syntex; dosis total 10.000 UI), y 15 días después, cada animal recibió una inyección IV de eCG (Novormon $^{\circledR}$, Syntex; dosis total 10.000 UI).

Las muestras de sangre para determinar la concentración sérica de eCG fueron tomadas 25 min antes y $30 \mathrm{~min}, 1,2,3,6,12,18$ y 24 h después de la administración de eCG IV o IM. Posteriormente las muestras de sangre fueron tomadas diariamente durante los siguientes 6 días post administración de eCG. A cada animal se le colocó un catéter intravenoso $20 \mathrm{G}$, para realizar las extracciones, el cual fue retirado luego de las primeras $24 \mathrm{~h}$. Todas las muestras de sangre obtenidas fueron centrifugadas y el suero almacenado a $-20{ }^{\circ} \mathrm{C}$ hasta que las concentraciones de eCG fueron determinadas mediante ELISA validado (Lecompte y Combarnous 1992). El antisuero de conejo fue 
provisto por el Dr Marcelo Aba (Facultad de Ciencia Veterinarias, Universidad Nacional del Centro del Provincia de Buenos Aires) y fue diluido 1/25.000. La preparación hormonal utilizada como referencia fue una preparación comercial (Novormon ${ }^{\circledR}$, Syntex SA, Argentina), y el volumen de la solución estándar y de las muestras fue de $200 \mu \mathrm{L}$. El coeficiente de variación intra ensayo fue de 8.1\%.

\section{Análisis estadístico}

Las concentraciones séricas de eCG fueron analizadas mediante ANOVA con el procedimiento MIXED de SAS $^{\circledR}$ (SAS Users Guide, 1989). Además, con los datos obtenidos se realizó un análisis farmacocinético no compartimental utilizando el programa informático WinNonlin Professional 5.0 (Scientific Consulting Inc., Cary, NC). Tras la administración IV de eCG se evaluaron los siguientes parámetros farmacocinéticos: semivida terminal $\left(\mathrm{T}^{1 / 2} 2_{\lambda z}\right)$, área bajo la curva, concentración en función del tiempo extrapolada al infinito $\left(\mathrm{AUC}_{0-\infty}\right)$, volumen de distribución $(\mathrm{Vd})$, clearance corporal (ClB) y tiempo medio de residencia (MRT). Luego de la administración IM se calculó concentración plasmática máxima (Cmax), el tiempo al cual se produce la Cmax (Tmax), T1/2,z, $\mathrm{Vd}, \mathrm{AUC}_{0-\infty}, \mathrm{y}$ biodisponibilidad (F).

\section{Marco bioético del uso de animales}

Este experimento se realizó respetando y de acuerdo con las recomendaciones internacionales especificadas en la guía para el cuidado y uso de los animales de laboratorio y utilizando las recomendaciones de la Academia de Ciencias de EEUU referidas al uso de caninos como animales de laboratorio (National Research Council 2002). Estas recomendaciones fueron tenidas en cuenta en lo referente a la atención 
médica veterinaria, medio ambiente, alimentación, sanidad, identificación, sujeción, administración de drogas, toma de muestras sangre y procedimientos quirúrgicos (National Research Council 2002).

\section{RESULTADOS}

Las concentraciones séricas medias de eCG (UI) fueron diferentes de acuerdo a la ruta de administración a lo largo del tiempo (interacción de ruta de administración por tiempo, $\mathrm{P}<0.001$; Figura 2.1).

El análisis farmacocinético reveló que la administración IV de eCG se caracterizó por una rápida fase de distribución y una lenta fase de eliminación. Las curvas de concentración-tiempo para eCG después de la administración IM revelaron una fase de absorción variable y una fase postabsortiva de eliminación prolongada. La concentración sérica máxima de eCG fue similar entre las rutas IM e IV $(6,17 \pm 0,97$ vs. $8,69 \pm 0,50 \mathrm{IU} / \mathrm{mL}, \mathrm{P}>0.08)$, mientras que Tmax fue más larga para la vía IM al compararla con la IV $(17,5 \pm 0,5$ vs. $11,66 \pm 0,33$ h, $\mathrm{P}<0.002)$. Cuando se comparó la eliminación de la droga luego de la administración IV e IM, se observó que la vida media de eliminación fue más corta para la vía IM que para la IV $(38,19 \pm 2,81$ vs. $59,08 \pm 2,81 \mathrm{~h} ; \mathrm{P}<0.03)$. No se encontraron diferencias significativas en el AUC $(307,70 \pm 5,71$ vs. $381,10 \pm 70,90 \mathrm{IU}$ h/ml; $\mathrm{P}>0.48)$. Después de la inyección IM, la biodisponibilidad absoluta fue del 100\%. Por otra parte, luego de la administración IV o IM, la eCG persistió en circulación en todas las perras por al menos $144 \mathrm{~h}$. 


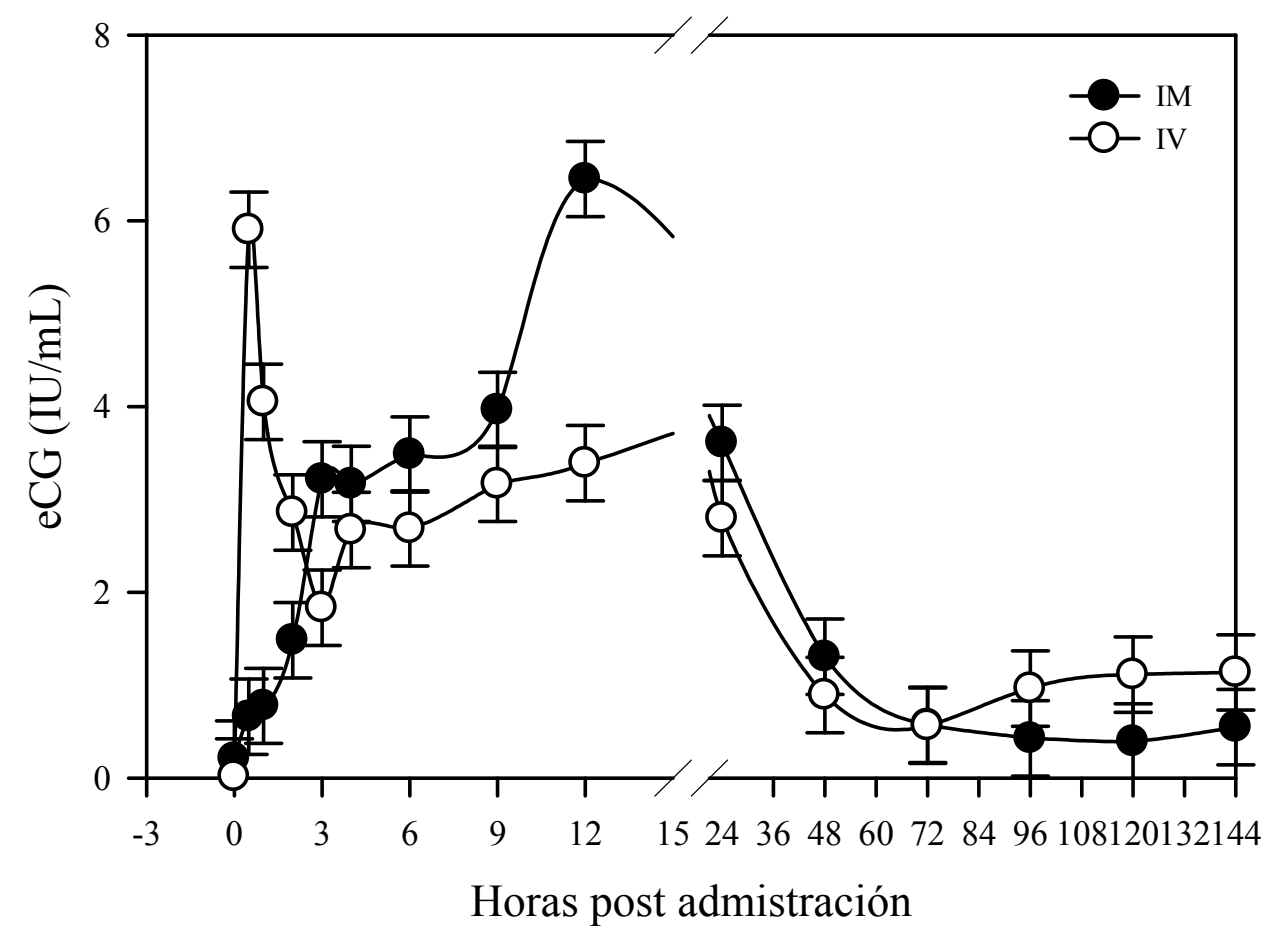

Figura 2.1. Cuadrado medio mínimo y error estándar de las concentraciones de eCG en suero sin extracción luego de la administración IM $(n=3)$ o IV $(n=3)$ en perras (interacción de ruta de administración por tiempo, $\mathrm{P}<0.001$ ). 


\section{DISCUSIÓN}

En los resultados obtenidos, pudimos observar que al igual que en otras especies de mamíferos eCG posee en la perra una vida media larga la cual es de alrededor de $38 \mathrm{~h}$ para la vía IM, con una permanencia en circulación de al menos 144 h. Estos resultados son semejantes a los observados en la gata doméstica por Swanson y col. (1996), quienes obtienen una vida media de eliminación luego de la administración im de eCG de $45 \pm 5$ h. En 1997 Swanson y col realizaron otro estudio el cual obtuvieron luego de la inyección im de eCG una vida media de 27,1 $\pm 1,7$ h y una permanencia en circulación de al menos 120 h. Swanson y col. (1996), adjudican las diferencias observadas en los dos trabajos realizados a la diferente cantidad de muestras obtenidas por animal en relación a la frecuencia de obtención de la muestra y a la extensión horaria del muestreo. Así mismo se puede observar que el número de animales estudiados es diferente (3 vs. 23).

Por otra parte, en este estudio, luego de la administración IM la biodisponibilidad obtenida para eCG fue del 100\% mientras que en gatas del trabajo realizado por Swanson y col. (1996), documentó valores del 52,5\%.

En bovinos Menzer Schams y (1979), hallaron valores semejantes a los encontrados en nuestro estudio en la perra, documentando una vida media de 40 a $51 \mathrm{~h}$ con una permanencia de valores detectables en suero de hasta 115-123 h. Así mismo Martinuk y col. (1991), realizaron un estudio farmacocinético de eCG en ovejas y obtuvieron valores de vida media similares al bovino y a los encontrados en nuestro experimento en la perra (Martinuk y col., 1991; Menzer y Schams, 1979). 
Por lo tanto se puede concluir que la vida media de eCG en la perra es no menor a 35 hs y que en la hembra canina al igual que en otras especies estudiadas, una única dosis de eCG es suficiente para obtener valores detectables en suero durante 5-6 d

Por consiguiente, debido al Tmax más prolongado y la vida media de eliminación más corta observadas en la via IM, se seleccionó esta ruta para ser usada en los Capitulos III, IV, y V. 


\section{CAPITULO III}

\section{BÚSQUEDA DE LA DOSIS EFECTIVA DE eCG}

\section{INTRODUCCIÓN}

Los protocolos que utilizan la administración secuencial de eCG y hCG con el fin de inducir ciclos con gonadotrofinas exógenas, han sido usados con éxito en diversas especies como bovino, ovino, felinos domésticos y silvestres (Goulding y col., 1996; Willard y col., 2006; Zeleke y col., 2005). Sin embargo cuando se implementaron protocolos diseñados en base a gonadotrofinas para inducir ciclos en perras, los resultados obtenidos fueron muy variables y en muchas ocasiones no se obtuvieron los resultados esperados, por lo que en la actualidad no se utilizan de manera corriente en la práctica diaria.

Si bien eCG ha sido ampliamente utilizada durante muchos años para lograr desarrollo folicular y ciclos fértiles en la perra, cuando se compararon los resultados obtenidos por diferentes investigadores, estos fueron muy diversos y en muchas ocasiones se logró desarrollo folicular, pero no se obtuvieron índices altos de ovulación y preñez. La eCG fue utilizada por primera vez para inducir celo en la perra por Scorgie en 1939 (Scorgie 1939 citado por Jhonston 2001), y a partir de este momento, muchos investigadores utilizaron diversos protocolos en el intento de lograr ciclos fértiles, obteniéndose resultados muy dispares en los estudios (Allen, 1982; Archbald y col., 1980; Barta y col., 1982; Christie y Bell, 1971; Greenblatt y Pund, 1941; Jones y col., 1973; Nakao y col., 1985; Thun y col., 1977; Wright, 1972; Wright, 1980; Wright, 1982). Estos investigadores implementaron varios protocolos, los cuales incluyeron la 
administración de la hormona en forma diaria o semanal, y por vía SC e IM (Johnston y col., 2001; Kutzler, 2005; Kutzler, 2007).

Las variaciones observadas en los resultados alcanzados por diferentes grupos de trabajo podrían estar relacionadas con variaciones en la intensidad de la acción farmacológica de las diversas formulaciones, así como las diferentes dosis y protocolos implementados. Por otra parte, la disponibilidad de esta hormona varía entre los países. Por ejemplo en Estados Unidos, está disponible sólo en combinación con hCG (PG $600^{\circledR}$, Merk Animal Health, Florida, Buenos Aires), este producto contiene 80 IU eCG y $40 \mathrm{IU} \mathrm{hCG} / \mathrm{mL}$.

Se ha observado que el éxito para lograr la inducción de ciclos difiere entre los diferentes autores, aunque los regímenes utilizados son muy semejantes. Por otra parte se presentan dificultades cuando se trata de comparar resultados de diferentes investigadores, esto se debe a que la mayoría utiliza escaso número de animales y la definición del anestro se realiza en base al comportamiento de la hembra y citología vaginal, de manera que la mayoría de las veces no se establece adecuadamente la distinción entre anestro temprano y tardío. Sin embargo se ha comunicado diferente respuesta en la inducción de ciclos en la perra en relación con el momento del anestro en el cual se trabaja. Vestergen y col. (1999), comparó la respuesta al tratamiento utilizando protocolos de inducción de ciclos con cabergolina administrada a hembras en anestro temprano, medio y tardío y comunicó un intervalo tratamiento-estro más corto en las perras que se encontraban en anestro tardío al compararlas con las que se encontraban en anestro medio y temprano.

Además de la respuesta ovárica poco predecible (Johnston y col., 2001), se han comunicado diversos inconvenientes asociados a la utilización de eCG y hCG en la 
perra, como hiperestrogenismo y trombocitopenia debidas a la sobrestimulación ovárica y superovulación (Arnold y col., 1989; Weilenmann y col., 1993), fallas en la implantación debido a hiperestrogenismo (Kennelly, 1969; Lehmann y col., 1975) y reacciones alérgicas a eCG (Carter, 1980). Los mencionados efectos indeseables pueden deberse tanto a las dosis altas utilizadas así como al número de dosis administradas en la perra, en comparación a la dosis única y mucho más baja usada en otras especies como la oveja y la vaca (Menchaca y Rubianes 2004; Pugh, 2002; Sá Filho y col., 2010). Es probable que una de las causas de las bajas tasas de nacimientos documentados al implementar protocolos con eCG sea la utilización de dosis elevadas de esta hormona.

Es así que del análisis de los trabajos publicados, en los que se utilizó eCG para inducir celo en la perra, se puede observar que en los primeros años en los que se implementaron protocolos con esta hormona las dosis administradas eran muy elevadas, y se suministraba la hormona durante períodos prolongados; más tarde los investigadores observaron que cuando se disminuía la dosis y el tiempo de administración se obtenían mejores resultados, con menos efectos indeseables en la hembra (Arnold y col., 1989; Johnston y col., 2001). Thum y col. (1977), comunicaron tasas de preñez del $58 \%$ administrando 1,25 -2,8 UI/kg durante 10 días; esta es la dosis más baja comunicada con la que se lograron buenos índices de preñez; sin embargo no se publican tasas de parición.

El objetivo de este trabajo fue evaluar el efecto estimulatorio de diferentes dosis eCG sobre la actividad ovárica. Se trabajó sobre la hipótesis de que el uso de una única dosis de eCG que no supere $50 \mathrm{UI} / \mathrm{Kg}$ permitiría lograr buenos resultados y evitaría la sobreestimulación ovárica, con el consecuente hiperestrogenismo y presencia de un ambiente uterino inadecuado para el embrión. 


\section{MATERIALES Y MÉTODOS}

Se utilizaron perras $(n=25)$ mestizas, sanas, en anestro tardío con un peso entre 15 y $20 \mathrm{~kg}$ en un diseño completamente aleatorizado (Petersen 1985). Se confirmó el estadio en el ciclo reproductivo mediante citología vaginal, concentraciones de P4 en suero y la información brindada por los propietarios sobre el intervalo interestro ocurrido en los ciclos anteriores.

Las perras fueron asignadas en forma aleatoria a uno de cinco tratamientos, y el primer día del protocolo recibieron una inyección IM de: 1) 5 UI/kg eCG (Novormon ${ }^{\circledR}$, Syntex SA; TRT1, n=5); 2) 10 UI/kg eCG (TRT2, n=5); 3) 20 UI/kg eCG (TRT3, n=5); 4) $44 \mathrm{UI} / \mathrm{kg}$ eCG (TRT4, n=5); y 5) $50 \mathrm{UI} / \mathrm{kg}$ eCG (TRT5, n=5). Cada animal recibió una única dosis de hormona. Las perras fueron controladas antes de la administración de eCG y diariamente post administración, para evaluar comportamiento de estro, signología del estro, así como obtención y observación diaria de muestras de citología vaginal para evaluar la respuesta al tratamiento. De cada animal se tomó una muestra de sangre el primer día del protocolo previo a la administración de eCG y una muestra de sangre cuando se evidenció la acción estrogénica en la imagen de la citología vaginal. Todas las muestras de sangre obtenidas fueron centrifugadas y el suero almacenado a $20^{\circ} \mathrm{C}$ hasta que las concentraciones $\mathrm{E}_{2} \mathrm{y} \mathrm{P}_{4}$ fueron determinadas por RIA (Coat-ACount $^{\circledR}$ Estradiol y Progesterona, Diagnostic Product Corporation, Los Angeles, CA). Se determinó $\mathrm{P}_{4}$ para confirmar que todas las perras se encontraban en anestro al inicio de estudio y $\mathrm{E}_{2}$ para evaluar respuesta al tratamiento.

Los coeficientes de variación para $\mathrm{P}_{4}$ intraensayo para el pool alto $(5,6 \mathrm{ng} / \mathrm{mL}) \mathrm{y}$ para el pool bajo $(1,0 \mathrm{ng} / \mathrm{mL})$ fueron de $3,4 \%$ y $6,1 \%$ respectivamente. Los 
coeficientes de variación para $\mathrm{E}_{2}$ intraensayo para el pool alto $(30 \mathrm{pg} / \mathrm{ml})$ y el pool bajo $(8 \mathrm{ng} / \mathrm{ml})$ fueron $5,0 \%$ y $2,9 \%$ respectivamente.

Las perras fueron evaluadas diariamente hasta que se evidenció el comienzo del estro o durante un período de 14 d cuando no se evidenció respuesta al tratamiento. Cada animal de estudio fue observado para evaluar el comportamiento de celo y los signos clínicos de estro, y se estableció una escala de tres grados (1 a 3) para evaluar la respuesta al tratamiento (Tabla 3.1).

Para realizar la citología vaginal se obtuvieron muestras de epitelio vaginal mediante dedo enguantado, el mismo se rotó ejerciendo una presión leve por el piso y las paredes de la vagina. Luego se realizó un extendido sobre un portaobjetos limpio. Las muestras obtenidas se dejaron secar al aire, se tiñeron con la Tinción 15 (Tinción 15 Biopur $^{\circledR}$ ) y se observaron a $100 \mathrm{X}$ y $400 \mathrm{X}$ para evaluar la cantidad de células parabasales, intermedias y superficiales observadas, así como la presencia de eritrocitos y neutrófilos. De acuerdo al porcentaje de cada tipo celular observado se estableció una escala de 5 grados citología vaginal de 1 a 5 (Tabla 3.2).

En todos los animales en los que se observó respuesta al TRT se documentó el día de comienzo del celo y se calculó el intervalo TRT-celo.

A todos los animales del estudio se les realizó un examen físico una vez por semana para evaluar la presencia de efectos adversos. 
Tabla 3.1. Clasificación de grados de comportamiento y signología de estro.

\begin{tabular}{ccc}
\hline Grados & Comportamiento de estro & Signos clínicos \\
\hline 1 & Sin atracción del macho & Sin signos externos de estro* \\
2 & $\begin{array}{c}\text { Atracción del macho, pero sin } \\
\text { receptividad para el servicio } \\
\text { Atracción del macho y } \\
\text { receptividad para el servicio }\end{array}$ & $\begin{array}{c}\text { Escasos signos externos de estro* } \\
\text { Significativos signos externos de } \\
\text { estro * }\end{array}$ \\
\hline
\end{tabular}

*Descarga sero-sanguinolenta, vulva edematosa y turgente.

Adaptado de Feldman Nelson (Feldman y Nelson 1987)

Tabla 3.2. Clasificación de grados de citología vaginal.

\begin{tabular}{lccccc}
\hline \multicolumn{5}{c}{ Citología Vaginal } \\
\hline Grados & $\begin{array}{c}\text { Células } \\
\text { Superficiales }\end{array}$ & $\begin{array}{c}\text { Células } \\
\text { Intermedias }\end{array}$ & $\begin{array}{c}\text { Células } \\
\text { Parabasales }\end{array}$ & Eritrocitos & Neutrófilos \\
\hline 1 & $5-10 \%$ & $80-90 \%$ & $5-10 \%$ & - & - \\
2 & $20-30 \%$ & $65-70 \%$ & $0-5 \%$ & - & - \\
3 & $60 \%$ & $40 \%$ & - & - & - \\
4 & $90-95 \%$ & $5-10 \%$ & $0-5 \%$ & Escasos & - \\
5 & $90-95 \%$ & $5-10 \%$ & $0 \%$ & Abundantes & + \\
\hline
\end{tabular}

Adaptado de Feldman Nelson (Feldman y Nelson 1987).

\section{Análisis estadístico}

Las variables categóricas fueron analizadas con PROC GENMOD y las continuas con PROC MIXED de SAS $^{\circledR}$ (SAS Users Guide, 1989).

\section{Marco bioético del uso de animales}

Este experimento se realizó respetando las mismas consideraciones bioéticas que en el Capitulo II. 


\section{RESULTADOS}

Antes de iniciar el tratamiento, se confirmó el anestro en todas las perras del estudio mediante los grados comportamiento de estro + signos clínicos de estro y citología vaginal (comportamiento de estro + signos clincos de estro y citología vaginal =1) y mediante la concentración de $\mathrm{P}_{4}$ séricas $(0,26 \pm 0,06 \mathrm{ng} / \mathrm{mL})$. Entre tres y cinco días después de realizado el tratamiento, todas las perras del TRT5, mostraron grados de comportamiento de estro + signos clincos de estro y citología vaginal significativamente mayores a los observados en los animales de los TRT1-4 (3,00 $\pm 0,11$ vs. $1,08 \pm 0,05, \mathrm{P}$ $<0.0001 ; 5,00 \pm 0,46$ vs. $2,21 \pm 0,21, \mathrm{P}<0.0001 ;$ respectivamente). Cuando se evaluaron los resultados de las concentraciones séricas de $\mathrm{E}_{2}$ se observó que las mismas permanecieron basales $(\leq 0,3 \mathrm{pg} / \mathrm{ml})$ en las perras del los TRT $1-4$, mientras que en las perras del TRT5 la media de las concentraciones séricas de esta hormona fue de 76,36士 $4,18 \mathrm{pg} / \mathrm{ml}$ siendo las diferencias significativas $(\mathrm{P}<0.0001)$. En las perras del TRT 5 la

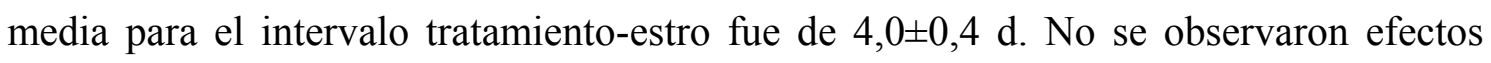
adversos en ninguna de las perras durante el período de estudio.

\section{DISCUSIÓN}

Muchas de las investigaciones realizadas en inducción de ciclos en la perra, en las que se implementó el uso de eCG, fueron realizadas durante las décadas del 70, 80 y principios de los 90 y se utilizaron altas dosis de hormona cuyo rango varió entre 20 UI/kg /día IM durante 5 d (Arnold y col., 1989; Leyva-Ocariz 1993; Weilenmann y col., 
1993) a 10 d (Arnold, 1989), 44 UI/kg IM o SC durante 9 d (Nakao y Aoto, 1985; Tsuda y col., 1995), 35,7 UI/kg SC por $10 \mathrm{~d}$ (Thun y col., 1977), 41,6 UI/kg IM durante 10 d (Chaffaux y col., 1984), 71,4 UI/kg IM durante 9 d ( Kusuma y Tainturier, 1993), $250 \mathrm{UI} / \mathrm{kg}$ IM durante $20 \mathrm{~d}$ (Wright, 1982), or $500 \mathrm{UI} / \mathrm{kg}$ IM durante $10 \mathrm{~d}$ (Chaffaux, 1984). Utilizando estos protocolos, una perra de $20 \mathrm{~kg}$ de peso corporal recibiría una dosis total de 2000 UI, 4000 UI, 7920 UI, 7140 UI, 8320 UI, 12852 UI, 50000 or 100000 of eCG para lograr la inducción del estro. Si evaluamos las dosis que se usan habitualmente en otras especies, podemos observar que en ovejas en estación reproductiva se utiliza una sola administración de 200 UI de eCG, mientras que en anestro 400 UI (Menchaca y Rubianes, 2004). Por otra parte en bovinos de carne, una única dosis de $400 \mathrm{UI}$ de eCG $48 \mathrm{~h}$ antes o en el momento de remover el dispositivo intravaginal de $\mathrm{P}_{4}$ es suficiente para inducir estro en protocolos de sincronización (Sá Filho y col., 2010; Bryan y col., 2010). De lo anteriormente expuesto se puede concluir que las dosis que se implementaron en la perra son elevadas y en muchas ocasiones causan superestimulación ovárica con el consecuente hiperestrogenismo y los efectos indeseables asociados al mismo.

En este experimento, estudiamos diferentes dosis de eCG para inducir desarrollo folicular en la perra. Para seleccionar las dosis consideramos los resultados de vida media y concentraciones de eCG en la perra obtenidas en el primer experimento y las dosis utilizadas por otros investigadores. De esta forma seleccionamos 5 dosis que tuvieron un rango de 5 a $50 \mathrm{UI} / \mathrm{kg}$ y pudimos observar que una única dosis de eCG de $50 \mathrm{UI} / \mathrm{kg}$ fue suficiente para inducir desarrollo folicular en la perra, mientras que con dosis inferiores no se logró respuesta. Este hecho se evidenció por los cambios observados en la citología vaginal, así como en las manifestaciones externas y 
comportamiento de estro en las perras que recibieron $50 \mathrm{UI} / \mathrm{kg}$ de eCG. La dosis efectiva de eCG es menor a las dosis que utilizaron anteriormente otros investigadores. Además, no observamos en las perras estudiadas efectos indeseables.

\section{CONCLUSIONES}

Podemos entonces concluir que una única dosis de $50 \mathrm{UI} / \mathrm{kg}$ de eCG es efectiva para inducir desarrollo folicular en la perra sin ocurrencia de efectos indeseables en las hembras. 


\section{CAPITULO IV}

\section{ESTUDIO DE LA RESPUSTA HORMONAL Y EL DESARROLLO FOLICULAR INDUCIDO LUEGO DE LA ADMINISTRACIÓN DE eCG}

\section{INTRODUCCIÓN}

Si bien los eventos endocrinológicos relacionados con las hormonas gonadales $\left(\mathrm{E}_{2} \mathrm{y} \mathrm{P}_{4}\right)$ e hipofisiarias (FSH y LH), en relación al desarrollo folicular y ovulación han sido ampliamente estudiados en la hembra canina (Johnston y col., 2001; Concannon y col., 1989; Concannon, 2009; Concannon, 2011), existen pocos estudios sobre las fluctuaciones séricas de otras hormonas como PRL y del factor de crecimiento IGF1 durante este período.

La acción del sistema dopaminérgico y la PRL sobre la actividad folicular durante el proestro y el estro ha sido poco estudiada en la hembra canina. En la mayoría de las especies la PRL puede ejercer efectos estimuladores o inhibidores del desarrollo folicular y secreción de $\mathrm{E}_{2}$. En ratas, los perfiles de secreción de PRL fluctúan a lo largo del ciclo estral, en esta especie el $E_{2}$ es el principal regulador de la secreción de PRL e induce el pico de PRL del proestro y el pico secundario que ocurre en el estro (Szawka y Anselmo-Franci, 2004). Así mismo, se sabe que el sistema dopaminérgico y la PRL poseen un rol importante en el control de la actividad reproductiva de la hembra canina y las investigaciones en otras especies indican que la prolactina es un requisito para mantener el crecimiento y desarrollo folicular. (de Gier y col., 2006).

Jones y col. (1976), comunicaron que $\mathrm{E}_{2}$ estimula in vitro, la liberación de PRL desde la pituitaria y que por lo tanto deberían esperarse altas concentraciones de PRL 
durante el proestro en la perra. De igual forma, Etreby y Gunzel (1974) comunicaron que en la perra, durante este período ocurre un incremento en las células productoras de PRL en la pituitaria anterior. Olson y col. (1982), comunicaron la elevación de las concentraciones séricas de PRL cinco días antes de la ocurrencia de la onda preovulatoria de LH.

Por otra parte es bien conocido que el IGF1 juega un rol central en la foliculogénesis y en la respuesta del ovario a FSH en la etapa terminal del desarrollo folicular en la mayoría de las especies domésticas (Reynaud y col., 2010). Igflestimula la proliferación y diferenciación de células de la granulosa en: ratas (Adashi y col1990), cerdos (Hammond y col, 1991) y ovejas (Monniaux y Pisselet, 1992) y estimula la producción de esteroides en las células de la teca (Adashi y col, 1992, Mazebourg y col 2003). En bovinos, porcinos, ovinos y caprinos, este factor de crecimiento incrementa su concentración sérica en relación al desarrollo folicular (Hashizume y col., 2000, Lenz Souza y col 2007, Spicer, y col 1994, Spicer, y col 2002, Zulu y col 2002). Existen pocas investigaciones realizadas en la hembra canina en relación a las concentraciones séricas de IGF1 durante el desarrollo folicular, pero posiblemente posea un rol semejante al de otras especies y por tanto incremente su concentración sérica durante este período. Reynaud and col. (2010), evaluaron las concentraciones de IGF1 en líquido folicular y suero durante la foliculogénesis en perras de diferentes tamaños. Estos investigadores comunicaron una correlación positiva en la concentración sérica y en el fluido folicular del factor de crecimiento así como una mayor concentración de IGF1 en animales de talla grande al compararlos con los de menor talla. En relación a estos hallazgos, estos investigadores comunicaron que 
al igual que en otras especies existe una asociación entre el tamaño corporal y las concentraciones séricas de IGF1 (Reynaud y col., 2010).

Como ya ha sido mencionado en el Capítulo I, la hembra canina como el resto de los cánidos ovula cuando las concentraciones séricas de $\mathrm{P}_{4}$ se encuentran en ascenso y las de $\mathrm{E}_{2}$ en descenso. La testosterona y androstenediona acompañan las fluctuaciones de $\mathrm{E}_{2}$. En los cánidos la ovulación ocurre aproximadamente 48 h después del pico de LH.

Existen controversias en el uso de hCG para inducir la ovulación, cuando se implementan protocolos de inducción de ciclos en la perra, debido a que en esta especie la ovulación es espontánea (Kutzler, 2010). Por otra parte eCG posee efecto FSH y LH y por tanto el estímulo podría ser suficiente para lograr la ovulación. Es así que la hCG se utiliza para lograr la sincronización del momento de la ovulación en los celos inducidos (Kutzler, 2007). La mayoría de los investigadores utiliza hCG en los protocolos de inducción de ciclos en la perra siendo la dosis más utilizada es de 500UI SC o IM luego de la administración de eCG. Esta hormona ha sido administrada el segundo día de estro (Archbald y col., 1980), el quinto día del tratamiento (Weilenmann y col., 1993), el décimo día del tratamiento (Arnold y col., 1989; Nakao y col., 1985; Archbald y col., 1980; Chaffaux y col., 1984; Johnston y col., 2001; Thun y col., 1977).

En resumen, si bien se han utilizado gonadotrofinas para inducir celos en la perra el momento de aplicación de hCG ha sido seleccionado en forma arbitraria. Así mismo si bien existen estudios previos en donde se evaluaron las fluctuaciones de las concentraciones séricas de PRL, androstenediona, e IGF1 durante el desarrollo folicular, ninguno de estos estudios se realizó luego de la administración de un protocolo combinado de eCG para inducir el desarrollo folicular y la ovulación en la perra. 
Por lo anteriormente expuesto, el objetivo de este experimento fue evaluar las fluctuaciones séricas de PRL, androstenediona, e IGF1 durante el desarrollo folicular en perras tratadas con eCG, y buscar el momento de administración de hCG para inducir ovulación. Nuestra hipótesis de trabajo fue que como ocurre en otras especies, PRL, androstenediona e IGF1 se incrementarán en relación al desarrollo folicular. Así mismo estas fluctuaciones junto con el estudio citológico vaginal permitirían caracterizar el desarrollo folicular y estimar el momento de administración de hCG para lograr la ovulación, el que debería ocurrir en el momento de elevación de LH.

\section{MATERIALES Y METODOS}

\section{Diseño Experimental}

Se utilizaron perras $(n=6)$ mestizas, sanas, en anestro con un peso entre 15 y 20 $\mathrm{kg}$ en un diseño completamente aleatorizado (Petersen 1985). Se confirmó su estadio en el ciclo reproductivo mediante citología vaginal y mediante las concentraciones de $\mathrm{P}_{4}$ en suero.

El primer día del protocolo, las perras recibieron una inyección IM de eCG (Novormon $^{\circledR}$, Syntex SA) de acuerdo a la dosis seleccionada en el Capitulo III. Las perras fueron controladas diariamente para evaluar comportamiento de estro y signología del estro (Grados 1-2, Tabla 3.1) y además se realizó en forma diaria la citología vaginal (Grados 1-3, Tabla 3.2) para evaluar la respuesta al tratamiento. La metodología de obtención de muestras y evaluación de los grados asignados fueron los mismos que los utilizados en el Capitulo III. 
De cada animal se obtuvieron dos muestras diarias de sangre desde el inicio del tratamiento hasta el d 10 post tratamiento ( $\mathrm{n}=20$ muestras/perra), o hasta el primer día del diestro. Todas las muestras de sangre obtenidas fueron centrifugadas y el suero almacenado a $-20^{\circ} \mathrm{C}$ hasta que las concentraciones $\mathrm{E}_{2}, \mathrm{P}_{4}$, androstenediona, PRL y IGF1 fueron determinadas. Se utilizó un RIA (Coat-A-Count ${ }^{\circledR}$ Estradiol y Progesterona, androstenediona Diagnostic Product Corporation, Los Angeles, CA, USA) para determinar $\mathrm{E}_{2}, \mathrm{P}_{4}$ y androstenediona. Para la determinación de IGF1 se realizó extracción ácido etanólica seguida de RIA (Breier y col, 1991; Diaz-Torga y col 2002) y para la determinación de PRL se utilizó ELISA (canine prolactin ELISA MKVCP 1; Demeditec Diagnostics GmbH Kiel, Germany Laboratorio; Ciudad, Pais). Los coeficientes de variación intraensayo para el pool alto $(4,8 \mathrm{ng} / \mathrm{mL})$ y para el pool bajo de $\mathrm{P}_{4}$ fue de $(1,0 \mathrm{ng} / \mathrm{mL})$ fueron de $6,0 \%$ y $7,3 \%$ respectivamente. Los coeficientes de variación intraensayo para el pool alto y el pool bajo de $E_{2}$ fueron $(43,5$ y 12,7 pg/ml) $8,0 \%$ y $16,7 \%$ respectivamente. Los coeficientes de variación intraensayo para el pool alto $(6,1 \mathrm{ng} / \mathrm{ml})$ y para el pool bajo $(1,0 \mathrm{ng} / \mathrm{ml})$ de androstenediona fueron de $9,8 \% \mathrm{y}$ $6,6 \%$ respectivamente.

Los Coeficientes de variación intraensayo para prolactina para el pool alto $(17,05 \mathrm{ng} / \mathrm{ml})$ y pool bajo $(6,6 \mathrm{ng} / \mathrm{ml})$ fueron $26,9 \%$ y $4,27 \%$ respectivamente.

Los Coeficientes de variación intraensayo para IGF1 para el pool alto $(79,48$ $\mathrm{ng} / \mathrm{ml})$ y pool bajo $(6,75 \mathrm{ng} / \mathrm{ml})$ fueron $9,61 \%$ y $25 \%$ respectivamente.

\section{Análisis estadístico}

Los grados de comportamiento de estro + signos clínicos de estro y la citología vaginal fueron analizados con GEMOND y las concentraciones hormonales con 
MIXED de SAS $^{\circledR}$ (SAS Users Guide, 1989). Los datos fueron presentados como cuadrado minimo medio \pm error estándar. La significancia fue dfinida como $\mathrm{P}<0.05$.

\section{Marco bioético del uso de animales}

Este experimento se realizaron respetando las mismas consideraciones bioéticas que en los Capitulos II y III.

\section{RESULTADOS}

Antes de la administración de eCG el anestro fue confirmado en todas las perras mediante los grados de comportamiento de estro + signos clínicos de estro y citología vaginal (grado $1 ; \mathrm{P}<0,01$; grado $1, \mathrm{P}<0,01$; respectivamente) y las concentraciones séricas de P4 $(0,23 \pm 0,08 \mathrm{ng} / \mathrm{mL})$.

Dos a siete días $(3,3 \pm 0.94$ d) posteriores a la administración de eCG, todas las perras respondieron al tratamiento y manifestaron signología y citología vaginal de celo (comportamiento de estro + signos clínicos de estro, grado 1,9, $\mathrm{P}<0,01$; citología vaginal, grado $1,9, \mathrm{P}<0,01)$. Tanto las manifestaciones externas, como la signología y citología fueron muy similares a las observadas en celos espontáneos.

$\mathrm{Al}$ analizar las concentraciones de $\mathrm{P}_{4}$ de las muestras obtenidas el primer día del diestro citológico (comportamiento de estro + signos clínicos de estro, grado 1,0, $\mathrm{P}<0.01$; citología vaginal, $3,0, \mathrm{P}<0,01$ ), observamos que tres de las perras no alcanzaron un adecuado pico de LH y no ovularon, mientras que las otras tres lograron un adecuado pico de LH y ovularon (2,80 vs. $85,33 \pm 6,18 \mathrm{ng} / \mathrm{mL} ; \mathrm{P}<0,01)$. Por otra parte, las 
concentraciones de $\mathrm{P}_{4}$ séricas al momento de la administración de eCG fueron similares en todas las perras $(0,23 \pm 0,08 \mathrm{ng} / \mathrm{mL} ; \mathrm{P}>0,37)$.

Si bien el intervalo desde la administración de eCG hasta el comienzo del celo fue similar en todas las perras $(3,3 \pm 0,94 \mathrm{~d})$, el intervalo desde el comienzo del celo hasta el primer día del diestro citológico y el intervalo desde la administración de eCG hasta el primer día del diestro citológico fueron más cortos en las perras que no ovularon al compararlas con las que ovularon $(5,00$ vs. $10,00 \pm 1,31 \mathrm{~d}, \mathrm{P}<0.05 ; 7,66$ vs. $14,66 \pm 0,78 \mathrm{~d}, \mathrm{P}<0,01)$.

Mientras que las concentraciones séricas de PRL y androstenediona se encontraron más bajas en las muestras obtenidas antes de la administración de eCG al compararlas con las obtenidas después de la administración de la hormona $(4,3 \pm 1,8$ ng/ml vs. $6,5 \pm 1,6 \mathrm{ng} / \mathrm{ml}, \mathrm{P}<0.05 ; 0,08 \pm 0,2 \mathrm{ng} / \mathrm{ml}$ vs. $0,42 \pm 0,16 \mathrm{ng} / \mathrm{ml}, \mathrm{P}<0,05)$, las concentraciones séricas de IGF1 fueron similares antes y después de la administración de la hormona $(286,0 \pm 32,2 \mathrm{ng} / \mathrm{ml}, \mathrm{P}>0,53)$.

Así mismo, cuando se compararon las concentraciones de PRL sérica antes de la administración de eCG, con las obtenidas durante el estro y el diestro no se encontraron diferencias significativas $(6,9 \pm 1,7, \mathrm{P}>0,19)$. Además las concentraciones séricas de IGF1 de las muestras obtenidas antes del comienzo el celo y durante el celo fueron superiores que las obtenidas en el diestro citólógico $(286,1 \mathrm{ng} / \mathrm{ml} \pm 29,8 \mathrm{ng} / \mathrm{ml}$ vs. $200,4 \mathrm{ng} / \mathrm{ml} \pm 29,2 \mathrm{ng} / \mathrm{ml}, \mathrm{P}<0,01)$.

Por el contrario, las concentraciones séricas de androstenediona fueron más bajas antes del comienzo del celo y durante el celo que en el diestro $(0,35 \pm 0,17 \mathrm{ng} / \mathrm{ml}$ y 0,38 $\pm 0,15 \mathrm{ng} / \mathrm{ml}$ vs. $0,68 \pm 0,17 \mathrm{ng} / \mathrm{ml}, \mathrm{P}<0,05)$. Estos resultados muestran que la $\mathrm{PRL}$, 
la IGF1 y la androstenediona modifican su concentración sérica durante el desarrollo folicular inducido por una única dosis de $50 \mathrm{UI} / \mathrm{kg}$ de eCG.

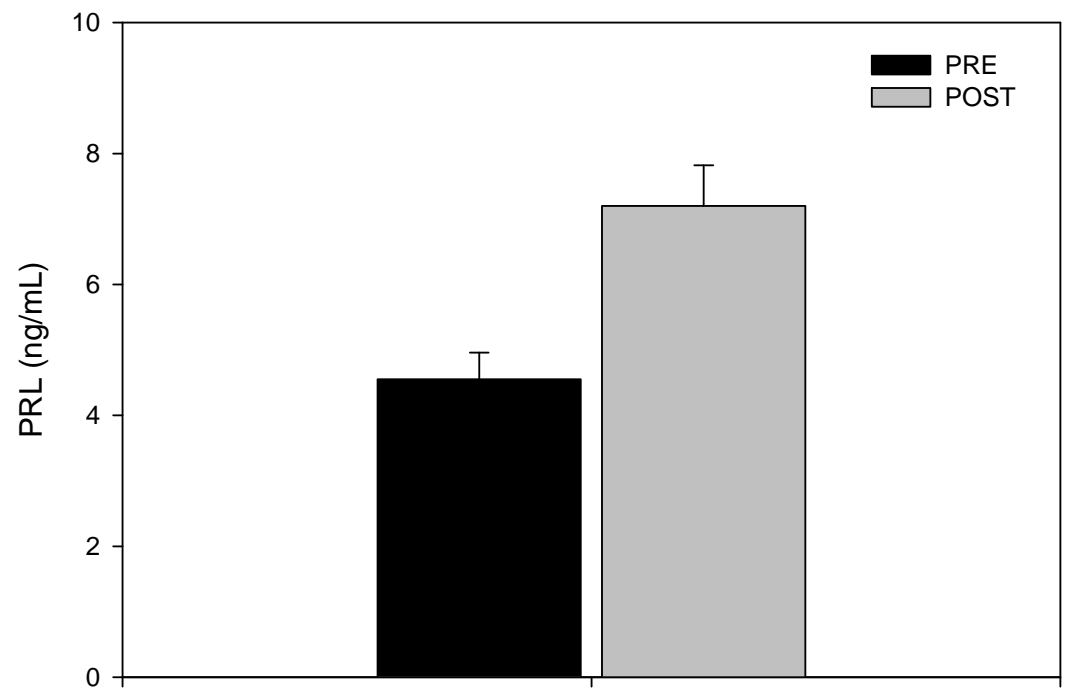

Fig 3.1. Concentraciones séricas de PRL antes y después de la administrar administración eCG.

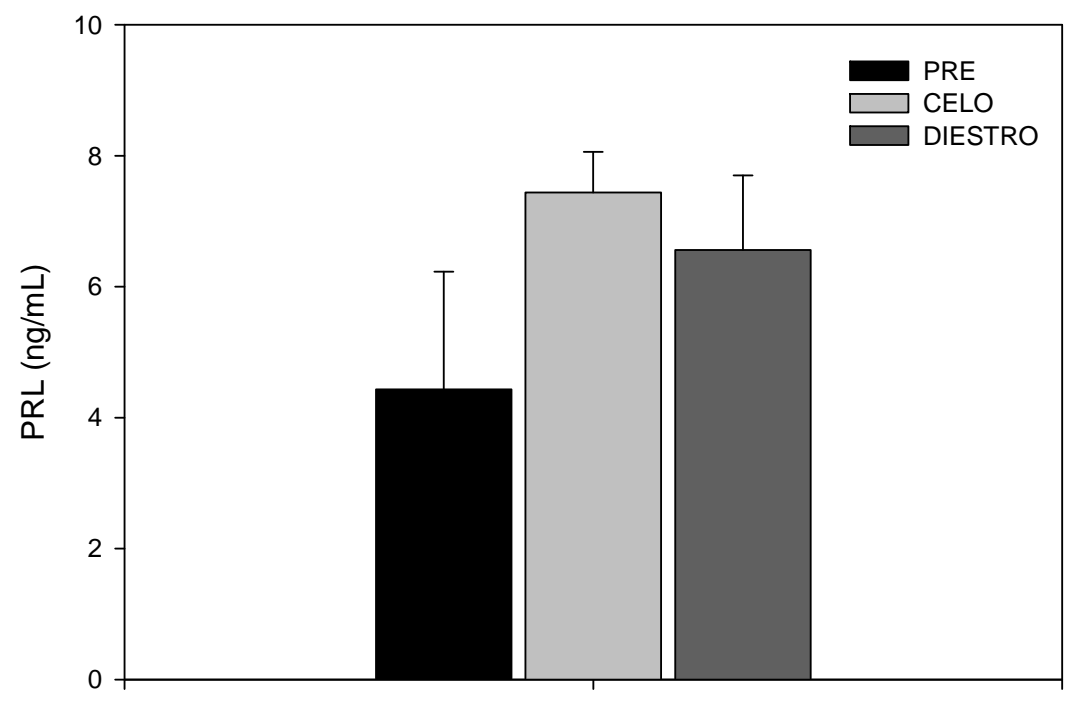

Fig 3.2. Concentraciones de PRL antes del celo, durante el celo y en el diestro. 


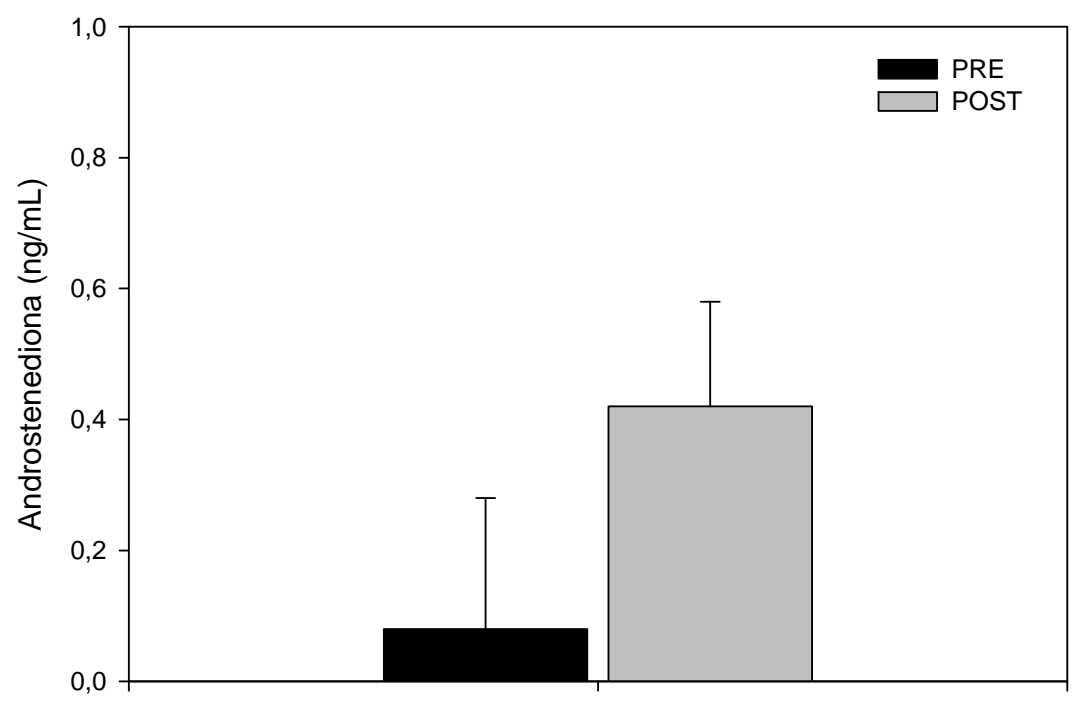

Fig 3.3. Concentraciones séricas de ANDR antes y después de la administrar administración eCG.

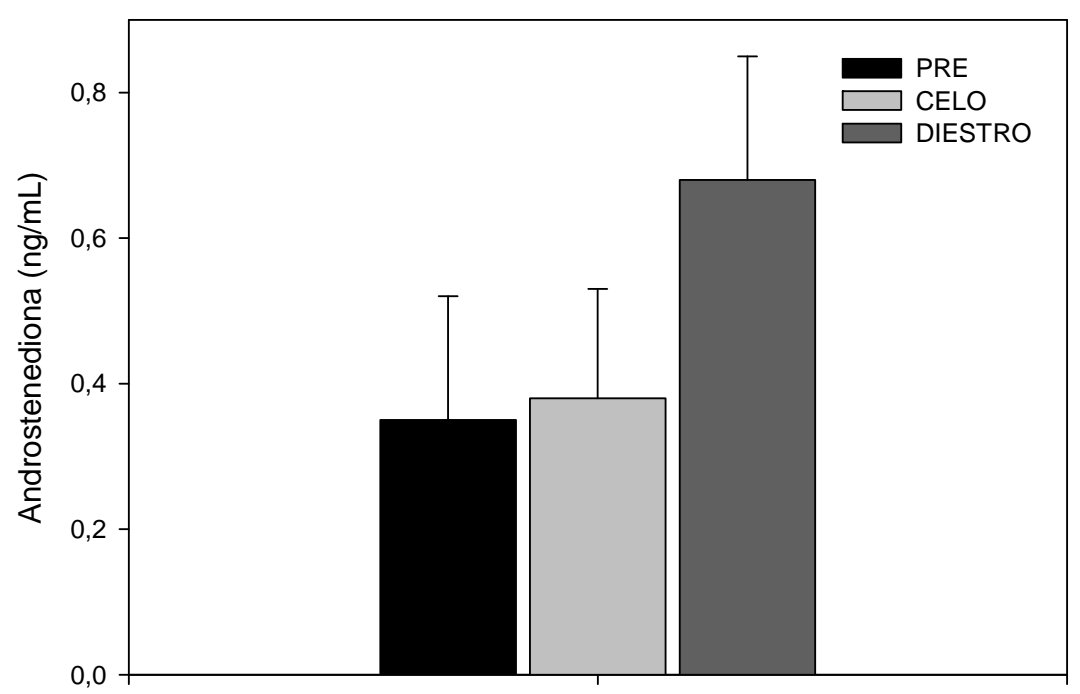

Fig 3.4. Concentraciones séricas de ANDR antes del celo durante el celo y en el diestro. 


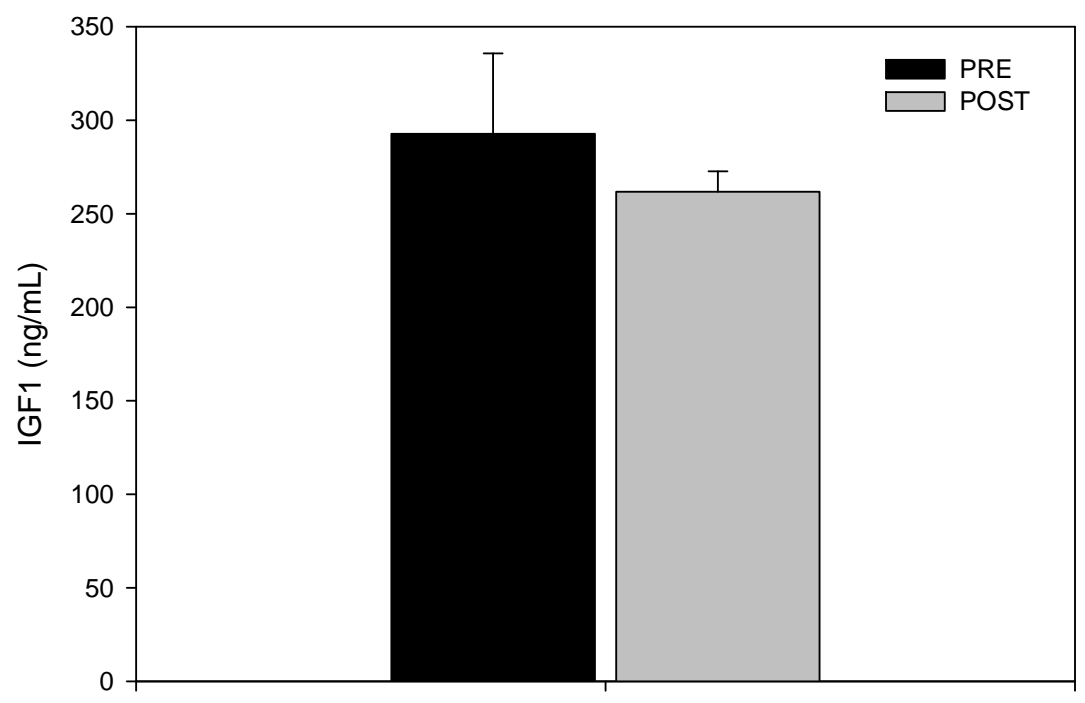

Fig 3.5. Concentaciones séricas de IGF1 antes y después de la administración de eCG.

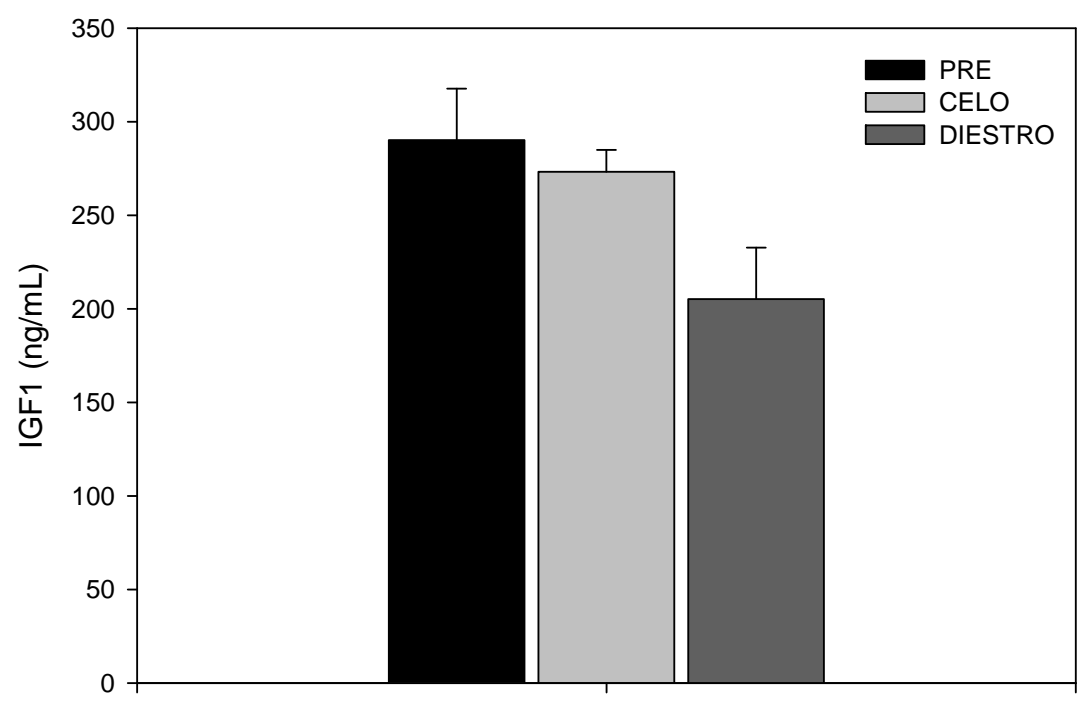

Fig 3.6. Concentraciones séricas de IGF1 antes del celo, durante el celo y en el diestro. 


\section{DISCUSION}

Nuestros hallazgos en relación a la concentración sérica de androstenediona concuerdan con los hallazgos de Concannon y col. (Concannon, 2009; Concannon, 2011; Concannon y col, 1985), quienes comunican un incremento de la concentración sérica de esta hormona durante el desarrollo folicular seguido de un descenso de la concentración sérica luego del pico de LH aumentando entre el día 6 y 18 del diestro. Probablemente esto esté relacionado con el aumento en la producción de andrógenos por las células de la teca, que sirve como precursor del $\mathrm{E}_{2}$. El exceso de andrógeno se observa como incremento de testosterona y androstenediona séricas junto a $E_{2}$ durante el desarrollo folicular.

En los protocolos de inducción de celo, la mayoría de los investigadores administran hCG al finalizar el tratamiento con gonadotrofinas o análogos GnRH (Jhonston y col 2001). Debido a que, en los ciclos espontáneos, la perra no posee ovulación inducida, podría no ser necesario estimular la ovulación mediante hCG en los ciclos inducidos. Sin embargo nuestros resultados muestran que no todas las perras en las que se induce el desarrollo folicular utilizando eCG logran ovular. Es así que creemos que es necesaria la administración de hCG para lograr ovulación en todos los animales.

Existen algunas observaciones en relación a las concentraciones de prolactina durante el ciclo estral en la perra. Spattani (2007) y Olson (1982) comunicaron una gran variabilidad entre animales en las concentraciones séricas de esta hormona durante el estro. De Gier y col (2006) mostraron que prolactina permanece constante a lo largo del ciclo estral tanto en ciclos espontáneos como en los inducidos con agonistas dopaminérgicos. Nuestro resultados concuerdan con los hallazgos de de Gier y col 
(2006) no observándose cambios en la concentración de prolactina durante el ciclo estral.

En bovinos, las concentraciones séricas de IGF1 podrían relacionarse con las concentraciones séricas de estradiol (Richard y col 1991). En concordancia con lo comunicado por Richards y col (1991), y Hashizume y col (2000), en nuestro trabajo las concentraciones séricas de este factor de crecimiento fueron más altas durante el estro que en el diestro.

\section{CONCLUSIONES}

Podemos concluir que la androstenediona, la PRL y la IGF1 modifican su concentración sérica durante el proestro y estro en la hembra canina y que la administración de hCG siete días después de la aplicación de eCG permitirá lograr la ovulación en las perras inducidas. Así mismo, el intervalo desde la administración de eCG hasta el primer día del diestro citológico en las perras que ovularon $(14,66 \pm 0,78 \mathrm{~d})$ indicaría que el pico de LH ocurrió alrededor del día 7 pos administración de la hormona, estando los óvulos maduros unos 4 días más tarde (el día 11 posadministración de eCG) y ocurriendo el diestro el día 14 posadministración de la eCG. Estos hechos determinarían al día 7 pos administración de la hormona como el día de aplicación de hCG. 


\section{CAPITULO V}

\section{ESTUDIO DE LA EFICACIA REPRODUCTIVA DEL USO COMBINADO DE eCG Y hCG}

\section{INTRODUCCIÓN}

En las últimas tres décadas se estudiaron e implementaron una gran cantidad de protocolos para inducir estro en la perra (de Gier y col., 2006; jhonston y col, 2001; Kutzler 2010; Okkens y Kooistra, 2006). Estos protocolos incluyen el uso de estrógenos sintéticos (diethylstilbesterol), agonistas dopaminérgicos (bromocriptina y cabergolina), agonistas GnRH (lutrelina, buserelina, fertirelina, deslorelina, y leuprolide) y gonadotrofinas exógenas (LH, FSH, hCG, eCG; England y Allen, 1991; Kutzler, 2007; Kutzler, 2010; Renton y col., 1981). Estos métodos se diferencian en su eficacia para inducir estro, en las tasas de preñez obtenidas luego de la inducción del estro y en la capacidad para mantener las preñeces logradas. Por otra parte algunos protocolos son muy costosos o de difícil implementación en la clínica diaria, como ocurre por ejemplo con los protocolos que requieren bombas de infusión (Concannon y col., 2006). Así mismo algunas hormonas no están disponibles en todos los países y además la aplicabilidad de alguno de estos métodos en la práctica clínica diaria es cuestionable debido a la posibilidad de que ocurran-efectos indeseables en las perras (Arnold y col., 1989; Johnston y col., 2001).

Los regímenes con gonadotrofinas exógenas que utilizan la administración secuencial de eCG y hCG son utilizados frecuentemente en los programas de inseminación artificial en felinos domésticos y silvestres (Howart y col., 1997; Moore y col., 1981). En contraposición, cuando se implementaron estos protocolos en la perra 
los resultados fueron muy variables, por lo que dejaron de usarse en la práctica diaria. Si bien, las gonadotrofinas han mostrado, ser altamente efectivas para inducir proestro en la perra, en muchos casos las tasas de ovulación fueron pobres y en otros ocurrió superovulación. Por otra parte en muchos de los estudios publicados no se comunican las tasas de preñez y las tasas de nacimientos fueron muy variables (Arnold y col. 1989; Johnston y col., 2001; Nakao y col., 1985; Tsuda y col., 1995).

Los efectos indeseables observados con mayor frecuencia cuando se utiliza eCG y hCG son respuesta ovárica impredecible, (Johnston y col., 2001) hiperestrogenismo y trombocitopenia debido a superestimulación ovárica y superovulación (Arnold y col., 1989; Weilenmann, 1993), falla en la implantación debido a hiperestrogenismo (Kennely, 1969; Lehmann y col., 1975), reacciones alérgicas a eCG (Carter, 1980) y falla lútea (Carter, 1980; Jones y col., 1973; Nakao y col., 1985). Los efectos indeseables mencionados podrían asociarse a la administración de altas dosis de eCG utilizadas en caninos en comparación con las dosis de eCG utilizada en otras especies como bovinos y ovinos.

Por otra parte la inclusión de hCG en los protocolos de inducción de celos en caninos es controversial debido a que los caninos presentan ovulación espontanea (Kutzler, 2010). Sin embargo, en otras especies que también ovulan de manera espontánea como equinos y bovinos se utiliza hCG y GnRH con el fin de sincronizar la ovulación en programas de inseminación artificial (Evans y col., 2006; de Rensis, 2006). Por lo tanto, la utilización de hCG en los protocolos de inducción de ciclos en la perra permitiría sincronizar las ovulaciones y esta sería la justificación de su uso. Cuando se evalúan los trabajos realizados por diferentes investigadores se puede observar que en muy pocos no se administró hCG (Renton y col., 1981; Allen, 1982; 
Kusuma y Tainturier, 1993). La dosis utilizada en la mayoría de los trabajos fue de 500 UI totales, el segundo día del estro (Archbald y col., 1980), el quinto día del tratamiento (Weilenmann y col., 1993) o el décimo día del tratamiento (Archbald y col., 1980; Arnold y col., 1989; Chaffaux y col., 1984; Nakao y Aoto 1985; Thun y col., 1977). Diversos investigadores han comunicado la ocurrencia de incompetencia lútea luego del tratamiento con eCG y hCG, al igual que ocurre luego de la utilización de agonistas GnRH y hCG (Kutzler, 2010). Esto ha sido también comunicado en otras especies como ovinos y bovinos (Kusuma y Tainturier, 1993; Van Haaften y col., 1989). Cirit y col. (2007), consideran que la utilización de hCG sería perjudicial.

En el Capitulo II se seleccionó la via IM como la ruta de administración más adecuada para la eCG; en el Capitulo III se seleccionó $50 \mathrm{UI} / \mathrm{kg}$ como dosis más adecuada de eCG para inducir una respuesta ovárica adecuada; y en el Capítulo IV se seleccionó la administración de una dosis de 500 UI totales de hCG siete días después de la eCG como método adecuado para inducir la ovulación. Por lo tanto un estudio clínico donde se pueda evaluar la eficacia clínica de este nuevo protocolo propuesto para inducir ciclos fértiles y sincronizar la ovulación en la perra permitirá determinar si es posible su uso en la clínica reproductiva diaria.

El objetivo de este experimento fue evaluar la eficacia de un protocolo de 50 UI/kg de eCG seguido siete días después de 500 UI totales de hCG en la inducción de ciclos fértiles y sincronización de la ovulación en la perra.

Nuestra hipótesis fue que una única dosis de eCG de 50 UI/kg seguida siete días después de 500UI de hCG es eficaz para inducir ciclos fértiles y sincronizar la ovulación en perras en anestro. 


\section{MATERIALES Y MÉTODOS}

\section{Diseño experimental}

Se utilizaron perras $(n=24)$ (Ovejero Alemán, $n=4$; Labrador, $n=3$; Pug, $n=10$; Samoyedo, $\mathrm{n}=1$; and West Highland Terrier, $\mathrm{n}=6$ ) sanas, enteras, de 2 a 5 años de edad, y con un peso entre 10 y $30 \mathrm{~kg}$ en un diseño completamente aleatorizado (Petersen, 1995). Se incluyeron en el experimento 5 machos (Ovejero Alemán, $n=1$; Labrador, $n=$ 1; Pug, $\mathrm{n}=1$, Samoyedo, $\mathrm{n}=1 \mathrm{y}$ West Highland, $\mathrm{n}=1$ ), de 2 a 5 años de edad para la implementación del servicio natural o la inseminación artificial de las hembras. Se determinó el momento del anestro mediante el historial de cada perra obtenido de los registros reproductivos del criadero y se confirmó mediante citología vaginal y concentraciones séricas de $\mathrm{P}_{4}(<1 \mathrm{ng} / \mathrm{mL})$. Las perras fueron alojadas en un canil acondicionado para tal fin y fueron asignadas en forma aleatoria a uno de dos tratamientos. En relación a los resultados obtenidos en los Capitulos II, II y IV; las perras asignadas al primer tratamiento $(\mathrm{TRT}, \mathrm{n}=16)$ recibieron una inyección de eCG (50 UI/kg IM; Novormon ${ }^{\circledR}$, Syntex SA) el primer día del protocolo y una inyección de hCG (500 UI IM; Ovusyn ${ }^{\circledR}$, Syntex SA) 7 d más tarde. Las perras asignadas al segundo tratamiento (PLA, $n=8)$ recibieron una inyección de solución salina (0 IU eCG IM) el primer día del protocolo y una segunda inyección de solución salina (0 IU hCG IM) siete días más tarde.

Las perras fueron controladas diariamente para detectar signología del estro, obtener y observar muestras de citología vaginal con el fin de evaluar la respuesta al tratamiento, utilizando los grados descriptos en el experimento Capitulo III.

Se obtuvieron muestras de sangre de los animales del grupo TRT y PLA antes de iniciar el tratamiento para determinar las concentraciones de $\mathrm{P}_{4}$ séricas y confirmar el 
anestro. En el grupo TRT se obtuvieron muestras de sangre el primer día del diestro citológico para determinar las concentraciones de $\mathrm{P}_{4}$ séricas y confirmar la ovulación mediante la presencia de un cuerpo lúteo activo. En el grupo PLA las muestras de sangre se obtuvieron una vez por mes hasta la aparición del proestro o durante cuatro meses. Todas las muestras fueron centrifugadas y el suero almacenado a $-20{ }^{\circ} \mathrm{C}$ hasta que se determinó $\mathrm{P}_{4}$ mediante RIA como se describió en el Capitulo III.

Además, se seleccionaron de manera aleatoria siete perras del grupo TRT, y se obtuvieron muestras de sangre antes de la administración de eCG y diez días después de la administración de eCG para realizar la evaluación de los parámetros hematológicos y bioquímicos. Las muestras para hematología fueron analizadas con un contador hematológico semiautomático (Sysmex F-820, Sysmex America, Inc.; Mundelein, USA). Los parámetros hematológicos evaluados fueron el recuento de eritrocitos $\left(10^{6} / \mu \mathrm{L}\right)$, recuento de leucocitos $\left(10^{3} / \mu \mathrm{L}\right)$, recuento de plaquetas $\left(10^{3} / \mu \mathrm{L}\right)$, neutrófilos en banda (\%), neutrófilos segmentados (\%), eosinófilos (\%), basófilos (\%), linfocitos (\%), monocitos $(\%)$, dosaje de hemoglobia (g/dL), y hematocrito (\%). Las muestras para bioquímica sanguínea fueron analizadas con un autoanalizador (Aeroset ${ }^{\circledR}$; Abbott Laboratories, Ltd. Saint-Laurent, Canada) utilizando reativos para bioquímica sanguínea (Alcyon $^{\circledR}$, Abbott Abbott Laboratories, Abbott Park, USA), y los parámetros bioquímicos evaluados fueron las proteínas totales $(\mathrm{g} / \mathrm{L})$, albúmina $(\mathrm{g} / \mathrm{L})$, globulinas $(\mathrm{g} / \mathrm{L})$, relación albúmina/globulina, creatinina $(\mathrm{mg} / \mathrm{dL})$, alanine amino-transferase (IU/L).

Todas las perras que respondieron al tratamiento y ciclaron, (comportamiento de estro y signos clínicos de estro grado 3, citología vaginal grado 5), fueron servidas o se les realizó inseminación artificial con semen fresco. El diagnóstico de preñez se realizó 
mediante palpación abdominal y ultrasonografía utilizando un transductor lineal multifrecuencia de 5,0-7,5-10,0 MHz (Mindray DP-600 VET, Shenzhen, China), 25-30 días después del primer día del diestro citológico. Se monitoreó el parto y se registró el tamaño de camada.

\section{Análisis estadístico}

Los datos fueron analizados por PROC MIXED y PROC GENMOD de SAS ${ }^{\circledR}$ (SAS Users Guide, 1989). Las variables dependiente analizadas incluyeron: los parámetros hematológicos y bioquímicos, grados de comportamiento de estro, signos clínicos del estro, y citología vaginal para el grupo TRT antes y después de la administración de eCG. El intervalo tratamiento-estro, tasas de preñez, número de cachorros nacidos y destetados. Los datos fueron presentados como cuadrados mínimos medios \pm error estandar. La significancia fue definida como $\mathrm{P}<0.05$.

\section{Marco bioético del uso de animales}

Este experimento se realizó respetando las mismas consideraciones bioéticas que en lls Capitulos II, III y IV.

\section{RESULTADOS}

Al inicio del tratamiento, todas las hembras TRT y PLA presentaron niveles séricos basales de $\mathrm{P}_{4}(0,72 \pm 0,31 \mathrm{ng} / \mathrm{mL})$. Antes del TRT el grado de citología vaginal fue similar entre el grupo TRT y PLA $(1,21 \pm 0,09$ vs. $1,00 \pm 0,12, \mathrm{P}<0,18)$. Tres a cinco días después de realizar el TRT, los grados de comportamiento de estro + signos 
clínicos de estro y de citología vaginal fueron superiores en el grupo TRT al compararlo con el PLA (grados de comportamiento de estro + signos clínicos de estro, 2,92 $\pm 0,05$ vs. $1,00 \pm 0,07, \mathrm{P}<0.001$; grados de citología vaginal, $4,78 \pm 0,09$ vs. $1,00 \pm 0,09, \mathrm{P}<$ $0,001)$.

En el grupo TRT todas las perras respondieron al tratamiento y esto se puso de manifiesto por el comienzo de los signos clínicos de estro dentro de los tres a cinco días de la administración de eCG. En el grupo PLA, todos los animales manifestaron celo entre 39 y 90 días después de la administración de solución salina. El intervalo medio desde el tratamiento hasta el comienzo del estro fue más corto en el grupo TRT al compararlo con el PLA $(4,14 \pm 3,38$ vs. $68,5 \pm 4,48 \mathrm{~d}, \mathrm{P}<0,001)$.

El intervalo interestral previo al tratamiento fue similar en grupo TRT y PLA $(199,62 \pm 7,26$ vs. $197,50 \pm 10,27$ d), pero el nuevo intervalo interestral, obtenido luego

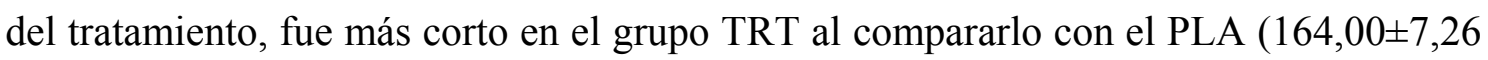
vs. $212,25 \pm 10,27 \mathrm{~d}$; interacción tratamiento por intervalo, $\mathrm{P}<0,007)$.

Luego de realizar el tratamiento, la concentración sérica de $\mathrm{P}_{4}$, se incrementó en todas las perras del grupo TRT $(0,72 \pm 0,31 \mathrm{ng} / \mathrm{mL}$ vs. $22,85 \pm 4,27 \mathrm{ng} / \mathrm{mL} ; \mathrm{P}<0,001)$ el primer día del diestro citológico. En el grupo PLA no se observaron cambios en la concentración sérica de $\mathrm{P}_{4}$ luego del tratamiento $(\mathrm{P}>0,84)$.

En el grupo TRT, el intervalo medio desde la administración del tratamiento hasta el primer día del diestro citológico fue de 16,64 $\pm 0,63 \mathrm{~d}$. Por lo tanto el pico de LH ocurrió aproximadamente 8,64 d después del tratamiento con eCG y 1,64 d después del tratamiento con hCG. El $94 \%$ de las perras del grupo TRT recibieron servicio, $(15 / 16$; IA, $n=7$; servicio natural $n=8)$, y el $80 \%(12 / 15)$ quedaron preñadas. E1 promedio del tamaño de camada fue de 3,62 $\pm 0,41$. 
La mayoría de los parámetros hematológicos y bioquímicos evaluados antes y después de la administración de eCG y hCG, no mostraron diferencias significativas ( $\mathrm{P}$ $>0.05$; recuento de eritrocitos, $7441428 \pm 20506710^{6} / \mu \mathrm{L}$; recuento de leucocitos, $11907 \pm 91110^{3} / \mu \mathrm{L}$; plaquetas, $339714 \pm 3658910^{3} / \mu \mathrm{L}$; neutrófilos en banda, $1.65 \pm 0.46$ $\%$; neutrófilos segmentados, $67.78 \pm 2.78 \%$; eosinófilos, $6.64 \pm \%$; basófilos, $0 \pm 0 \%$; linfocitos, $22.35 \pm 1.25 \%$; monocitos, $0.92 \pm 0.33 \%$; hemoglobina, $18.17 \pm 0.56 \mathrm{~g} / \mathrm{dL}$; hematocrito, $48.46 \pm 1.09 \%$; proteínas totales, $7.63 \pm 0.18 \mathrm{~g} / \mathrm{L}$, albúminas, $4.55 \pm 0.13 \mathrm{~g} / \mathrm{L}$; globulinas, $3.15 \pm 0.17 \mathrm{~g} / \mathrm{L}$; relación albúmina/globulinas, $1.50 \pm 0.09$; creatinina, $1.39 \pm 0.04 \mathrm{mg} / \mathrm{dL})$. Se observaron diferencias significativas en la concentración de alanino aminotransferasa (ALT), la que sufrió un incremento significativo luego del tratamiento $(66.00$ vs. $73.42 \pm 0.26 \mathrm{IU} / \mathrm{L}, \mathrm{P}<0.049)$. Todos los parámetros hematológicos y bioquímicos se encontraron dentro de los valores normales pre y pos tratamiento (Kaneko y col, 1997; Schalm, 2000). Ninguno de los animales mostró efectos colaterales adversos luego del tratamiento con eCG y hCG.

\section{DISCUSIÓN}

A lo largo de los últimos años, se ha intentado implementar diversos métodos de inducción de ciclos en la perra utilizando una gran variedad de agentes farmacológicos (Kutzler, 2005; Kutzler, 2007). Como se puede observar en los diversos trabajos de revisión sobre inducción de ciclos en la hembra canina (Kutzler, 2005; Kutzler, 2007; Kutzler, 2010), se han usado diferentes protocolos que incluyen eCG y hCG pero con resultados muy variables (England y Allen 1991; Kutzler, 2007; Renton y col., 1981). Muchos de estos estudios han sido realizados durante las décadas de los 70, $80 \mathrm{y}$ 
comienzos de los 90 y se han utilizado dosis elevadas de eCG con un rango que fue desde $20 \mathrm{IU} / \mathrm{kg}$ única dosis IM a $500 \mathrm{IU} / \mathrm{kg}$ única dosis IM durante 5 a $20 \mathrm{~d}$ (Arnold y col., 1989; Chaffaux y col., 1984; Leiva-Ocariz, 1993; Nakao y Aoto 1985; Thun y col., 1977; Tsuda y col., 1995; Weilenmann, 1993). Es así que si se utilizaran estos protocolos de inducción de ciclos, una perra con un peso de $20 \mathrm{Kg}$ recibiría una dosis total de $2000 \mathrm{IU}, 4000 \mathrm{IU}, 7920 \mathrm{IU}, 7140 \mathrm{IU}, 8320 \mathrm{IU}, 12852 \mathrm{IU}, 50000$ or 100000 de eCG. Si comparamos estas dosis con las utilizadas habitualmente en otras especies como por ejemplo ovinos y bovinos, podremos observar que en ovejas durante estación reproductiva se utilizan 200 UI de eCG y durante el anestro 400 UI de eCG para lograr inducción y sincronización de celo (Menchaca y Rubianes, 2004). En bovinos de leche, en protocolos de sincronización se utiliza una única dosis de 400 UI de eCG 48 h antes o al momento de retirar el dispositivo intravaginal de $\mathrm{P}_{4}$ (Bryan y col., 2010; Sá Filho y col., 2010). Claramente se puede observar que en la perra se han utilizado dosis elevadas de eCG y durante períodos prolongados, esto resulta en superestimulación ovárica e hiperestrogenismo. Los altos porcentajes de perras que entraron en celo y quedaron preñadas en este experimento utilizando una única dosis de $50 \mathrm{UI} / \mathrm{kg}$, estarían relacionados con la implementación de dosis más bajas que las utilizadas en estudios previos, lo cual evitaría la superestimulación ovárica y los consecuentes efectos adversos.

El intervalo tratamiento-estro obtenido es semejante al obtenido por Kutzler y col. (2009), y Volkman y col. (2006), cuando utilizaron agonistas GnRH y mucho más corto que en protocolos en los que se utilizan agonistas dopaminérgicos. Además cuando se utilizan protocolos con agonistas dopaminérgicos el intervalo tratamientoestro fue muy variable y prolongado pudiendo variar entre 4 y 41 días (Zoldag, 2001), 
mientras que cuando se utilizan agonistas GnRH el período es de 3 a 5 d (Volkman y col., 2006) y $6 \pm 2$ d (Volkman y col., 2006). Los resultados de este estudio muestran un intervalo de 4,14 $\pm 3,38$ días al utilizar el protocolo de eCG/hCG el cual es similar al intervalo tratamiento-estro ocurrido con agonistas GnRH.

En estudios previos, la incompetencia lútea prematura con la subsecuente pérdida de la preñez fue comunicada como un problema habitual en perras tratadas con eCG (Jones y col., 1973; Nakao y Aoto 1985; Tsuda y col., 1995; Weilenmann y col., 1993). En un estudio, el tratamiento con eCG fue seguido por la declinación progresiva de las concentraciones séricas de $\mathrm{P}_{4}$ por debajo de $1 \mathrm{ng} / \mathrm{mL}$ entre los días 38 y 40 de iniciado el estro (Barta y col., 1982). De igual forma otros autores han comunicado pérdida de la preñez debido a la presencia de un CL incapaz de mantener la gestación luego de realizar el tratamiento con eCG (Jones y col., 1973; Nakao y Aoto 1985; Tsuda y col., 1995; Weilenmann y col., 1993). La falla lútea ha sido también comunicada en otras especies como ovejas (Haresign y col., 1975), bovinos de carne (Kessler y col., 1981) y bovinos de leche (Morrow y col., 1966). En contraposición con estas observaciones, en este estudio no se observó incompetencia lútea y todas las perras tratadas con eCG fueron capaces de mantener la gestación y parieron cachorros normales. Estos hallazgos mostrarían que eCG no actúa en detrimento de la vida media del CL.

Debido a que la perra ovula de manera espontánea, la utilización de hCG para inducir la ovulación es controversial. En otras especies que también ovulan de manera espontánea, como la oveja, la yegua y la vaca utilizan una dosis única de hCG para inducir la ovulación (De Rensis y col., 2010; Evans y col., 2006; Menchaca y Rubianes, 2004). Mientras que muchos protocolos de inducción de ciclos implementan la 
administración de 500 UI de hCG para inducir la ovulación (Johnston y col., 2001; Kutzler, 2007; Kusuma y Tainturier, 1993; Kutzler, 2010; Tsuda y col., 1995; Weilenmann y col., 1993) en un estudio reciente no se observaron beneficios sobre la ovulación al administrar hCG los días 1 y 3 del realizado el tratamiento con eCG (Cirit y col., 2007). En este estudio administramos una dosis única de 500 UI hCG siete días después de la administración de eCG para inducir la ovulación y obtuvimos tasas de preñez del $80 \%$. Este resultado se correlaciona con los resultados obtenidos en el Capitulo III, en el que sólo administramos eCG y se registró ovulación en el 50\% de las hembras, lo que quedó demostrado por la elevación de la progesteronemia en el diestro; esta observación justifica la utilización de hCG.

\section{CONCLUSIONES}

Los resultados obtenidos muestran que $50 \mathrm{IU} / \mathrm{kg}$ de eCG, combinada siete días después con 500 IU de hCG fueron efectivos para inducir un ciclo estral normal y fértil en perras, sin ocurrencia de efectos colaterales adversos. El ciclo inducido ocurrió alrededor de los 164 días posteriores al celo anterior obteniéndose una tasa de preñez del 80\%. Así mismo se logró una reducción del intervalo interestral en promedio de 48 días. 


\section{CONCLUSIONES GENERALES}

De los resultados obtenidos en el presente trabajo de tesis surge la observación de que los efectos adversos asociados a la administración de eCG se encuentran relacionados con el uso de altas dosis de esta hormona y pueden evitarse utilizando dosis reducidas de la misma.

El uso de $50 \mathrm{UI} / \mathrm{Kg}$ de eCG en anestro tardío, seguida de la administración de 500 UI de hCG siete días más tarde hizo posible la obtención de altas tasas de preñez y tamaños de camada aceptables. Estas observaciones, asociadas a la predicción de la ocurrencia del celo al aplicar el mencionado protocolo hacen que el mismo prometa ser de aplicación rutinaria en los establecimientos productivos caninos. 


\section{BIBLIOGRAFÍA}

1. Adashi EY, Resnick CE, Hurwitz A, Ricciarellie E, Hernandez ER, Roberts CT, Leroith D, Rosenfeld R.The intraovarian IGF system. Growth Regul. 1992a. $2,10-15$.

2. Adashi EY, Resnick CE, Rosenfeld RG. Insulin-like growth factor-I (IGF-I) and IGF-II hormonal action in cultured rat granulosa cells: mediation via type I but not type II IGF receptors. Endocrinology. 1990. 126, 216-222.

3. Aggarwal B B, Papkoff H. Plasma clearance and tissue uptake of native and desialylated equine gonadotropins. Dom. Anim. Endocrinol. 1985; 2: 173181.

4. Allen WE. Attempted oestrus induction in four bitches using pregnant mare serum gonadotrophin. J Small Anim Pract. 1982; 23: 223-31.

5. Allen W R, Stewart F. Equine chorion gonadotropin. In McKinnon A O, Voss J L. Equine Reproduction. 1993, Williams \& Wilkins p 81-93.

6. American Society for Reproductive Medicine. Gonadotropin preparations: past, present, and future perspectives 2008; 90: 3, 13-20.

7. Archabal LF, Baker BA, Clooney LC. A surgical method for collecting canine embryos after induction of estrus and ovulation with exogenous gonadotropins. Vet Med Small Anim Clin. 1980; 75: 228-238.

8. Archbald LF, Ingraham RH, Godke RA. Inability of progestogen pretreatment to prevent premature luteolysis of induced corpora lutea in the anestrus bitch. Theriogenology. 1984; 21: 419-26.

9. Arnold S, Arnold P, Concannon PW, Weilenmann R, Hubler M, Casal M, Dobeli Fairburn A, Eggenberger E, Rusch P. Effect of duration of PMSG 
treatement on induction of estrus, pregnancy rates, and the complications of hyperoestrogenism in dogs. J Reprod Fertil. 1989; 39: 115-122.

10. Barta M, Archbald L F, Godke R A. Luteal function of induced corpora lutea in the bitch. Theriogenology. 1982; 18: 541-9.

11. Beach F A, Dunbar I F, Buehler M G. Sexual characteristics of female dogs during successive phases of the ovarian cycle. Horm Behav. 1982; 16: 414442.

12. Bell ET, Christie DW. Duration of proestrus, oestrus and vulvar bleeding in the beagle bitch. Br J Vet. 1971; 127: 25-28.

13. Ben-Jonathan, N. Dopamine: a prolactin-inhibiting hormone. Endocr. Rev. 1985, 6: 564_/589.

14. Bouchard G F, Gross S, Ganjam V K. Oestrus induction in the bitch with the synthetic oestrogen diethylstilbestrol. J Reprod Fertil. 1993; 47: 515-516.

15. Bouchard GF, Youngquist RS, Vaillancourt D. Seasonality and variability of the interestrous interval in the bitch. Theriogenology 1991; 36: 41-50.

16. Breier BH, Gallaher BW and Gluckman PD. Radioimmunoassay for insulinlike growth factor-I: solutions to some potential problems and pitfalls. J Endocrinol 128: 347-357, 1991

17. Bryan MA, Bó GA, Heuer C, Emslie FR. Use of equine chorionic gonadotrophin in synchronised AI of seasonal-breeding, pasture-based, anoestrous dairy cattle. Reprod Fertil Dev. 2010; 22: 126-31.

18. Cain JL, Cain GR. Feldman, EC. Use of pulsatile intravenous administration of gonadotropin-releasin hormone to induce fertile estrus in bitches. Amer J Vet Res 1988; 49: 1993- 1996. 
19. Carter JG. Hormone treatment of nonproductive bitches. Can Vet J. 1980; 21: 158.

20. Chaffaux S, Locci D, Pontois M, Deletang F, Thibier M. Induction of ovarian activity in anoestrous beagle bitches. Br Vet J. 1984; 140: 191-5.

21. Christie DW, Bell ET. Some observations on the seasonal incidence and frequency of oestrus in breeding bitches in Britain. J Sm Anim Pract 1971; 12: $159-67$.

22. Cirit U, Bacinoglu S,; Cangul I T,; Horoz Kaya k,; Muzaffer Tas,; Aka K. The effects of a low dose of cabergoline on induction of estrus and pregnancy rates in anestrous bitches. Animal Reproduction Science. 2007; 101: p134144.

23. Concannon P W. Induction of fertile oestrus in anoestrous dogs by constant infusion of GnRH agonist J Rep Fert. 1989; 39: 149-160.

24. Concannon PW. Biology of gonadotropin secretion in adult and prepubertal female dogs. J Reprod Fertil Suppl. 1993, 47: 3-27.

25. Concannon PW. Reproductive biology and breeding management of the female dog. Rev Bras Reprod Anim. 2003; 27: 157-165.

26. Concannon P W. Endocrinologic Control of Normal Canine Ovarian Function Reprod Dom Anim. 2009; 44: 2p 3-15.

27. Concannon P W. Reproductive cycles of the domestic bitch. Animal Reproduction Science. 2011; 124: 200-210.

28. Concannon P W, Castracane V D. Serum androstenedione and testosterone concentrations during pregnancy and non pregnant cycles in Dogs. Biology of Reproduction. 1985, 33: 1078-1083. 
29. Concannon PW, Cowan R, Hansl W. LH release in ovariectomozed dogs in response to estrogen withdrawal and its facilitation by progesterone. Biol Reprod, 1979, 20: 523-531.

30. Concannon PW, Hansel W, Visek WJ. The ovarian cycle of the bitch: plasma estrogen, LH, progesterone. Biol Reprod 1975; 13: 112-121.

31. Concannon PW, Lasley B, Vanderlip S. LH release, induction of oestrus and fertile ovulations in response to pulsatile administration of $\mathrm{GnRH}$ to anoestrous dogs. J Rep Fert. 1997; 51: 1-54.

32. Concannon PW, Vestergen J. Estrus induction in dogs: Use of gonadotropin therapies and dopamine agonist. En Proceedings of the Annual Meeting of the Society for Theriogenology, Montreal September 17-20. Nashville, Society for Theriogenology. 1997, p. 245-247.

33. Concannon PW, Weinstein P, Whaley H. Suppression of luteal function in dogs by luteinizing hormone antiserum and by bromocriptine. J Reprod Fertil 1987; 81: 175-180.

34. Concannon PW, Whaley S, Anderso SP. Increased LH pulse frequency associated with termination of anestrus during the ovarian cycle of the dog. Biol. Reprod. 1986; 34: 119.

35. Concannon PW, McCann JP, Temple M. Biology and endocrinology of ovulation, pregnancy and parturition in the dog. Reprod Fertil. 1989; Suppl 39: $3-25$.

36. Concannon P W. Temple M, Montanez A,; Newton L. Effects of dose and duration of continuous GnRH-agonist treatment on induction of estrus in 
37. de Gier J, Kooistra H S, Djajadiningrat-Laanen S C, Dieleman S J, Okkens A C. Temporal relations between plasma concentrations of luteinizing hormone, follicle-stimulating hormone, estradiol-17b, progesterone, prolactin, and amelanocyte-stimulating hormone during the follicular, ovulatory, and early luteal phase in the bitch. Theriogenology. 2006, 65: 1346-1359.

38. De La Sota RL, Soto AT, Gobello MC. Farmacología del estro y del parto. En Botana Lopez LM, Landoni MF, Martin-Jimenez T. Farmacología y Terapéutica Veterinaria. McGraw-Hill Interamericana. 2002, p 423-432.

39. De Rensis a, G. Spattini B, R. Ballabio c, R.J. Scaramuzzi. The effect of administering a dopamine agonist (Cabergoline) on follicular and luteal development during pro-estrus and estrus in the female greyhound F. Theriogenology. 2006; 66: 887-895.

40. Diaz-Torga G, Feierstein C, Libertun C, Gelman D, Kelly MA, Low MJ, Rubinstein M and Becu-Villalobos D. Disruption of the D2 dopamine receptor alters GH and IGF-I secretion and causes dwarfism in male mice. Endocrinology 143: 1270-1279, 2002.

41. Dumon C, Fontbone A. Reproduction du chien et du chat. Ed PMCAC. 82, avenue de Villiers 75017 Paris.1992; p.1-26.

42. England GCW. Small animal reproduction. Work Shop. Facultad de Ciencias Veterinarias. UNLP. 2004. p 1-20.

43. England GCW, Allen WE. Repeatability of events during spontaneous and gonadotrophin-induced oestrus in bitches. J Reprod Fertil 1991; 93: 443-8. 
44. Etreby, M. F. and Gunzel, P. Sex hormones - effects on prolactin cells in the rat, dog, monkey, and man, Acta Endocrinol. 1974; 189: 1-15.

45. Evans MJ, Gastal EL, Silva LA, Gastal MO, Kitson NE, Alexander SL, Irvine CHG. Plasma LH concentrations after administration of human chorionic gonadotropin to estrous mares. Anim Reprod Sci. 2006; 94:191-4.

46. Feldman EC, Nelson RW. Canine female reproduction. En Feldman EC, Nelson RW (eds). Canine and feline endocrinology and reproduction. Philadelphia, WB Saunders. 1987; p. 399-480.

47. Feldman E, Nelson R. Feline reproduction. In canine and feline endocrinology and reproduction, $2^{\text {nd }}$ ed. WB Saunders, Philadelphia. 1996; p. $741-768$.

48. Fernandes PA, Bowen RA, Kostas AC. Luteal function in the bitch: changes during diestrus in pituitary concentration of and the number of luteal receptors for luteinizing hormone and prolactin. Biol Reprod. 1987; 37: 804811.

49. Fevold SL, Hisaw FL, Leonard SL. (1931) The gonad-stimulating and the luteinizing hormones of the anterior lobes of the hypophysis. Am. J Physiol. 97:291-301. Citado por Comité of American Society 2008

50. Fontaine E, Mir F, Vannier F, Gérardin A, Albouy M, Navarro C. Fontbonne A. Induction of fertile oestrus in the bitch using Deslorelin, a GnRH agonist. Theriogenology. 2011; 76: 1561-1566.

51. Fosberg LC, Wallen A. Effects of whelping and season of the year on the interoestrus intervals in dog. J Small Anim Pract. 1992; 33: 67-70. 
52. Frawley, L.S. Role of the hypophyseal neurointermediate lobe in the dynamic release of prolactin. Trends Endocrinol. Metab. 1994, 5: 107_/112.

53. Fuller JL. Photoperiodic control of estrus in the Basenji. J Hered.1956; 47: 179-180. (Citado por Johnston 2001).

54. Funakoshi, T.; Yanai, A.; Shinoda, K.; Kawano, M.M.; Mizukami, Y. Gprotein-coupled receptor 30 is an estrogen receptor in the plasma membrane. Biochemical and biophysical research communications. 2006, 346: 904-906.

55. Garthwaite, T.L., Hagen, T.C. Evidence that serotonin stimulates a prolactinreleasing factor in the rat. Neuroendocrinology. 1979, 29: 215-220.

56. Gerres S, Hoffmann B. Investigation on the role of progesterone in the endocrine control of overt pseudopregnancy in the bitch: application of an antigestagen and effects on corpus luteum function. Animal Reproduction Science. 1994, 35: 281-189.

57. Goodman Gilman A, Goodman LS, Rall TW, Murad F. Las bases farmacológicas de la terapéutica. Ed Panamericana Junín 831 Buenos Aires. 1996; p. 1306-1309.

58. Gouldingi D, Williams D H, Rochei J F, Boland M P. Factors affecting superovulation in heifers treated with PMSG. Theriogenology. 1996; 45:765773.

59. Greenblatt, R.B. \& Pund, E.R. The gonadotrophins: a clinical and experimental study. Southern Med. 1941; 36: 730-742.

60. Gunzel-Apel AR, Zabel S, Bunck CF, Dieleman SJ, Einspanier A, Hoppen HO. Concentrations of progesterone, prolactin and relaxin in the luteal phase 
61. Hmmond JM, Mondscheil JS, Samaras SE. The ovarian insulim-like growth factor, a local amplification mechanism for steroidogenesis and hormone action. J Steroid Biochem Mol Biol. 1991 40: 411-418.

62. Handaja Kusuma P S, Jackson GL. Induction of estrus and ovulation in the bitch, using exogenous gonadotropins. Am J Vet Res. 1977; 38: 363.370.

63. Haresign W, Foster JP, Haynes NB, Crighton DB, Lamming GE. Progesterone levels following treatment of seasonally anestrous ewes with synthetic LH-releasing hormone. J Reprod Fertil 1975; 43:269-79.

64. Hashizume T, Ohtsuki K, Matsumoto N. Plasma insulin-like growth factor-I concentrations increase during the estrous phase in goats Domestic Animal Endocrinology. 2000, 18: 253-263

65. Heape W. The sexual season of mammals and the relationships of pro-estrus to menstruations. Part 1. Q J Microbiol Sci.1900; 44: 1-70 (Citado por Johnston 2001).

66. Herbert C A., Trigg T E. Applications of GnRH in the control and management of fertility in female animals. Anim Reprod. Sci. 2005; 88: 14153

67. Hinuma, S., Habata, Y., Fujii, R., Kawamata, Y., Hosoya, M., Fukusumi, S., Kitada, C., Masuo, Y., Asano, T., Matsumoto, H., Sekiguchi, M., Kurokawa, T., Nishimura, O., Onda, H., Fujino, M. A prolactin-releasing peptide in the brain. Nature. 1998, 393: 272_/276. 
68. Hoffmann B, Riesenbeck A, Klein R. Reproductive endocrinology of bitches Animal Reproduction Science. 1996; 42 (19): 275-288.

69. Howart JG, Roth TL, Byers A, Swanson WF, Wildt DE. Sensitivity to exogenous gonadotropins for ovulation induction and laparoscopic artificial insemination in the cheetah and clouded leopard. Biol Reprod. 1997, 56: 1059-68.

70. Jeffcoate I A. Concentrations of luteinizing hormone and oestradiol in plasma and response to injection of gonadotrophin releasing hormone analogue at selected stages of anoestrus in domestic bitches. J. Reprod. Fertil. 1992, 94: 423-429.

71. Jeffcoate IA. Endocrinology of anestrous bitches. J Reprod Fertil. 1993; 47: $69-76$.

72. Jeffcoate I. Phisiology and endocrinology of the bitch. En Simpson GM, England GCW, Harvey M. Manual of small animal reproduction and neonatology, Ed. BSAVA, England. 1998; p. 1-9.

73. Jochle W, Andersen AC. The estrous cycle in the dog: a review. Theriogenology 1977; 7:113-140.

74. Jochle W, Arbeiter K, Post, K. Effect of pseudo pregnancy, pregnancy and interestrus interval of pharmacological suppression of prolactin secretion in female dogs and cats. J Reprod Fertil. 1989 (Suppl); 39: 199-207.

75. Johnston SD, Kuztritz MVR, Olson P. Canine and feline Theriogenology, Ed. WB Saunders. Philadelphia, 2001; p. 262-264.

76. Johnston SD, Romagnoli SE. Canine reproduction. Vet Clin North Small Anim Pract.1991; v 21. 
77. Jones G E, Boyns A R, Bell E T, Christie D W, and Parkes M F. Immunoreactive luteinizing hormone and progesterone during pregnancy and following gonadotrophin administration in beagle bitches. Acta Endocrinol. $1973 ; 72: 573-81$.

78. Jones G E, Brownstone A D, Boyns A R. Isolation of canine prolactin by polyacrylamide gel electrophoresia. Acta Endocrinol. 1976; 82: 691-705

79. Kennelly $\mathrm{J}$ J. The effect of mestranol on canine reproduction. Biol Reprod 1969; 1: 282-8.

80. Kaneko J, Harvey J, Bruss M. Clinical Biochemistry of Domestic Animals. $5^{\text {th }}$ Edition, Ed. Academic Press, 1997, pp. 303-480.

81. Kessler DJ, Weston PG, Pimentel CA, Troxel TR, Vincent DL, Hixon JE. Dimunition of the in vitro response to luteinizing hormone by corpora lutea induced by gonadotropin releasing hormone treatment of postpartum suckled beef cows. J Anim Sci 1981; 53:749-54.

82. Kooistra, H.S. Okkens A.C. Secretion of prolactin and growth hormonein relation to ovarian activity in the dog. Reprod. Dom. Anim. 2001; 36: 115-19.

83. Kooistra, H.S. Okkens A.C. Secretion of growth hormone and prolactin during progression of the luteal phase in healthy dogs: a review. Molecular and Cellular Endocrinology. 2002, 197: 167_/172.

84. Kooistra HS, Okkens AC, Bevers MM, Popp-Snijders C, van Haaften B, Dieleman SJ, Schoemaker J. Bromocriptine -induced premature oestrus is associated with changes in the pulsatile secretion pattern of folliclestimulating hormone in beagle bitches. J Reprod Fertil. 1999; 117: 387-393. 
85. Kusuma PS, Tainturier D. Comparison of induction of oestrus in dogs using metergoline, metergoline plus human chorionic gonadotrophin, or pregnant mares' serum gonadotrophin. J Reprod Fertil Suppl 1993; 47:363-70.

86. Kutzler M A. Induction and syncronization of estrus in dogs. Theriogenology. $2005 ; 64: 766-775$.

87. Kutzler M A. Estrus induction and synchronization in canids and felids. Theriogenology. 2007; 68: 354-374

88. Kutzler MA. Effect of estrus induction on pregnancy rates in domestic bitches and queens. Clinical Theriogenology 2010; 2: 191-207.

89. Kutzler M, Lam S V, Volkmann D. Comparison between vestibular and subcutaneous insertion of deslorelin implants for oestrus induction in bitches. Reprod Dom Anim. 2009; 44 (Suppl. 2): 83-86

90. Lafuente, A., Marco, J., Esquifino, A.I. Physiological roles of thyrotrophinreleasing hormone and vasoactive intestinal peptide on the pulsatile secretory patterns of prolactin in pituitary-grafted female rats. J. Endocrinol. 1994, 142: $581 \_/ 586$.

91. Lecompte F. and Combarnous Y. Enzime Immunoassay (EIA) for equine chorionic gonadotropin / pregnant serum gonadotropin (eCG/PMSG) Journal of immunoassay. 1992; 13: (4), 483-493.

92. Lecompte F,; E. Harbeby ; Cahoreau C,; Klett D,; Combarnous Y. Use of the immature rat uterotrophic assay for specific measurements of Chorionic Gonadotropins and Follicle-Stimulating Hormones in vivo bioactivities. Theriogenology, 2010; 74 (5): 756-764. 
93. Lehmann F, Just-Nastansky I, Behrendt B. Effect of postovulatory administered oestrogens on corpus luteum function. Acta Endocrinol 1975; 79: $329-36$.

94. Lenz Souza M I, Ramirez Benavides G F, Uribe Velasquez L F. Papel del factor de crecimiento semejante a la insulina (IGF1) en la regulación de la función ovárica. Biosalud. 2007; 149-159.

95. Leyva-Ocariz H. Effect of hiperadrenocorticism and diabetes mellitus on serum progesterona concentrations during early metoestrus of pregnant and non pregnant mares'serum gonadotropin in domestic dogs. J Reprod Fertil 1993 (Suppl); 47: 371-377.

96. Lindsay F E F. The normal endoscopic appearance of the caudal reproductive tract of the cyclic and non-cyclic bitch: post uterine endoscopy. J Small Anim Pract. 1983, 24: 1-15.

97. Loose-Mitchell D S., Stancel G M. Estrógenos y progestágenos. En Goodman Gilman A, Goodman LS, Rall TW, Murad F. Las bases farmacológicas de la terapéutica. Ed Mc Graw Hill. 2003; p. 1613-1647.

98. Lopez, F.J., Dominguez, J.R., Sanchez-Franco, F., Negro-Vilar, A. Role of dopamine and vasoactive intestinal peptide in the control of pulsatile prolactin secretion. Endocrinology 1989, 124: 527_/535.

99. Martinuk S D, Manning a w, Black W, Murphy BC. Effects of carbohydrates on the pharmacokinetics and biological activity of equine Chorionic Gonadotropin In vivo1. Biology of Reproduction. 1991; 45: 598-604.

100. Matsumoto, H., Noguchi, J., Horikoshi, Y., Kawamata, Y., Kitada, C., Hinuma, S., Onda, H., Nishimura, O., Fujino, M. Stimulation of prolactin 
release by prolactin-releasing peptide in rats. Biochem. Biophys. Res. Comm. 1999, 259: 321_/324.

101. Mazerboug S, Bondy CA, Zhou J, Monget P. The insulin like growth Factor system: a key determinant role in the growth and selection of ovarian follicle? A comparative species study. Reprod Dom Anim 2003, 247-258.

102. McDonald LE. Hormonas de la hipófisis. En Booth NH, McDonald LE. Farmacología y terapéutia veterinaria. Primera Edición. Ed. Acribia, S. A. Zaragoza España.1996; p. 599-600.

103. Menchaca A, Rubianes E. New treatments associated with timed artificial insemination in small ruminants. Reprod Fertil Dev. 2004; 16: 403-16.

104. Menzer C, Schams D. Radioimmunoassay for PMSG and its application to in-vivo studies. J Reprod Fert 1979; 55: 339-45.

105. Mondain-Monval M, Fastard W, Smith A J. Relationships between gonadotropins, inhibin and sex steroid secretion during the periovulatory period and the luteal phase in the blu fox (Alopex lagopus) J Reprod Fertil. 1993; Suppl 47:47-56.

106. Monniaux D, Pisselet C, Fontaine J. Uncoupling between proliferation and differentiation of ovine granulosa cells in vitro. J Endocrinol 142:497-510, 1994.

107. Moore HDM, Bonney RC, Jones DM. Successful induced ovulation and artificial insemination in the puma (felis concolor). Vet Rec 1981; 108: 2823. 
108. Morrow DA, Roberts SJ, McEntee K, Gray HG. Postpartum ovarian activity and uterine involution in dairy cattle. J Am Vet Med Assoc 1966; 149: 596609.

109. Moses DL, Shille VM. Induction of estrus in greyhound bitches with prolonged idiopathic anestrus or with suppression of estrus after testosterone administration. JAVMA 1988; 192: 1541-1545.

110. Nakao T, Aoto Y, Fukushima S. Induction of estrus in bitches with exogenous gonadotropins, and pregnancy rate and blood preogesterone profiles. Jpn J Vet Sci 1985; 47: 17-24.

111. Nakao T, Yukiyo A, Fukushima S, Moriyoshi M, Kawata K. Induction of estrus in bitches with exogenous gonadotropins, and pregnancy rate and blood progesterone profiles. Jap J Vet Sci 1985; 47: 17-24.

112. National Research Council. Guía para el cuidado y uso de los animales de laboratorio. Ed Lomelí, C. (ed) Estampa de artes gráficas. 2002

113. Nickson D, Renton JP, Harvey MJA, Boyd JS, Ferguson JM, Eckersall PD. (1992) Oestrus induction in the bitch. In: Proc 12th Int Cong Anim Reprod, vol. 4. p. 1799-801.

114. Noakes DE, Parkinson TJ, England GCW. Arthurs' Veterinary Reproduction and Obstetrics. Ed. W. B. Saunders. London. 2001.

115. Okkens AC, Bevers MM, Dieleman SJ. Shortening of the interestrous interval and the lifespan of the corpus luteum of the cyclic dog by bromocryptine treatment. Vet Q 1985; 7: 173-175.

116. Okkens A C, Bevers MM, Dieleman S J.Evidence for prolactin as the main luteotrphic factor in the cyclic dog. Vet. 1990, Q 12 (4): 193-201. 
117. Okkens A C, Dieleman S J, Bevers M M, Lubberink A A and Willemse A H. Influence of hypophysectomy on the lifespan of the corpus luteum in the cyclic dog. J Reprod Fertil 1986, 77(1):187-92.

118. Okkens A C and Kooistra H S. Anoestrus in the Dog: a Fascinating Story. Reprod Dom Anim. 2006, 41: 291-296.

119. Olson PN. Concentrations of testosterone in canine serum during late anestrus, proestrus, estrus, and early diestrus. Am J Vet Res. 1984a; 45: 145.

120. Olson P N. Vaginal citology. Part 1. A useful tool for staging the canine estrous cycle. Comp Cont Ed Pract Vet. 1984b; 6: 288.

121. Olson P N, Bowen R A, Behrendt M D. Concentrations of reproductive hormones in canine serum throughout late anestrus, proestrus and estrus. Biol Reprod. 1982; 27:1196-1206.

122. Olson PN, Mulnix JA, Nett TM. Concentrations of luteinizing hormone and FSH in the serum of sexually intact and neutered dog. Am J Vet Res. 1992, $53: 762-766$.

123. Onclin K, Murphy B, Vestergen J P. Comparision of estradiol, LH and FSH patterns in pregnant and nonpregnant beagles bitches. Theriogenology. 2002, 57: $1957-1972$.

124. Parker K L., Schimmer B P Hormonas hipotalámicas y sus factores de liberación hipotalámicos. En Goodman Gilman A, Goodman LS, Rall TW, Murad F. Las bases farmacológicas de la terapéutica. Ed Mc Graw Hill. 2003; p. $1557-1577$.

125. Petersen RG. Design and Analysis of Experiments. Marcel Dekker, Inc. New York, 1985; p. 429. 
126. Phemister RD, Holst PA, Spanos JS. Time of ovulation in the beagle bitch. Biol Reprod. 1973, 8:74-82.

127. Prieto Gomez B, Velázquez-Paniagua M. Fisiología de la reproducción: hormona liberadora de gonadotrofinas. Rev Fac Med UNAM. 2002 45: 6, 252-57.

128. Pugh DG. Sheep and goat medicine. Saunders, Philadelphia, Pennsylvania. 2002; pp. 149-53.

129. Renton J P, Muro C D, Heathone RH, Carmichel S. Some aspects of the etiology, diagnosis and treatment of infertility in the bitch. J Reprod Fertil $1981 ; 61: 289-94$.

130. Reynaud K, Chastant-Maillard S, Se'verine Batard, Sandra Thoumire and Philippe Monget. IGF system and ovarian folliculogenesis in dog breeds of various sizes: is there a link? Journal of Endocrinology. 2010, 206: 85-92.

131. Richards MW, Wettemann RP, Spicer LJ \& Morgan GL Nutritional anestrus in beef cows: effects of body condition and ovariectomy on serum luteinizing hormone and insulin-like growth factor-I. Biology of Reproduction 1991; 44: $961-966$.

132. Runner M N. Development of mouse eggs in the anterior chamber of the eye. Anat Rec 1947; 98:1-17.

133. Sá Filho MF, Ayres H, Ferreira RM, Marques MO, Reis EL, Silva RC, Rodrigues CA, Madureira EH, Bó GA, Baruselli PS. Equine chorionic gonadotropin and gonadotropin-releasing hormone enhance fertility in a norgestomet-based, timed artificial insemination protocol in suckled Nelore (Bos indicus) cows. Theriogenology 2010; 73:651-8. 
134. SAS ${ }^{\circledR}$ User's Guide. Version 6, 4 th Edition. Cary, NC. Statistical Analysis Institute, Inc. 1989; p. 314.

135. Schalm's Veterinary Hematology. $5^{\text {th }}$ Edition, Ed. Lippincott, Williams and Wilkins, 2000, pp. 1057-63.

136. Scrogie NJ. (1939) The treatment of sterility in the bitch by use of gonadotrophic hormones. Vet Rec ;51: 265-8. En Jhonston 2001.

137. Senger PL. Pathways to pregnancy and parturition. Second Edition. Current Conception, INC. 2003.

138. Shille VM, Thatcher MJ, Lloyd ML. Concentrations of LH and FSH during selected periods of anestrus in the bitch. Biol Reprod. 1987; 36: 184.

139. Shille VM, Thatcher MJ, Lloyd ML. Gonadotrophic control of follicular development and the use of exogenous gonadotrophins for induction of oestrus and ovulation in the bitch. J Rep Fert 1989; 39: 103-113.

140. Shille VM, Thatcher MJ, Simmons KJ. Efforts to induce estrus in the bitch, using pituitary gonadotropins. JAVMA 1984; 184: 1469-1473.

141. Sokolowski JH. The effects of ovariectomy on pregnancy maintenance in the bitch. Lab Anim Sci. 1971; 21: 696-699.

142. Sokolowski JH. Reproductive patterns in the bitch. Vet Clin North Anim. 1977; 7: 653-666.

143. Spattini G, Borghi v, Thuro'czy j, Balogh L, Scaramuzzi R J, De Rensis F. Follicular development and plasma concentrations of LH and prolactin in anestrous female dogs treated with the dopamine agonist cabergoline. Theriogenology. 2007; 68: 826-833. 
144. Spicer L, Chamberlain C, Maciel S. Influence of gonadotropins on insulinlike growth factor 1(igf1) induced steroid production by bovine granulose cells. Dom. Anim. Endoc. 2002; 22: 237-254.

145. Spicer L, Hanrahan Z, Zavy M, Enright W. Relationship between ovulation rate and concetntrations of insulin like growth factor -1 in plasma during the estrous cycle in various genothypes of sheep.J. Rperod. Fertil. 1993; 97: 403409.

146. Stabenfeldt G H, Edqvist LE. Procesos de la reproducción de la hembra. En Swenson MJ, Reece WO. Fisiología de los animales domésticos de Dukes. Quinta edición. UTEHA (Noruega), editores. 1999; p. 678-685.

147. Swanson W F, Graham K, Horohov D W, Thompson D L, Godkel R A. Ancillary follicle and secondary corpora lutea formation following exogenous gonadotropin treatment in the domestic cat and effect of passive transfer of gonadotropin neutralizing antisera .Theriogenology. 1996; 45: 561-572.

148. Swanson W F, Wolfe B A, Brown J L, Martin-Jimenez T, Riviere J E, Terri L. Roth T L, Wildt D E. Pharmacokinetics and ovarian-stimulatory effects of equine and human chorionic gonadotropins Administered Singly and in Combination in the Domestic Cat' Biology of Reproduction. 1997; 57, 295 302

149. Szawka R E, Anselmo-Franci J A. A secondary surge of prolactin on the estrus afternoon, Life Sci. 2004; 75: 911-922.

150. Thun R, Watson P, Jackson GL. Induction of estrus and ovulation in the bitch, using exogenous gonadotropins. Am J Vet Res. 1977 38: 483-6. 
151. Trigg TE, Wright PJ, Armour AF, Williamson PE, Junaidi A, Martin GB, Doyle AG, Walsh J. Use of a GnRH analogue implant to produce reversible long-term suppression of reproductive function in male and female domestic dogs. J Reprod Fertil Suppl. 2001, 57: 255-61.

152. Tsuda T, Nakao S, Nakao T. The induction of superovulation in the bitch with pregnancy mare serum gonadotropin and human chorionic gonadotropin. J Reprod Dev 1995; 41: j89-j95.

153. Uribe-Velásquez L F, Restrepo-Cadavid R, Osorio J H. Cambios en la secreción de los esteroides ováricos y de la hormona luteinizante durante el ciclo estral en la oveja Una revisión. Biosalud. 2010; (9): 1, p. 64 - 78

154. Vanderlip SL, Wing AE, Felt P. Ovulation induction in anestrous bitches by pulsatile administration of gonadotropin-releasin hormone. Lab Anim Sci $1987 ; 37: 459-464$.

155. Van Haften B, Dieleman SJ, Okkens A C. Induction of oestrus and ovulation in dogs by treatment with eCG and/or bromocriptine. J Reprod Fertil. 1989; 39: 303-339 (Abstract).

156. Verstegen J, Onclin K, Silva LDM. Use of ultra-pure porcine LH to induce follicular growth, estrus and pregnancy in the bitch. Biol Reprod. 1993; 48 (Suppl 1): 127.

157. Verstegen J, Onclin K, Silva L, Concannon P. Effect of stage of anestrus on the induction of estrus by the dopamine agonist cabergoline in dogs. Theriogenology. 1999; 51: 597-611.

158. Verstegen-Onclin k, J. Verstegen. Endocrinology of pregnancy in the dog: A review. Theriogenology. 2008, 70: 291-299. 
159. Verstegen J, Onclin K, Silva LDM. Early termination of anestrus and induction of fertile estrus in dogs by the dopamine super-agonist cabergoline. (Abstract). Biol Reprod.1994; 50 (Suppl 1): 157.

160. Volkmann D H, Kutzler M A, Wheeler R, Krekeler N. The use of deslorelin implants for the synchronization of estrous in diestrous bitches. Theriogenology. 2006, 1497-1501.

161. Volkmann D H, Kutzler M A, Wheeler R, Krekeler N, Klewitz J, Lamb S V. Failure of hCG to support luteal function in bitches after estrus induction using deslorelin implants. Theriogenology. 2006; 66: 1502-1506

162. Walter B, Otzdorff C, Brugger N, Braun J. Estrus induction in Beagle bitches with the GnRH-agonist implant containing $4.7 \mathrm{mg}$ Deslorelin. Theriogenology. 2011; (75) 1125-1129.

163. Wanke MM, Farina J, Loza MH. Induction of estrus in bitches with normal and persistent anestrus using human menopausal gonadotropin (hMG). Theriogenology 1997; 47: 935-942.

164. Weilenman R, Arnold S, Dobeli M, Rusch P, Zerobin K. Estrus induction in bitches by the administration of PMSG and hCG. Schweiz Arch Tierheilkd $1993 ; 135: 236-41$.

165. Willard S T, Dickerson T, Dodson R, Weis A, Godfrey R W. Administration of 6-methoxybenzoxazolinone (MBOA) does not augment ovulatory responses in St. Croix White ewes superovulated with PMSG. Animal Reproduction Science. 2006; 93: 280-291. 
166. Wildt D T, Chacraborty P K, Panko W B. Relationship of reproductive behavioral, serun luteinizing hormone and time of ovulation in the bitch. Biol Reprod. 1978; 18: 561-570.

167. Wildt DE, Seager SWJ, Chakraborty PK. Behavioral ovarian and endocrine relationships in the pubertal bitch. J Anim Sci 1981; 53:182-191.

168. Wright PJ. A study of the response of the ovaries of bitches to pregnant mare serum (PMS) and human chorionic gonadotrophin (HCG). In: Proc 7th Int Cong Anim Reprod AI, vol. 2. 1972. p. 1075-9.

169. Wrigth P J. The induction and ovulation in the bitch using pregnant mare serum gonadotrophin and human chorionic gonadotrophin. Aust Vet J 1980; 56: $137-40$

170. Wrigth P J. The induction of oestrus in the bitch using daily injections of pregnant mare serum gonadotrophin. Aust Vet J 1982; 59: 123-124.

171. Yen, S.-H., Pan, J.-T. Nitric oxide plays an important role in the diurnal change of tuberoinfundibular dopaminergic neuronal activity and prolactin secretion in ovariectomized, estrogen/progesterone-treated rats. Endocrinology. 1999, 140: 286_/291.

172. Yu X F, Cho S J, Bang J I,Lee H S, Lee H S, Kwon T K, Deb G K, Kong I K. Effect of equine chorionic gonadotropin on the efficiency of superovulation induction for in vivo and in vitro embryo production in the cat. Theriogenology. 2010; (73): 413-420.

173. Zeleke M, Greyling J P C, Schwalbach L M J, Muller J, Erasmus J A. Effect of progestagen and PMSG on oestrous synchronization and fertility in Dorper ewes during the transition period. Small Ruminant Research. 2005; 56: 47-53 
174. Zhou J, Adesanya O, Vatzias G, Hammond JM, Bondy C. Selective expression of insulin-like growth factor system components during porcine ovary follicular election.Endocrinology. 1996, 137: 4893-4901.

175. Zoldag L, Fekete S, Csaky I, Bersenyi A. Fertile estrus induced in bitches by bromocrytpine, a dopamine agonist: a clinical trial. Theriogenology 2001; $55: 1657-66$.

176. Zulu V, Nakada k, Sawamukai Y. Insulin like growth factor 1 as a possible hormonal mediator of nutritional regulation in reproduction in cattle. J. Vet. Med. Sci. 2002; 64: 657- 665. 


\section{BIOGRAFIA PERSONAL}

La Médica Veterinaria María Cecilia Stornelli nació en la ciudad de La Plata el 12 de junio de 1971. Realizó sus estudios secundarios en el Colegio Liceo Víctor Mercante de la Universidad Nacional de La Plata. Ingresó a la Facultad de Ciencias Veterinarias de la UNLP en Marzo de 1989 y obtuvo el título de Médico Veterinario en agosto de 1994.

En el año 1996, ingresó como docente del Servicio Central de Cirugía en el area de Anestesiología de esta facultad y permaneció hasta 1999, cuando comenzó a desempeñar funciones en el Laboratorio Central de Análisis Clínicos del Hospital de la FCV.UNLP. En 2001 se incorporó como docente de la Cátedra de Reproducción Animal en el area de Pequeños Animales. Actualmente se desempeña como ayudante ordinario en La Cátedra de Reproducción Animal y como Ayudante Diplomado interino en el Laboratorio Central de Análisis Clínicos.

Reconociendo la imperiosa necesidad de la especialización, la mencionada profesional, en el año 2000 comenzó a trabajar en el área de Reproducción de Pequeños Animales, área en la que desde entonces ha desarrollado tareas dictando numerosos cursos a profesionales y publicando varios trabajos científicos y de divulgación técnica.

En 2000, comenzó a desarrollar su actividad en investigación como Docente Investigadora del Programa de Incentivos, y más tarde, en 2005, comenzó a desarrollar su Tesis Doctoral en esta Facultad bajo la dirección de la Doctora María Alejandra Stornelli en la Cátedra y el Servicio de Reproducción Animal. 